BEATRIZ CALIL PADIS CAMPOS

\title{
Ensino de massoterapia: habilidades envolvidas na relação fisioterapeuta-paciente
}

Dissertação apresentada à Faculdade de Medicina da Universidade de São Paulo para obtenção do título de Mestre em Ciências

Área de concentração: Movimento, Postura e Ação Humana

Orientadora: Prof $^{\mathrm{a}}$. Dr ${ }^{\mathrm{a}}$. Fátima Aparecida Caromano

São Paulo

2007

pdfMachine - is a pdf writer that produces quality PDF files with ease! Get yours now !

"Thank you very much! I can use Acrobat Distiller or the Acrobat PDFWriter but I consider your product a lot easier to use and much preferable to Adobe's" A.Sarras - USA 


\section{Dados Internacionais de Catalogação na Publicação (CIP)}

Preparada pela Biblioteca da

Faculdade de Medicina da Universidade de São Paulo

Creprodução autorizada pelo autor

Campos, Beatriz Calil Padis

Ensino de massoterapia : habilidades envolvidas na relação fisioterapeutapaciente/ Beatriz Calil Padis Campos. -- São Paulo, 2007.

Dissertação(mestrado)--Faculdade de Medicina da Universidade de São Paulo. Departamento de Fisioterapia, Fonoaudiologia e Terapia Ocupacional.

Área de concentração: Movimento, Postura e Ação Humana.

Orientadora: Fátima Aparecida Caromano.

Descritores: 1.Ensino 2.Massagem 3.Fisioterapia (Especialidade)

4.Comportamento 5.Comunicação 5.Condutas terapêuticas

USP/FM/SBD-342/07 


\section{Agradecimentos}

À minha orientadora Prof.a. Dra. Fátima Aparecida Caromano que em todos os momentos se demonstrou disposta a me ensinar e a contribuir para o ensino de

Fisioterapia no Brasil.

Aos alunos e pacientes participantes deste trabalho que, sem eles esta pesquisa não se tornaria real.

A todos os funcionários do Centro de Docência e Pesquisa e da Faculdade de Medicina da Universidade de São Paulo pelo profissionalismo, responsabilidade e apoio, auxiliando nosso percurso dentro da Instituição.

Aos membros da banca de qualificação Professor Titular Dr. Celso Ricardo Fernandes de Carvalho, Professora Dra. Silvia Maria Amado João e Professora Dra. Patrícia Castelucci pela valiosa contribuição.

Agradeço aos meus pais Terezinha e Emiliano que sempre dedicaram muito amor às suas filhas, mostrando o valor da vida nas sutilezas e na simplicidade das coisas. Que com seus olhares, ora perto ora distante, observam cada passo e acompanham o desabrochar de cada uma de nós. Obrigada mãe e pai, vocês são minha inspiração. Amo vocês. 
Agradeço às minhas irmãs Mariana e Tânia que com muito carinho e paciência me confortaram e me apoiaram nesta longa e desejada jornada compreendendo minha ausência em muitos momentos. Obrigada irmãs.

À minha tia Nur que com sua sabedoria e conhecimento despertou uma das minhas maiores paixões.

A Jair e Isabela meus amados, obrigada por estarem perto de mim.

À Professora Doutora Emilia Campos de Carvalho que com seu conhecimento e dedicação me ensinou muito sobre pesquisa, auxiliando muito especialmente neste trabalho.

À Maria, Fernanda e André, indispensáveis na minha vida.

À Naemi pela revisão deste trabalho.

À toda minha família pois tenho vocês em meu coração.

Aos meus amigos e colegas de trabalho que me incentivaram na longa dedicação a esta pesquisa.

A Deus por abençoar minha vida e iluminar os meus caminhos. 


\section{NORMALIZAÇÃO ADOTADA}

Esta dissertação está de acordo com as seguintes normas, em vigor no momento desta publicação:

Referências: adaptado de International Committee of Medical Journals Editors (Vancouver)

Universidade de São Paulo. Faculdade de Medicina. Serviço de Biblioteca e Documentação. Guia de apresentação de dissertações, teses e monografias. Elaborado por Anneliese Carneiro da Cunha, Maria Julia de A. L. Freddi, Maria F. Crestana, Marinalva de Souza Aragão, Suely Campos Cardoso, Valéria Vilhena. $2^{\mathrm{a}}$ ed. São Paulo: Serviço de Biblioteca e Documentação; 2005.

Abreviaturas dos títulos dos periódicos de acordo com List of Journals Indexed in Index Medicus. 
Lista de abreviaturas

Lista de figuras

Lista de quadros

Resumo

Summary

1 Introdução

2 Revisão da Literatura.

2.1 Ensino na graduação em Fisioterapia..................................................... 5

2.2 Habilidades profissionalizantes envolvidas na relação fisioterapeuta- 7 paciente.

2.3 Comunicação na área da saúde.................................................................. 9

2.3.1 Comunicação terapeuta-paciente............................................................. 11

$2.4 \quad$ Autocuidado físico do fisioterapeuta........................................................... 13

2.5 Elaboração de programa de ensino - selecionando conteúdo e forma de 16 ensino didático.

3 Objetivos

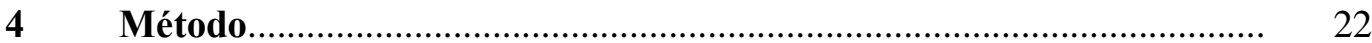

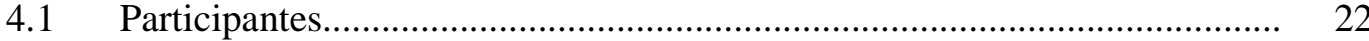

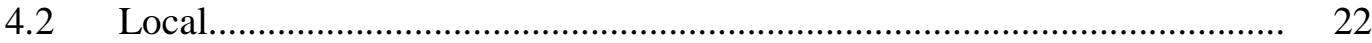

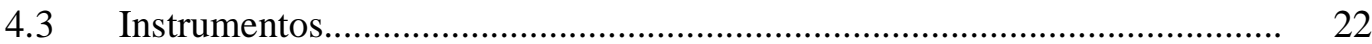

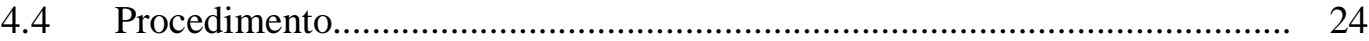

4.4.1 Identificação das habilidades profissionalizantes envolvidas na relação 24 fisioterapeuta-paciente.

4.4.2 Validação, por peritos, da seqüência e definição operacional das 30 habilidades profissionalizantes envolvidas na relação fisioterapeutapaciente.

4.4.3 Treinamento de monitores.

4.4.4 Desenvolvimento do programa de treinamento das habilidades junto aos alunos 


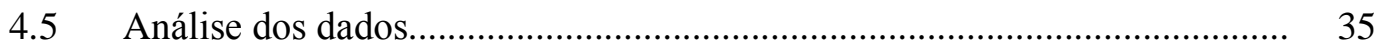

4.5.1 Desempenho no uso das habilidades profissionalizantes na relação 35 fisioterapeuta-paciente.

4.5.2 Avaliação dos alunos sobre experiência de aprendizagem e treinamento realizado de habilidades profissionalizantes a partir de relato escrito..

$5 \quad$ Aspecto Ético

6 Resultados

6.1 Caracterização dos sujeitos....................................................................... 39

6.2 Caracterização dos peritos............................................................................ 39

6.3 Resultados da validação das definições operacionais e seqüência temporal 40 das habilidades.

6.4 Resultados referentes às atividades avaliadas na situação aluno-paciente.... 41

6.4.1 Tempo total da prova........................................................................... 41

6.4.2 Tempo total da intervenção...................................................................... 41

6.4.3 Resultados das habilidades avaliadas pelo instrumento de filmagem.......... 41

6.4.3.1 Autocuidado Físico................................................................... 46

6.4.3.2 Comunicação.......................................................................... 47

6.5 Resultado da avaliação dos alunos sobre a experiência de aprendizado e 48 treinamento realizado a partir do relato escrito.

$7 \quad$ Discussão

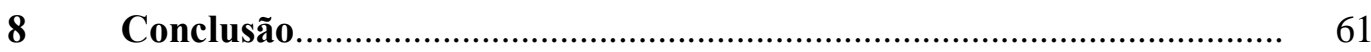

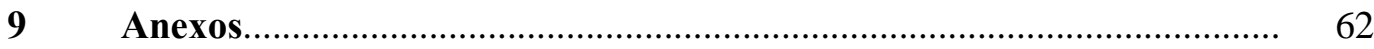

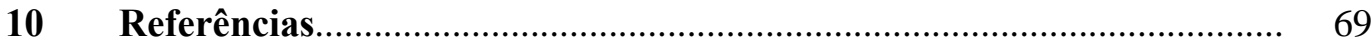

Apêndice

Lista de abreviaturas 
RTM

TCLE

FMUSP

CDP

Lafi.Com

FC
Recursos Terapêuticos Manuais

Termo de consentimento livre e esclarecido

Faculdade de Medicina da Universidade de São Paulo

Centro de Docência e Pesquisa

Laboratório de Fisioterapia e Comportamento

Freqüência Cardíaca

\section{Lista de figuras}

Figura 1

Postura de Esgrimista.

Figura

Ilustração da adequação das habilidades.

44

Figura 3

Freqüência do desempenho das habilidades dos alunos....

Figura 4

Resultado em minutos da forma e postura utilizada

durante a prova prática.

Figura 5 Resultado da forma de comunicação utilizada.

Lista de quadro

Quadro 1 Objetivos, atividades e instrumentos 
Campos BCP. Ensino de Massoterapia: habilidades envolvidas na relação fisioterapeuta-paciente. [Dissertação]. São Paulo: Faculdade de Medicina, Universidade de São Paulo, 2007. 76p.

\section{RESUMO}

Introdução: No curso de Fisioterapia, na disciplina de Recursos Terapêuticos Manuais, o aluno estará na situação de aprendizagem onde atuará como fisioterapeuta, aprenderá os recursos terapêuticos manuais e exercitará a aplicação de anamnese e de testes de avaliação funcional direcionados para aplicação de massagem. O conteúdo referente ao treinamento técnico do aluno deve focar os recursos terapêuticos e suas bases, mas não deve excluir a promoção de habilidades profissionalizantes envolvidas na relação fisioterapeuta - paciente. Objetivos: verificar a eficácia de um programa de treinamento de habilidades profissionalizantes envolvidas na relação fisioterapeuta-paciente durante sessão de massoterapia e identificar a opinião dos alunos sobre a experiência realizada. Sujeitos: Vinte e cinco graduandos em Fisioterapia. Método: I. Identificar as habilidades envolvidas na relação fisioterapeuta-paciente a partir da literatura e observação de 120 sessões de massoterapia. II. Validar a definição operacional das habilidades junto a dez peritos; III. Organizar a forma de ensino e aplicar o programa de treinamento das 21 habilidades selecionadas. IV . Analisar o desempenho dos alunos nas habilidades treinadas, classificadas em adequada, parcialmente adequada, inadequada ou não realizada durante prova prática. $\boldsymbol{V}$. Analisar o relato escrito dos alunos sobre o programa proposto. Resultados: Todos os alunos realizaram 12 das 21 habilidades treinadas de forma adequada. As habilidades: acomodar o paciente sentado, mensurar a freqüência cardíaca pré intervenção, questionar sobre intercorrência física ou emocional, fornecer feedback verbal foram realizadas de forma parcialmente adequada por 5 alunos, sendo que os demais as realizaram de forma adequada. Não ocorreu situação de execução inadequada de habilidade. Os relatos escritos, analisados e categorizados, mostraram que 19 dos 25 alunos afirmaram ser a atividade treinada importante e necessária. Destes, 15 citaram que o treinamento facilitou a relação com o paciente e a compreensão da realidade clínica. $O$ treinamento do autocuidado físico foi destacado como importante para o desenvolvimento profissional e apropriado para o contexto de ensino por dez alunos. Conclusão: o programa mostrou-se eficiente em capacitar os alunos para as habilidades propostas tendo sido bem aceito e recomendado pelos alunos.

Descritores:

1.Ensino, 2. massagem, 3. comportamento, 4. fisioterapia, 5. comunicação, 6. condutas terapêuticas. 
Campos BCP. Massotherapy Teaching: abilities involved in the physical therapistpatient relation [dissertation]. Sao Paulo: Faculdade de Medicina, Universidade de São Paulo. 76p.

\section{SUMMARY}

Introduction: In the discipline of Manual Therapeutic Resources of the Physiotherapy course, the students will be in a learning setting in which they will act as a physical therapist, will learn the manual therapeutic resources and will exercise the application of anamnesis and functional evaluation tests targeted to massage application. The contents referring to the technical training of the student should focus on the therapeutic resources and their bases, but should not exclude the promotion of the professionalizing abilities involved in the physical therapist-patient relation. Objectives: To check the efficacy of a training program of professionalizing abilities involved in the physical therapist-patient relation during the massotherapy session and identify the students'opinions about the experiment carried out. Participants: Twenty-five physicaltherapy undergraduate students. Methods:I. Identify the abilities involved in the physical therapist-patient relation starting from the literature and observation of 120 massotherapy sessions. II. Validate the operating definition of the abilities with ten experts: III. Organize the teaching manner and employ the training program of the 21 abilities selected. $\boldsymbol{I V}$. Analyse the students' performance as to the trained abilities, ranked as adequate, partially adequate, inadequate or not undertaken during the practical test. $\boldsymbol{V}$. Analyse the students' written report on the proposed program. Results: All the students undertook 12 out of the 21 trained abilities in an adequate manner. The abilities accommodate the patient in a sitting position, measure the preintervention heart rate, question about intercurrent physical or emotional conditions, supply an oral feedback - were undertaken in a partially adequate manner by 5 students, and the others undertook them in an adequate manner. There wasn't any situation of inadequate ability execution. The written reports, analysed and categorized, showed that 19 out of the 25 students stated that the trained activity is relevant and necessary. Out of those, 15 mentioned that the training facilitated the relation with the patient and the understanding of the clinical reality. The training of the physical self-care was pointed out as relevant to the professional development and appropriate to the teaching context by 10 students. Conclusions: The program proved to be efficient at enabling the students to the proposed abilities; it was well accepted and recommended by the students.

Descriptors:

1. Teaching, 2. massage, 3. behavior, 4. physical therapy, 5.communication, 6. therapeutical approaches. 


\section{INTRODUÇÃO}

A cena do atendimento em massoterapia clínica se estabelece numa situação com pelo menos dois sujeitos: paciente e fisioterapeuta.

Esta relação, nada passiva, é pactuada por meio de comportamentos verbais e não verbais à medida que o paciente "entrega" seu corpo juntamente com suas angústias e disfunções àquele em quem deposita uma expectativa de resultado com sucesso, sob seu ponto de vista. Por outro lado, o profissional fisioterapeuta, também se credita responsável pelo resultado promissor.

Dificuldades nesta relação repleta de nuances serão avaliadas neste trabalho que focará especificamente as habilidades profissionalizantes.

Neste estudo, o aluno simulou a ação do fisioterapeuta no emprego de anamnese e de testes de avaliação funcional direcionados para aplicação de massagem. Experimentou situações de contato físico na situação aluno-aluno, quando exerceu o papel de fisioterapeuta ou paciente. Nesta situação, o conteúdo referente ao treinamento técnico do aluno focalizou diferentes métodos de massoterapia clínica e suas bases, mas não excluiu a promoção de habilidades envolvidas na relação fisioterapeuta-paciente, que também inclui habilidades de autocuidado físico, essencialmente ergonômicas, avaliadas em situação real de terapia.

Definir e desenvolver as habilidades profissionais tem se mostrado difícil para os educadores em Fisioterapia, cabendo ao docente, na função de formador, estabelecer e promover o desenvolvimento de habilidades profissionalizantes permitindo aos alunos reflexão sobre a relação fisioterapeuta-paciente na atuação 
profissional, especialmente durante a aplicação de massoterapia clínica, por ser este um recurso que demanda exposição e contato físico.

Todos esses momentos requerem ética e profissionalismo, já que o corpo manipulado apresentará diferentes respostas ao ser tocado e tratado. Bevilacqua et al. ${ }^{1}$ dizem, "examine o seu doente respeitosa e cordialmente, evitando assim os prejuízos da tensão emocional e da inibição. Todo doente é capaz de distinguir um exame apressado e superficial daquele interessado e cuidadoso."

Cabe ressaltar que a aprendizagem e treinamento referentes às habilidades envolvidas com a relação fisioterapeuta-paciente devem ocorrer de forma seqüencial durante os quatro anos de graduação.

Normalmente na disciplina de Recursos Terapêuticos Manuais (RTM) existe um direcionamento e uma maior atenção ao ensino de técnicas de massoterapia e manipulação.

Existem dois conteúdos não prioritários nesta disciplina que, normalmente, não são ensinados de forma sistematizada. Eles são introduzidos na forma de informações. São eles: as habilidades profissionais envolvidas na relação fisioterapeuta-paciente e o autocuidado físico durante a execução de manobras; focalizando as formas posturais corretas de atendimento, evitando compensações corporais e sobrecargas musculoesqueléticas, reconhecendo as possibilidades do aluno e se adaptando aos seus limites físicos.

O futuro profissional fisioterapeuta deve aprender não só a técnica a ser utilizada nos pacientes, como também a incorporar uma conduta profissional adequada, respeitando a individualidade do paciente e estabelecendo uma relação profissional formal para com este. 
No treinamento de comportamentos e habilidades, a fim de estabelecer uma boa relação fisioterapeuta-paciente, faz-se necessária a aprendizagem e a utilização de uma forma de comunicação clara, direcionada ao tratamento, à orientação e as necessidades clínicas do paciente. Deve ocorrer a adequação da linguagem, com o intuito de promover uma boa compreensão das pessoas em geral, desde que respeitando a formalidade profissional, ético-jurídica e religiosa. O paciente deve estar ciente de que seu corpo será "entregue" ao tratamento, tendo o conhecimento das abordagens terapêuticas que serão aplicadas pelo profissional, seus efeitos e possíveis intercorrências.

O relacionamento profissional adequado entre fisioterapeuta e paciente deverá favorecer segurança, conforto e confiança, pois muitas vezes, observando e investigando os sinais e sintomas apresentados pelo paciente, o fisioterapeuta detectará os aspectos emocionais, sociais, ambientais e somáticos que são desencadeados ou desencadeantes da patologia ou da disfunção ${ }^{1}$. Para Rios ${ }^{2}$, a fala dos pacientes nos revela o quanto a doença, para eles, é algo externo às suas vidas quando, na verdade, está ligada ao modo de ser e viver de cada um. Payton ${ }^{3}$ mostra que o comportamento afetivo é fator necessário para uma interação efetiva entre o fisioterapeuta e o paciente.

Por outro lado, o profissional fisioterapeuta usa seu corpo como instrumento de trabalho, seja executando manobras técnicas ou servindo como resistência a um determinado movimento, mobilizando segmentos corporais; ou ainda, utilizando a si mesmo como modelo de movimento ou postura para o paciente. $\mathrm{O}$ aprendizado, treinamento e manutenção da qualidade física é uma questão de conforto para o fisioterapeuta. 
As atividades realizadas pelo fisioterapeuta requerem esforços constantes e repetitivos que podem provocar lesões ou levar a exaustão, como já foi demonstrado em diferentes estudos ${ }^{4,5,6}$. Enquanto profissional da área da saúde, seu autocuidado abrange a dimensão corporal e emocional, pois o profissional convive com questões ligadas a dores, doenças, disfunções, estresse familiar e até a morte. O ideal seria o fisioterapeuta ter uma rotina de autocuidado físico, emocional e de higiene, que conduzisse com disciplina e perseverança.

O ensino de habilidades envolvidas na relação terapeuta-paciente tem sido bastante empregado científica e didaticamente no ensino médico ${ }^{7,8,9}$. Publicações didáticas sobre este tema são recentes na Fisioterapia, embora existam poucas pesquisas que apresentem elementos esclarecedores no que se refere a conteúdos e formas de ensino nesta área ${ }^{10,11,12}$. 


\section{REVISÃO DA LITERATURA}

\subsection{Ensino na graduação em Fisioterapia}

Marques $^{13}$ observou que os problemas de ensino na Fisioterapia são semelhantes aos das classes do ensino superior em geral, porém agravados de um lado pela função reabilitadora da disciplina, pela indefinição do objeto de trabalho do campo profissional e pela indefinição do objeto de estudo da área de conhecimento que fundamenta a profissão e, por outro lado, pela rápida expansão do número de cursos. Salienta, também, a freqüência com que o fisioterapeuta não faz valer a autonomia profissional a que tem direito por lei, ou seja, recebe junto com o doente, uma prescrição médica enumerando técnicas, número de sessões que o paciente deve realizar, os recursos e inclusive o tempo de aplicação de cada terapia e se submete a essas prescrições, desrespeitando assim a lei que lhe assegura o direito à tomada de decisões no que diz respeito à área de sua especialidade.

De acordo com o Documento de Recomendação para o Ensino de Ética e Deontologia $^{14}$ nos cursos de Fisioterapia, com a proposta de padronização de conteúdo disciplinar e de metas de atuação para o desenvolvimento dos conhecimentos inerentes a esta disciplina, estabeleceu-se que os professores, de forma geral, deverão estimular a discussão da prática profissional embasada na ética e na deontologia, a partir das experiências nas diversas situações de ensino; proporcionar interação entre os docentes e discentes e as diversas disciplinas no concernente à prática profissional pautada na ética e legislação; priorizar os campos de prática profissional como ambientes desencadeadores de discussão e desenvolvimento de atitudes e também estimular docentes e discentes para a realização de pesquisa na área de ética e deontologia. 
Para que o ensino de fisioterapia se modifique, Marques ${ }^{13}$ relatou a necessidade de que haja esforços conjuntos de professores, profissionais e alunos no sentido de criar condições para que o círculo vicioso de professores sem formação adequada gerando profissionais despreparados seja rompido. Uma das formas seria preparar profissionais aptos a atuar de forma competente, com profissionalismo e respeito aos pacientes, com condições de rever freqüentemente a sua atuação e modificando-a, se necessário.

Bloom (1956) apud Hayes ${ }^{15}$ cita que a formação profissional do fisioterapeuta consiste em educação de conhecimentos, habilidades e atitudes profissionais. Os educadores baseiam-se nos três domínios de aprendizado descritos por Bloom, sendo eles: cognitivo, psicomotor e afetivo. O domínio cognitivo e psicomotor seriam habilidades técnicas desenvolvidas pela prática, treino, estudo e repetição. O fator afetivo estaria ligado a habilidades mais sutis tais como uma relação interpessoal, capacidade de percepção da ligação do fator emocional com a patologia, desenvolvimento de formas mais adequadas para abordar a queixa apresentada pelo paciente.

Questiona-se o quanto os aspectos afetivos e sociais do paciente estariam dentro ou fora do padrão de normalidade e o quanto isso afetaria no agravamento de sua doença. Desta forma o profissional, em sua atuação, deve estar preparado para perceber e identificar essas alterações para poder encaminhar o paciente para um profissional especializado.

O treinamento da habilidade afetiva do aluno vem sendo gradualmente integrado ao aprendizado dos domínios cognitivo e ao psicomotor, proporcionando ao aluno a capacidade de desenvolver essa habilidade em sua prática. 
Para Altamaier et al. ${ }^{16}$ e Hojat et al. ${ }^{17}$ o aspecto cognitivo aborda treinamento técnico e habilidade prática. $\mathrm{O}$ aspecto não cognitivo abrange respostas comportamentais, habilidades interpessoais e comunicação.

May ${ }^{18}$ ressalta que, segundo professores que atuam na prática clínica, a maior dificuldade dos alunos em fazer a transição da situação de sala de aula para a realidade é o aspecto não cognitivo, pois são características não treinadas de maneira formal durante o ensino.

No ensino da massoterapia podemos descrever como aspectos cognitivos: a técnica a ser desenvolvida, a postura utilizada pelo fisioterapeuta, a relação formal fisioterapeuta-paciente, a educação (ensino e orientação referente ao tratamento) do paciente, a administração do tempo da terapia e a capacidade de pensar, refletir, comparar, analisar, criticar, justificar, argumentar e produzir. Já o aspecto nãocognitivo abrange a forma da comunicação verbal e não verbal, o processo afetivo (sendo tanto o social quanto o profissional do terapeuta) com o paciente e a ética.

\subsection{Habilidades profissionalizantes envolvidas na relação fisioterapeuta-} paciente

Quando o aluno de Fisioterapia se gradua, entende-se que ele tenha aprendido habilidades cognitivas, psicomotoras e não cognitivas necessárias para prover atendimentos competentes. As habilidades não cognitivas são mais difíceis de serem avaliadas, principalmente quando o aluno ou recém formado tem conhecimento, habilidades manuais e técnicas satisfatórias e bem embasadas. Deficiência nas habilidades, como por exemplo alto nível de ansiedade, inabilidade para interpretar o 
paciente, dificuldade de aprender com seus erros e desconforto com informações ambíguas, são geralmente os fatores básicos para um atendimento carente ${ }^{19}$.

May $^{18}$ apresenta um modelo de avaliação de atributos profissionais para graduandos em Fisioterapia apontando dez habilidades para avaliar o grau de competência do aluno, sendo elas: capacidade de aprendizado, habilidades interpessoais, uso efetivo do tempo, pesquisas, uso construtivo do feedback do paciente, resolução dos problemas, profissionalismo, responsabilidade, pensamento crítico e administração do estresse.

Em 1999, Hayes ${ }^{15}$ observou que deveria enfatizar uso dos fatores não cognitivos, como as habilidades interpessoais de comunicação, para assegurar a competência profissional dos estudantes, visto que a coleta de dados abrangente durante a anamnese é essencial para a ação clínica fisioterapêutica.

May ${ }^{18}$ incentivou, por meio do seu estudo, que educadores iniciassem a utilização das habilidades não cognitivas como uma ferramenta importante para seus ensinamentos, além de despertar interesse nas pesquisas sobre habilidades para os graduandos de Fisioterapia.

O profissional fisioterapeuta deverá estar apto a lidar com vidas em situações de fragilidade e dependência, tomar decisões, realizar intervenções, estar em contato próximo e prolongado com o paciente e seus familiares. Esta demanda, se não for bem administrada, pode tornar o profissional mais propenso a um desgaste físico e emocional $^{20}$. Machado ${ }^{21}$ conclui "Não existe apenas um fator responsável pelo sofrimento dos trabalhadores, mas uma rede de processos que se interpenetram, gerando situações de sofrimento". 


\subsection{Comunicação na área da saúde}

A literatura, na área da saúde, tem identificado a importância da comunicação interpessoal no início da prática clínica por incluir a habilidade de trabalhar em equipe e a habilidade de ganhar confiança e o respeito dos pacientes ${ }^{22-26}$.

Porrit $^{27}$ afirma que a comunicação é base para toda interação humana e que a qualidade da interação é afetada pelos contextos sociais nos quais a comunicação ocorre.

Ruesch e Bateson $^{28}$ afirmaram existir quatro níveis de comunicação: intrapessoal (dentro da pessoa), interpessoal (um para um), grupo (um para muitos, muitos para um) e cultural (de muitos para muitos).

Segundo Littlejohn ${ }^{29}$, os contextos em que as comunicações se processam correspondem: interpessoal, pequeno grupo, organizacional e de massa. O interpessoal envolve duas pessoas interagindo face a face; o de pequeno grupo envolve até 15 pessoas; o organizacional ocorre no âmbito das organizações e é marcado pela hierarquia e pela formalidade; o de massa envolve comunidades, coletividades ou sociedades.

A comunicação na área da saúde vem merecendo pesquisas de estudiosos. A pesquisa da comunicação na Fisioterapia é importante pela busca de conhecimentos que podem favorecer as práticas profissionais.

Para Stefanelli ${ }^{30}$ não existe uma teoria global de comunicação que explique suas origens, seu desenvolvimento nos indivíduos ou na sociedade, ou mesmo suas funções ou papéis. As inúmeras formas de identificar, compreender e analisar a comunicação têm enriquecido a compreensão desse processo. 
Sundeem ${ }^{31}$ e Stefanelli ${ }^{32}$ acreditam que o processo de comunicação pode ser afetado por vários fatores ou variáveis. Esses permitem trazer tanto benefícios como prejuízos para a adequada compreensão das mensagens, podendo surgir fatos que impeçam a evolução adequada do processo. As principais variáveis presentes no contexto da saúde são: profissional da saúde e o paciente, a linguagem usada, o ambiente ou contexto, a disponibilidade de ambos e a oportunidade profissional.

É importante que o profissional da saúde faça uso consciente de sua competência em comunicação, pois tudo que ele é, diz ou faz, pode afetar o comportamento do paciente. O linguajar utilizado tanto pelo profissional, quanto pelo paciente, deve ter um significado comum a fim de que a mensagem seja aprendida e compreendida por ambos. O profissional deve usar um vocabulário que possa ser compreendido, de acordo com a origem, escolaridade, cultura e crenças do paciente valendo-se do máximo de clareza possível ao empregar as palavras. Por fim, ambos precisam ter capacidade para ouvir. O ambiente envolve não só o espaço físico utilizado pelas pessoas, como também as pessoas que interagem nele, sua cultura, mobiliário, iluminação, arejamento, temperatura, ruídos, condições de tempo e espaço. A disponibilidade pessoal do profissional é necessária e deve estar livre para ser utilizada quando os pacientes assim precisarem. O senso de oportunidade diz respeito à sensibilidade do profissional em perceber se o momento é oportuno ou não para dar orientações ao paciente ${ }^{30}$. 


\subsubsection{Comunicação terapeuta-paciente (interpessoal)}

De acordo com Ruesch e Bateson $^{28}$ a comunicação utilizada na relação terapeuta-paciente, é a interpessoal. As teorias que tratam da comunicação interpessoal buscam compreender a natureza do estabelecimento e manutenção das relações; o processo de percepção interpessoal que se estabelece nas interações e como se dá a apresentação do eu a outros; como os interlocutores se percebem e se compreendem e os graus variados de atração ou rejeição no relacionamento.

Para Stefanelli ${ }^{30}$ a comunicação interpessoal tem sido uma das mais estudadas na Enfermagem e nem sempre os achados desses estudos têm se mostrado positivos. São inúmeros os exemplos de afastamentos ou distanciamento de pacientes, de uso de comportamentos autoritários ou assimétricos. Por outro lado, conhecer esses referenciais e aplicá-los na análise da relação enfermeiro-paciente, propiciam tanto divulgar as formas como tais comportamentos estão sendo utilizados, como também apresentam novas alternativas para melhorar o desempenho comunicacional dos profissionais.

Portanto, o conhecimento do desempenho da comunicação nesse contexto pode ser útil para a promoção de mudanças e para torná-la mais adequada. Considera-se que o conhecimento dos aspectos assertividade, responsividade e versatilidade do estilo de comunicação de uma pessoa e da do outro com quem interage, seja necessário para maximizar os objetivos da comunicação ${ }^{33}$.

A empatia, confiança e respeito são elementos básicos para que a comunicação humana seja efetiva, terapêutica ou adequada ${ }^{32,32,34}$.

A comunicação terapêutica, segundo Stefanelli ${ }^{30}$, é a competência do profissional de saúde em usar o conhecimento sobre comunicação humana para 
ajudar o outro a descobrir e utilizar sua capacidade e potencial a fim de solucionar conflitos; a reconhecer as limitações pessoais; a ajustar-se ao que não pode ser mudado e a enfrentar os desafios à auto-realização, procurando viver da forma mais saudável possível, tendo como meta encontrar motivação para viver com autonomia.

O silêncio, muitas vezes, também pode ser utilizado de forma terapêutica como estratégia para estimular a expressão verbal de idéias e sentimentos do paciente, porém não se preconiza a permanência de duas pessoas em mutismo. $\mathrm{O}$ profissional tem que ter discernimento para saber quando falar e quando permanecer em silêncio. O tempo de tolerância ao silêncio oscila de uma pessoa para outra. Em geral é de curta duração, pois se for muito longo provocará ansiedade em ambos os participantes da interação.

Stefanelli ${ }^{30}$ ainda afirma que há dificuldade de ensino, aprendizado e uso na prática da comunicação na área da saúde para não torná-la estereotipada ou padronizada. Cada ser humano é único e, ao se beneficiar da assistência à saúde, ele tem que ser considerado como tal, exigindo, portanto, uma assistência personalizada e humanizada.

Dentre as habilidades de comunicação, $\operatorname{Rossi}^{35}$ salienta que a comunicação interpessoal se estabelece como habilidade pessoal, resultado de atitudes suficientes e necessárias para uma relação terapêutica e que a adequação desta habilidade se faz essencial para se obter as informações para o diagnóstico e tratamento. 


\subsection{Autocuidado físico do fisioterapeuta}

Dortch $^{36}$ sugere que as tarefas profissionais devam respeitar os fatores constitucionais de cada indivíduo, ou seja, sexo, biotipo, idade, condição física e psicológica e que os trabalhadores precisam ser devidamente preparados antes de serem efetivados em seus empregos.

Para Helfenstein ${ }^{37}$, um programa de exercícios laborais pode ser instituído, envolvendo capacidade aeróbica, alongamento e exercícios de flexibilidade. Um indivíduo com condicionamento físico e boa flexibilidade terá melhor resistência e desempenho no trabalho.

O fisioterapeuta, assim como alguns profissionais da área da saúde, executa rotineiramente atividades como transferência de pacientes dependentes, assistência ao paciente durante a marcha, resistência manual, trabalhos no chão/solo e atividades com sobrecarga.

Stubbs $^{38}$ e Videman ${ }^{39}$ apontaram que muitos fisioterapeutas apresentam dores musculoesqueléticas advindas do exercício de atividade ocupacional e sabe-se que atualmente o número de fisioterapeutas com dores musculoesqueléticas provenientes do trabalho é bastante alto e um evento constante.

O trabalho não deve impor ao indivíduo que ele realize suas tarefas em posturas que proporcionem estresse biomecânico aos músculos, tendões, ligamentos e articulações. A força muscular é limitada em certas posições e os músculos não conseguem manter contrações estáticas prolongadas sem ocasionar fadiga. Portanto, o espaço físico e os equipamentos utilizados devem ser projetados também para evitar as posturas inadequadas. As macas, por exemplo, deveriam ser ajustáveis em 
sua altura e cada fisioterapeuta necessitaria ter um banco para trabalhar sentado, quando necessário.

Cromie $^{4}$ observou que $62,5 \%$ dos fisioterapeutas apresentavam dor lombar, já Bork $^{5}$ e ainda Cromie perceberam que além da dor lombar, encontraram respectivamente, dor cervical $(24,7 \%$ e $47,6 \%)$, dor em ombros $(18,9 \%$ e $22,9 \%)$, dor torácica $(28,7 \%$ e $41 \%)$, dor em punhos e mãos $(29,6 \%$ e $21,8 \%)$ e dor em joelhos $(10,9 \%$ e $11,2 \%)$

Um achado interessante encontrado pela maioria dos pesquisadores citados, como Molumphy ${ }^{40}$ e Scholey ${ }^{41}$, é que o primeiro episódio de dor musculoesquelética relacionada ao trabalho ocorre nos primeiros anos de prática ou entre os fisioterapeutas jovens. Molumphy ${ }^{40}$ encontrou que $29 \%$ dos fisioterapeutas apresentaram dores num período de doze meses de trabalho, sendo que $64 \%$ desta população tinha 30 anos ou menos. Percebeu também que apenas o conhecimento técnico e a experiência dos fisioterapeutas não evitavam os danos.

Cromie $^{4}$ observou que um em cada seis fisioterapeutas australianos, trabalhadores de todas as áreas da fisioterapia, necessitaram mudar de carreira por causa da doença ocupacional.

Trelha e al. ${ }^{42}$ salientam as conseqüências de um trabalho fisioterapêutico sem a ajuda de outro profissional ao mostrar que a profissão de fisioterapeuta requer grande esforço físico, por se tratar de um trabalho que solicita a realização de movimentos de membros superiores e tronco, muitas vezes em postura forçada. $\mathrm{O}$ manuseio e transporte de peso ocorrem quando o profissional leva equipamentos de um local para o outro, ou quando precisa mobilizar e transferir o paciente. 
Sabe-se também que, na maioria das atividades da fisioterapia, o mobiliário é inadequado. Essa situação é agravada quando o atendimento passa a ser domiciliar pois, geralmente os móveis disponíveis são impróprios para os procedimentos fisioterapêuticos ${ }^{10}$.

Além do mobiliário inadequado e do esforço que, muitas vezes, o fisioterapeuta tem que fazer para o atendimento, tem ocorrido um excesso de carga horária diária trabalhada. No Brasil, os salários baixos e a ideologia de ascensão social pressionam o profissional a assumir dois ou mais empregos, sacrificando assim o seu descanso, lazer e vida familiar. Ao invés de trabalhar 30 horas por semana e ter o resto do tempo para suas atividades pessoais, em razão de uma baixa remuneração, o fisioterapeuta frequentemente trabalha em dois ou mais empregos com uma carga aproximada de 60 horas por semana, objetivando uma maior remuneração, porém sobrecarregando o seu físico e tendo conseqüências emocionais.

Existem três fatores de risco primário associado ao trabalho, segundo Silverstein $^{43}$ : repetição do movimento, posturas incorretas e alto nível de força solicitada. Infelizmente, o profissional fisioterapeuta fica exposto a todos esses fatores, o que demanda maior preocupação com sua formação sobre autocuidados físicos.

O estudo de Trelha et al. ${ }^{42}$ verificou que os profissionais em início de carreira apresentavam maior sintomatologia, possivelmente pela inexperiência e pela maior dificuldade em pedir auxílio a outras pessoas para, por exemplo, levantar ou transferir o paciente.

Na maior parte dos movimentos de massagem, a posição do terapeuta é um aspecto essencial da técnica. A conscientização quanto à postura é uma combinação 
de posição do corpo, descarga de peso corporal e direção da pressão. A boa postura, portanto, é aquela na qual o terapeuta tem os pés bem apoiados no chão, e plena liberdade de movimento ${ }^{10}$.

De acordo com o alto índice de dores ocupacionais em fisioterapeutas, os autores sugerem que intervenções sejam feitas durante a graduação para que essa incidência seja diminuída ${ }^{4,5,44}$.

\subsection{Elaboração de programa de ensino - selecionando conteúdo e forma de ensino didático}

Segundo Marques ${ }^{13}$,

"Ensinar é uma atividade que só é efetiva se resultar em aprendizagem do aluno, e como em outras áreas da atividade humana, o conhecimento científico pode ser um instrumental poderoso para nortear um fazer competente. Ao ensinar, cabe ao professor, a responsabilidade pela proposição de objetivos e, em função deles, arranjar um conteúdo de atividades e programá-las para que o aluno possa, ao realizá-las, interagir com o ambiente e adquirir as habilidades necessárias no grau de competência desejado.”

Ainda segundo Marques ${ }^{13}$ “a avaliação do desempenho do aluno é indispensável para comprovar a eficácia do ensino, enfatizando que o professor organize um conjunto de atividades em pequenas etapas de ensino para que o aluno possa adquirir as habilidades no grau de competência desejado.”

Mantovani $^{45}$ salienta que o estudante procura o conhecimento e a racionalidade de três formas, pelo conhecer para satisfazer a curiosidade, pelo 
conhecer para se sentir seguro e pelo conhecer para transformar. As duas primeiras são mais fáceis de conseguir, porém, quanto à última, aquela que melhora sua qualidade profissional, poucos têm acesso aos benefícios trazidos por ela, pois não se adaptam e não transformam o meio.

Segundo Gonçalves ${ }^{46}$, para o desenvolvimento do ensino médico há uma preparação durante a graduação onde o aprender "a ser médico" envolve a aquisição de conhecimentos e informações essenciais ao diagnóstico das doenças e das formas de contorná-las ou superá-las. Além disso, o aluno precisará desenvolver habilidades que permitam realizar o exame do doente, bem como executar manobras e procedimentos destinados ao tratamento da doença. Mas, principalmente, o aluno precisará reconhecer e aprimorar atitudes e habilidades que lhe permitam relacionarse com o doente de maneira adequada. Para tanto, será necessário reconhecer naquele que o procura, em busca de tratamento, alguém que precisa ser ouvido e compreendido, mais do que apenas ser "tratado".

Neste contexto, o aluno vem sendo encorajado pelo educador a assumir a responsabilidade por seu próprio aprendizado. Porém, o estudante pode imaginar que sua formação depende da memorização do maior número possível de informações; em conseqüência, não consegue formar uma idéia clara sobre quais habilidades, atitudes e valores são de fato fundamentais. Assim, as escolas da área da saúde devem enfatizar que tais elementos são tão importantes quanto a aquisição de conhecimentos.

De acordo com Masetto ${ }^{47}$, as universidades brasileiras, em geral, ainda são muito acadêmicas, primam pelas teorias, laboratórios, salas de aulas tradicionais, metodologia e avaliação convencional. 
Gonçalves $^{46}$ ainda questiona sobre os aspectos humanos na formação na área da saúde e observa que a prática médica deve comprometer-se com o homem integral, "indivíduo + pessoa", para que possa atingir seus objetivos reais. Ela deve procurar enxergar o homem em seus componentes físicos, químicos e biológicos, mas também nos componentes mentais e psicológicos, emocionais e afetivos, sociais e espirituais. Gonçalves ${ }^{46}$ conclui que conhecimentos não serão jamais elementos suficientes para atribuir a algum profissional, competência clínica e, em conseqüência, desempenho médico satisfatório. O médico, preparado apenas com elementos cognitivos, correrá o risco de ser um mero executor de técnicas e “receitador" de drogas e medicamentos. "Ao lado de conhecimentos fundamentais o profissional deverá esforçar-se conscientemente por ganhar habilidades essenciais e principalmente desenvolver habilidades capazes de colorir suas atitudes em relação às pessoas e o mundo".

Masetto $^{47}$ resume os fatores relacionados com o processo de aprendizagem, ao afirmar que este refere-se ao processo de crescimento e desenvolvimento de uma pessoa em sua totalidade, abarcando minimamente três áreas do ser humano: - a do conhecimento: que compreende toda a parte mental e intelectual do homem, onde ela não poderá se esgotar em assimilar algumas informações ou conhecimentos obtidos e repeti-los; - a de habilidades humanas e profissionais que abrange tudo que fazemos com os conhecimentos adquiridos; - e a área de atitudes e valores que compreende o desenvolvimento de valores pessoais, como ética, respeito aos outros, opiniões, honestidade intelectual, criticidade, curiosidade, criatividade e autonomia.

O futuro profissional fisioterapeuta, como profissional da área da saúde, deve aprender não só a técnica e os fundamentos a serem utilizados junto aos pacientes, 
mas também como ter uma conduta profissional adequada, respeitando a individualidade do paciente e estabelecendo uma relação profissional formal para com este ${ }^{42,48}$. Para tanto, torna-se necessário que desenvolva habilidades cognitivas, psicomotoras e comportamentais indispensáveis para proporcionar um atendimento competente $^{19}$.

$\mathrm{Na}$ área da saúde em geral, o emprego de simulação de tratamento como estratégia de ensino tem sido citado na literatura e demonstrado ser eficiente no processo de aprendizado ${ }^{49,50}$. Por meio das simulações, objetiva-se imitar fatos ou situações da vida real, facilitando o momento de transição para a clínica. O processo educativo ocorre num contexto de realidade onde diferentes tipos de educação ou opções pedagógicas podem existir ${ }^{51}$.

No contexto do ensino, professores da área da saúde são responsáveis pelas abordagens conceituais que levem em consideração o conteúdo do processo da disciplina, de modo a permitir o aprendizado e a aplicação prática dos conceitos. Para tanto, os docentes utilizam diferentes métodos de ensino, incluindo a simulação. Esta estratégia possibilita a oportunidade de exercitar as técnicas específicas de massoterapia e a promoção de habilidades profissionalizantes envolvidas na relação fisioterapeuta-paciente, de forma dinâmica e interativa, permitindo aos alunos reflexão sobre suas responsabilidades no desempenho de ações profissionais. Embora seja necessário considerar as dificuldades na utilização dessas habilidades, sabe-se que qualifica a assistência de fisioterapia promovendo um cuidado mais direcionado ao paciente $^{51}$. 
Estudos sobre o desempenho na execução de técnicas também começam a se fazer presentes nos últimos anos na literatura fisioterapêutica, colaborando para formação de um panorama mais amplo e completo sobre o ensino de fisioterapia ${ }^{52,53}$. 


\section{OBJETIVOS}

Frente ao exposto, os objetivos deste estudo foram:

1) verificar a eficácia de um programa de treinamento de habilidades profissionalizantes envolvidas na relação fisioterapeuta-paciente durante sessão de massoterapia;

2) identificar a opinião dos alunos sobre a experiência realizada. 


\section{MÉTODO}

A presente proposta teve por base metodológica a pesquisa observacional de delineamento com intervenção e descrição, por observar, descrever e explorar aspectos de uma situação.

4.1. Participantes: Graduandos do quarto semestre letivo do curso de Fisioterapia da Faculdade de Medicina da Universidade de São Paulo (FMUSP).

Critérios de inclusão: 1) ser aluno regularmente matriculado na disciplina de Recursos Terapêuticos Manuais (RTM) durante o $4^{\circ}$ semestre letivo; 2) o aluno manifestar concordância em participar da pesquisa, com anuência escrita, a partir da assinatura no termo de consentimento livre e esclarecido (TCLE), Anexo 1, proposto no projeto de pesquisa e aprovado pela Comissão de Ética para Análise de Projeto de Pesquisa-CAPPesq da Diretoria Clínica do Hospital das Clínicas e Faculdade de Medicina da Universidade de São Paulo, protocolo número 946/05 (Anexo 2).

Critérios de exclusão: interesse em interromper a participação, em qualquer fase da pesquisa.

4.2. Local: A pesquisa foi realizada em uma sala de aula de massoterapia, medindo 6 X 10 metros, localizada no CDP (Centro de Docência e Pesquisa do Departamento de Fisioterapia, Fonoaudiologia e Terapia Ocupacional da FMUSP) onde foi garantido um ambiente reservado e silencioso, e também no Laboratório de Fisioterapia e Comportamento (Lafi.Com) do Curso de Fisioterapia da Universidade de São Paulo para a observação da prova prática final.

4.3. Instrumentos: Os instrumentos de coleta de dados foram elaborados de forma a que atendessem aos objetivos da pesquisa, sendo: 
Instrumento 1 - $\underline{\text { Filmagem }}$ em vídeo VHS com a gravação da prova final dos alunos, avaliado individualmente por meio de check list;

Instrumento 2 - $\underline{\text { Check list }}$ construído para assegurar que a checagem de todas as 21 habilidades treinadas fossem realizadas de acordo com suas definições operacionais (Apêndice 1, 2 e 3);

Instrumento 3 - Relato escrito entregue pelos alunos ao final da pesquisa para avaliação da disciplina, monitoria e ensino de habilidades profissionalizantes, a partir de uma questão aberta (Apêndice 4).

O Quadro 1 demonstra as correspondências entre os objetivos propostos, as atividades desenvolvidas e os instrumentos utilizados para favorecimento da compreensão no presente estudo.

Quadro 1 - Objetivos, atividades e instrumentos

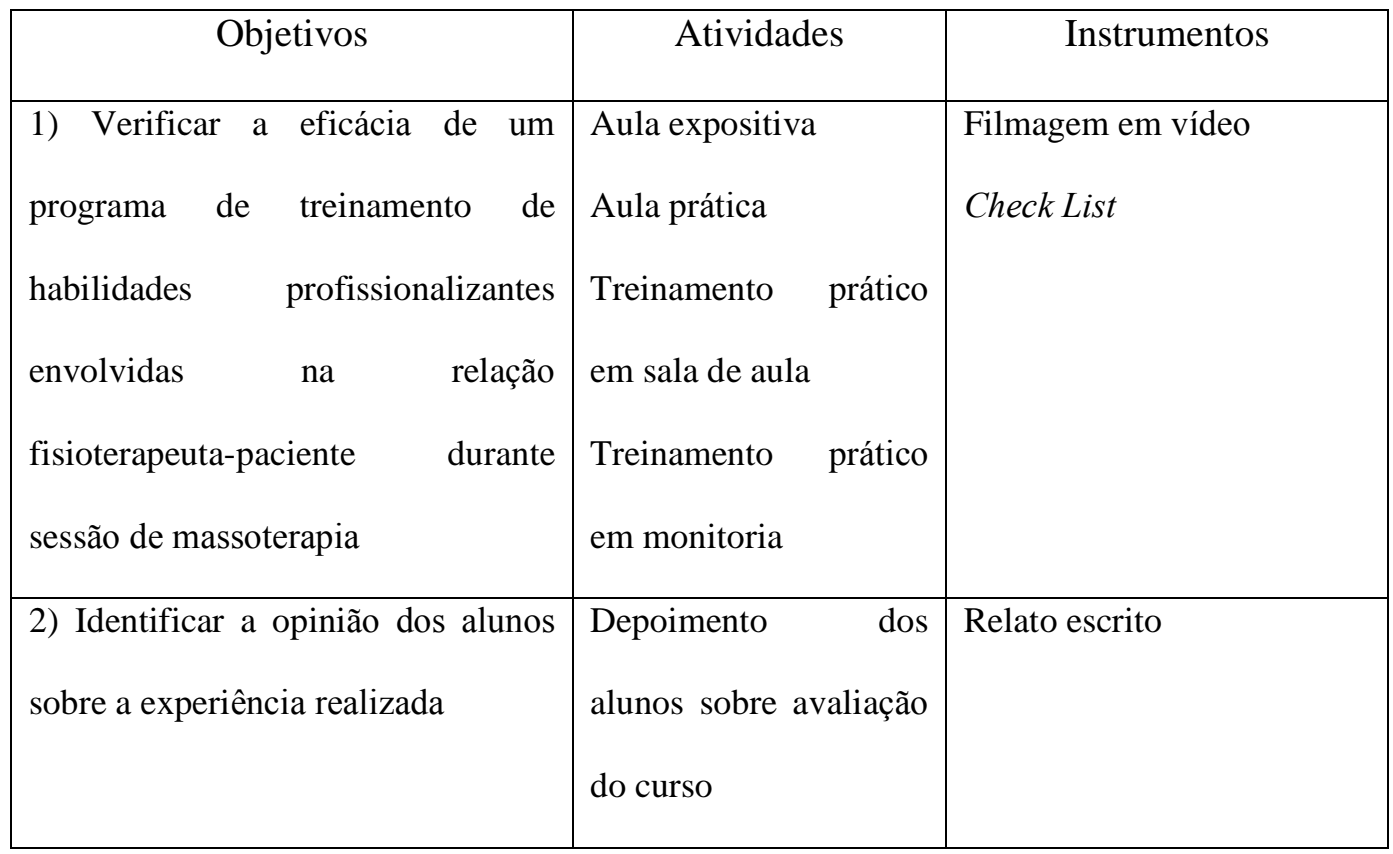


4.4. Procedimento: Os procedimentos envolvidos na realização desta pesquisa foram divididos em 3 fases:

\subsubsection{Identificação das habilidades profissionalizantes envolvidas na} relação fisioterapeuta-paciente

A seleção das habilidades ocorreu a partir da análise da literatura ${ }^{16,18,19,54} \mathrm{e}$ observação direta realizada previamente pela responsável da disciplina e pela pesquisadora em 120 sessões de massoterapia, desenvolvidas por 10 alunos com treinamento em massoterapia, junto a 10 pacientes, sendo 1 paciente para cada aluno. (Apêndice 5).

Foram selecionadas para o presente estudo 21 habilidades, enumeradas a seguir, juntamente com as definições operacionais. Estas definições permitiram, posteriormente, categorizar a avaliação do aprendizado.

Todas as habilidades desenvolvidas pelos alunos, exceto a comunicação verbal, foram avaliadas considerando a escala Likert $^{55}$ de três pontos sendo adequada (3) quando todas as características contidas na definição operacional fossem atingidas; parcialmente adequada (2) quando pelo menos uma das exigências individuais das habilidades não fosse atingida, inadequada (1) quando a habilidade foi realizada de forma incorreta; foi ainda considerada como não realizada quando o aluno não executou a habilidade.

As 21 habilidades e a definição operacional estão relacionadas a seguir:

1.Vestimenta do fisioterapeuta: Foi considerada adequada quando o aluno se apresentou com cabelo preso e/ou penteado, ausência de maquiagem ou maquiagem suave, avental ou roupa branca sem decotes, sapatos adequados e confortáveis, 
acessórios como brinco ou presilhas discretos, ausência de chinelo, shorts, saia curta, bermuda ou roupas transparentes.

2. Preparo do local para tratamento: Foi considerado adequado se, para o preparo do local de tratamento, foram providenciados toalhas limpas, travesseiro, cadeira e materiais utilizados na massoterapia, como creme ou óleo, adstringente, algodão e toalha de mão, ficha de evolução, caneta e relógio.

3. Chamada do paciente: Foi considerada adequada a chamada formal do paciente, chamando-o pelo nome, apresentando-se e acompanhando-o até a sala de atendimento.

4. Acomodação do paciente sentado: Foi considerada adequada quando o aluno auxiliou ou supervisionou a acomodação do paciente, em cadeira, para realização de coleta da freqüência cardíaca e dados de anamnese.

5. Mensuração de freqüência cardíaca pré-intervenção: Considerada adequada a mensuração da freqüência cardíaca quando o paciente foi posicionado sentado, de forma confortável e com o braço apoiado. A técnica utilizada foi a de palpação do pulso radial, durante um minuto utilizando-se dos dedos indicador e médio, com o polegar fixado no dorso do punho do paciente, sendo que o examinador usou a mão direita para examinar o pulso esquerdo.

\section{Questionamento sobre intercorrências físicas ou emocionais durante a} semana: Foi considerado adequado quando o aluno fez um questionamento para verificar algum tipo de intercorrência durante a semana que precedeu o atendimento e que possa ter desencadeado dor ou desconforto musculoesquelético, sem que o paciente pudesse ficar constrangido ao relatar fatos pessoais. 
7. Avaliação funcional básica do paciente: Considerada adequada quando o aluno iniciou sua avaliação clínica baseando-se na anamnese e observações da postura. Também, se durante a massoterapia, o aluno realizou sua intervenção relacionando os achados funcionais e de anamnese com possíveis causas de dor e/ou desconforto.

8. Feedback sobre a avaliação: O aluno deveria dar informações claras, em linguagem simples, ao paciente, sobre os achados e sobre o raciocínio clínico da avaliação funcional, para que sua habilidade fosse considerada como adequada.

9. Explicação sobre a intervenção a ser realizada: Para ser considerada adequada o aluno deveria dar informações ao paciente sobre a massagem clássica de corpo inteiro, técnica utilizada nesta pesquisa, que utiliza-se de manobras suaves como deslizamento, amassamento e percussão, promovendo o relaxamento das tensões musculares, atenuando dores localizadas.

10. Drapejamento: $O$ aluno deveria auxiliar o desnudar do paciente e manter as regiões não tratadas cobertas com toalha ou lençol, fornecendo uma situação de segurança e conforto ao paciente, para ser considerado adequado.

11. Posicionamento na maca: Posicionar o paciente de forma que o mesmo se sinta confortável, utilizando-se, para tanto, rolinhos, travesseiros e lençóis para que esta habilidade seja considerada adequada.

12. Autocuidado físico do fisioterapeuta: $\mathrm{O}$ aluno deveria executar a massagem em posturas treinadas em sala de aula e durante monitoria, de forma a diminuir as sobrecargas articulares e realização de força muscular desnecessária. O ensino do autocuidado físico na prática de massoterapia baseou-se nas posturas estabelecidas e descritas por Cassar ${ }^{10}$. As posturas foram consideradas adequadas quando por um (1) minuto a postura escolhida foi mantida de forma correta sem compensações 
corporais, segundo os critérios de Cassar $^{10}$. Foram consideradas parcialmente adequadas quando durante um (1) minuto a postura oscilasse de correta para incorreta e considerada inadequada quando o aluno mantivesse por um (1) minuto apenas a postura incorreta. As posturas utilizadas por Cassar ${ }^{10}$ estão descritas e exemplificadas abaixo e ilustradas no Apêndice 6:

- Postura de esgrimista: Esta postura facilita a aplicação do deslizamento em uma área corporal grande, sem nenhuma curvatura do tronco para frente. O pé dianteiro fica alinhado com a maca de tratamento, enquanto o pé posicionado atrás é girado lateralmente. Quando o joelho dianteiro é flexionado, o corpo move-se para frente e o peso é transferido para o pé que está à frente. À medida que o joelho se estende e endireita-se, o corpo move-se para trás e o peso é transferido para o pé que está atrás. Neste movimento, a pressão passa pelos braços e chega às mãos. As costas ficam eretas e os cotovelos levemente flexionados.

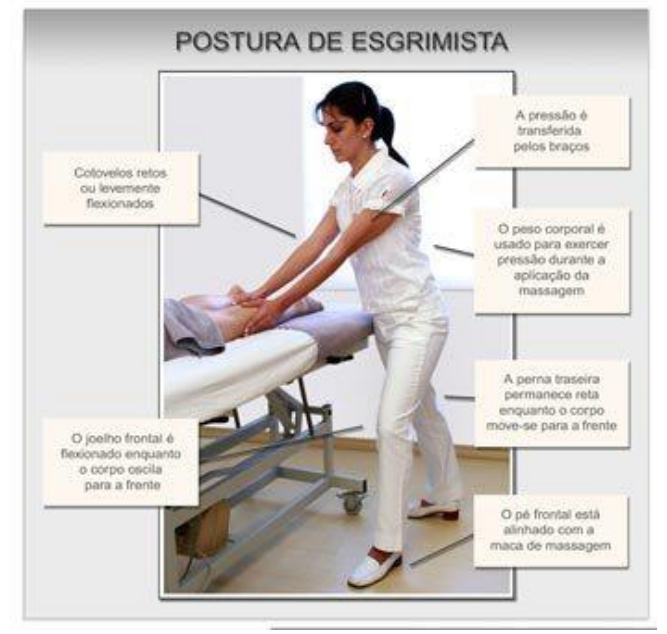

Figura 1 - Postura de Esgrimista

- Postura do tái chi: O terapeuta permanece a uma pequena distância da maca, paralela a esta. Com as costas eretas, o peso do corpo é transferido de uma para outra perna, ao mover-se de um lado para o outro. 
- Postura ereta: O profissional fica com as costas retas e os pés juntos ou levemente afastados. O corpo permanece paralelo à maca e, invariavelmente, repousa contra ela. Embora mantenha as costas eretas, o fisioterapeuta pode inclinar-se de leve para frente na altura da pelve sem colocar tensão nos músculos das costas.

- Postura do vaivém: O terapeuta permanece afastado da maca, com os pés colocados um atrás do outro. A posição dos pés é determinada pelo peso necessário para a manobra da massagem e conforto do fisioterapeuta. Manter os pés bem afastados permite a transferência de maior peso corporal para os braços. $\mathrm{O}$ movimento corporal nessa postura é para frente e para trás. À medida que o peso se desloca para o pé dianteiro, o calcanhar traseiro é levantado levemente, para elevar o corpo e alterar o centro de gravidade.

- Postura inclinada: As pernas estão paralelas e os pés afastados. Enquanto o corpo se inclina para frente, a descarga de peso, sob forma de pressão, é transferida dos braços para as mãos.

- Sentada na borda da maca de tratamento: Nesta posição a descarga de peso do corpo não pode ser aplicada com facilidade. Sentar na borda da maca é contrabalançado pela colocação de um dos pés no chão.

13. Intervenção: Aplicação da técnica massagem clássica de corpo inteiro, conforme treinado em sala de aula e descrito em item 9. A massagem foi realizada em membros superiores e inferiores, face, abdome e dorso.

14. Mensuração de freqüência cardíaca pós-intervenção: Considerada adequada conforme descrita anteriormente no item 5, porém, neste momento, o paciente encontra-se na posição deitada. 
15. Ajudar o paciente a sentar-se: Foi considerado adequado quando o aluno auxiliou o paciente a sentar-se na maca, após a massagem, para evitar contratura muscular, vertigem ou algum outro desconforto.

16. Ajudar o paciente sair da maca: $O$ aluno deveria utilizar a escadinha e/ou apoio manual, evitando qualquer tipo de acidente ao paciente, para que a habilidade fosse considerada adequada.

17. Ajudar o paciente a vestir-se: $O$ paciente deveria ser assistido, se necessário.

18. Acomodar o paciente sentado em cadeira para receber as orientações finais e/ou esclarecimentos.

19. Confirmar retorno e despedir-se: Neste caso não houve retorno, porém se despedem formalmente.

20. Preenchimento da ficha de avaliação - Evolução: A escrita dos dados da intervenção foi considerada adequada quando o aluno preencheu os dados coletados na anamnese, na avaliação funcional básica e registrou intercorrências durante o atendimento, caso tenham ocorrido (Apêndice 7).

21. Comunicação verbal oral: A avaliação da comunicação foi feita utilizando as diretrizes de Stefanelli ${ }^{30}$ sobre comunicação terapêutica e não terapêutica.

A comunicação terapêutica utiliza-se das técnicas de ouvir reflexamente, usar terapeuticamente o silêncio, verbalizar a aceitação, verbalizar interesse, usar frases com sentido aberto ou reticentes, repetir comentários ou últimas palavras ditas pelo paciente, fazer perguntas, devolver a pergunta feita, usar frases descritivas, permitir ao paciente que escolha o assunto, colocar em foco a idéia principal, verbalizar dúvidas, dizer não, estimular a expressão de sentimentos subjacentes, usar terapeuticamente o humor, estimular comparações, esclarecimento de termos 
incomuns, descrever os eventos em seqüencia lógica, repetir a mensagem do paciente.

Já as técnicas não terapêuticas constam de não saber ouvir, dar conselhos, usar jargões técnicos ou linguagem científica, falsa tranquilização, julgar o comportamento, induzir respostas, manter-se na defensiva, pôr o paciente à prova, mudar de assunto subitamente, comunicar-se unidirecionalmente, falta de capacidade de concentração e comunicação de atenção, pressuposição da compreensão da mensagem, ausência do linguajar comum.

Os diálogos entre aluno-paciente foram transcritos, a partir da coleta nos vídeos, e suas sentenças categorizadas como terapêutico ou não terapêutico e também contada a freqüência de cada categoria.

As habilidades selecionadas para o presente estudo entendidas como eticamente corretas e essenciais para o desenvolvimento profissional do aluno compuseram o programa desenvolvido com os alunos.

O objetivo de ensinar, aos alunos do $4^{\circ}$ semestre, tais habilidades, baseia-se na convicção de que a partir do aprendizado das mesmas o aluno poderá avaliar de forma crítica sua experiência e desenvolvimento na relação fisioterapeuta-paciente e estabelecer uma forma de intervenção compatível com suas necessidades, possibilidades e expectativas profissionais e pessoais.

\subsubsection{Validação, por peritos, da seqüência e definição operacional das} habilidades profissionalizantes envolvidas na relação fisioterapeuta-paciente

Com o objetivo de validar a seqüência e definições operacionais, a lista de 21 habilidades foi encaminhada para avaliação de peritos. Para ser considerado perito 
na análise das habilidades envolvidas na relação fisioterapeuta-paciente, foram utilizados os critérios de seleção de peritos adotados por Fehring ${ }^{56}$ que considera aspectos como a formação, graus obtidos, publicações na área e reconhecimento científico destes especialistas, adaptados para o uso em Fisioterapia:

- Titulo de Mestre

- Mestre com tema da dissertação associada ao tema da pesquisa (ensino, massoterapia, análise de habilidades profissionalizantes em situação de ensino)

- Pesquisa apresentada sobre o tema da pesquisa (ensino, massoterapia, análise de habilidades profissionalizantes em situação de ensino) em evento de relevância internacional

- Pesquisa publicada sobre o tema da pesquisa (ensino, massoterapia, análise de habilidades profissionalizantes em situação de ensino) em periódico de referência

- Doutorado

- Prática clínica que inclua uso de massoterapia como recurso terapêutico manual com duração de mais de um ano

- Especialização que inclua comprovada prática clínica

A recomendação deste autor é que será um perito, aquele que tiver uma pontuação acima de 5 pontos, sendo que 4 pontos são creditados aos portadores de titulação de mestre; 2 pontos para pesquisa apresentada sobre o tema da pesquisa em evento de relevância internacional; 2 pontos para pesquisa publicada sobre o tema da pesquisa em periódico de referência; 2 pontos para doutorado; 2 pontos para especialização que inclua comprovada prática clínica. É atribuído 1 ponto para dissertação em mestrado associada ao tema da pesquisa e 1 ponto para prática clínica 
que inclua uso de massoterapia como recurso terapêutico manual com duração de mais de um ano.

O grupo de peritos constitui-se de profissionais que atuam na área de ensino e/ou de massoterapia. Esses peritos opinaram não só sobre as definições operacionais, mas também quanto à seqüência temporal das habilidades propostas durante $\mathrm{o}$ atendimento de massoterapia.

A ficha de avaliação a ser preenchida pelos peritos constou das 21 habilidades com suas definições e seqüência de execução. Os peritos deram notas para cada item utilizando uma escala de pontuação organizada segundo critérios proposto por Likert $^{55}$, composta de cinco pontos, nas quais os peritos atribuíram um valor conforme sua pertinência, sendo que os valores, atribuídos pelos peritos, indicaram a representatividade de cada habilidade e sua definição (Apêndice 8 e 9).

As médias ponderadas foram obtidas pela somatória dos pesos assinalados para cada resposta e então divididas pelo número total de respostas (Fehring, 1986). Sendo assim, para cada definição operacional calculou-se a freqüência de respostas assinaladas em cada item da escala tipo Likert; próximo passo constituiu na multiplicação destas freqüências com seus respectivos escores: 5 (muito $\underline{\text { característica })}=1,0 ; 4$ (razoavelmente característica $)=0,75 ; 3$ (característica $)=0,5$; 2 (pouco característica $)=0,25$ e 1 (não característica $)=0$; a somatória dos produtos destas multiplicações foi dividida pelo número de sujeitos, obtendo-se a média ponderada para cada uma das definições (Apêndice 8).

Utilizou-se também o modelo da escala Likert ${ }^{55}$ para pontuar a opinião dos peritos quanto à seqüência das habilidades propostas. Sendo 3 para quando concorda $=1,0 ; 2$ para concorda parcialmente $=0,5$ (quando sugere mudança em até 5 das 21 
habilidades); $1=0,0$ para discorda (quando o perito sugere mudança em mais de 6 habilidades) (Apêndice 9).

A partir destas médias ponderadas optou-se pela exclusão das definições operacionais com valores menores ou iguais a 0,50. À semelhança de Fehring (1987), considerou-se que a definição que atinge um escore maior ou igual a 0,80 significa que os peritos concordam que a descrição é muito indicativa da habilidade testada.

No final da seqüência de habilidades e de suas definições, deixou-se um espaço para sugestões de mudanças. Os instrumentos de coleta de dados foram entregues em mãos aos peritos.

\subsubsection{Treinamento de Monitores}

Os dez (10) monitores, que auxiliaram no desenvolvimento do programa, eram alunos regularmente matriculados no curso de Fisioterapia e aprovados na disciplina de Recursos Terapêuticos Manuais e, de forma voluntária, participaram deste estudo. Receberam orientação sobre habilidades profissionalizantes envolvidas na relação fisioterapeuta-paciente, em sessão de massoterapia, no semestre anterior à aplicação do programa durante a disciplina RTM e treinamento de 40 horas oferecido pela professora da disciplina e pesquisadora que consistiu de aulas teóricas, práticas e discussões. Posteriormente, cada monitor realizou 12 atendimentos de massoterapia acompanhando um paciente, sob supervisão das pesquisadoras. Foram treinados e orientados quanto à utilização da lista de habilidades propostas a partir da literatura. 


\subsubsection{Desenvolvimento do programa de treinamento das habilidades}

junto aos alunos

Como recurso didático foi escolhido o treinamento a partir de demonstração, com oito períodos de quatro (4) horas de treinamento, por repetição durante simulação junto aos alunos em sala de aula e oito períodos de quatro (4) horas de treinamento com monitores. Cada aula foi dividida em duas horas teóricas e duas horas práticas. Na parte teórica, foram enfatizadas as técnicas e efeitos fisiológicos da massagem e, durante o treinamento prático, foi enfocada a seqüência de habilidades propostas, considerando suas definições operacionais. Foi entregue um cartilha com imagens e descrições das posturas de autocuidado utilizadas na massagem clássica (Apêndice 6).

Durante as aulas práticas, foi realizada demonstração (modelo prático) das técnicas de massoterapia pela professora e um aluno voluntário fazia o papel de assistente da professora, auxiliando na execução das demais habilidades estipuladas no roteiro, desde o preparo do local de trabalho até a despedida do paciente-aluno. Após a fase de demonstração, os alunos se dividiram em trios para o treinamento prático, enquanto o professor e o pesquisador observaram cada aluno atendendo seu colega, corrigindo-o quando necessário e dando um feedback sobre as habilidades realizadas.

Na mesma semana, o aluno agendava horário com um dos monitores para treinamento durante uma (1) hora. 
4.5. Análise dos dados: A aquisição das habilidades práticas foi avaliada de duas formas:

\subsubsection{Desempenho no uso das habilidades profissionalizantes na relação}

\section{fisioterapeuta-paciente}

O resultado do aprendizado foi obtido por meio da avaliação das habilidades treinadas pelos alunos durante a prova prática, tendo sido seu registro efetuado pela gravação de filmes VHS. A prova prática foi realizada ao final do desenvolvimento do programa. Durante a prova, o aluno deveria apresentar a seqüência de habilidades e suas definições operacionais como critérios de avaliação. A atividade de prova consistiu em atender um paciente, em situação real, por meio da aplicação de massagem clássica de corpo inteiro. Para tanto, contou-se com a colaboração de pessoas consideradas saudáveis, sem queixa, no papel de paciente. Estes pacientes tiveram o conhecimento do termo de consentimento livre e esclarecido (TCLE) e aquiescência em participar do estudo (Anexo 3). O tempo máximo estipulado para a realização desta etapa foi de uma hora e trinta minutos por aluno.

Mesmo sendo uma prova prática, com convidados externos, e os pacientes sendo atendidos por sorteio feito pela pesquisadora, teve-se o cuidado de reproduzir uma situação semelhante à treinada em sala de aula.

Para a coleta dos dados da prova prática foram utilizados os instrumentos de filmagem e check list com o objetivo de avaliar o desempenho dos alunos nas habilidades treinadas, sendo cada prova analisada individualmente.

Cada prova foi realizada em sala individual, com uma câmera filmadora posicionada a uma distância de três metros, possibilitando que toda a sessão de 
terapia fosse gravada com boa qualidade, maximizando a observação do paciente e do terapeuta, desde a chamada do paciente até o término do atendimento.

Durante a realização da prova, a professora da disciplina ou a pesquisadora permaneciam do lado de fora da sala de prova, disponíveis para resolver eventuais problemas que ocorressem durante o atendimento.

Para assegurar a confiabilidade dos resultados obtidos, 16 dos 24 vídeos foram avaliados por um examinador independente, com conhecimento do conteúdo aplicado, para comparação dos resultados. O coeficiente de confiabilidade foi estabelecido para cada habilidade, utilizando-se a fórmula proposta por Fehring ${ }^{58}$ :

$$
\mathbf{R}=\underline{\mathbf{A}}
$$

Onde "R" significa o coeficiente de confiabilidade entre observadores; " $A$ " o número de concordâncias; "D" o número de discordâncias. O resultado acima de 0,80 demonstra concordância entre os examinadores.

No final do programa e disciplina, os alunos receberam a prova prática com relatório escrito sobre seu desenvolvimento feito pelo pesquisador, com feedback sobre cada habilidade realizada e sugestões individuais para melhora da aplicação da técnica de massagem e de suas habilidades, proporcionando ao aluno a possibilidade de refletir criticamente sobre suas ações e atitudes profissionais. Este material foi entregue em envelope lacrado para que apenas o aluno tivesse acesso ao conteúdo. 


\subsubsection{Avaliação dos alunos sobre experiência de aprendizagem e treinamento realizado de habilidades profissionalizantes a partir de relato escrito}

A apresentação deste item teve como propósito atender ao objetivo número 2. Para tal, foi requisitada, por meio de uma (1) questão aberta, a opinião individual dos alunos sobre o programa aplicado. Esta questão aberta foi entregue por uma terceira pessoa, que não foi nem a professora e nem a pesquisadora, para que não houvesse forma de identificação do material escrito (Apêndice 4). Foi solicitado aos alunos que, de forma escrita e não identificada, dessem sua opinião, sugestões ou críticas com relação à disciplina, à monitoria e ensino de habilidades profissionalizantes. Os relatos foram analisados de forma quantitativa, sendo as respostas organizadas por categorias. 


\section{ASPECTO ÉTICO}

Esta pesquisa foi aprovada pela Comissão de Ética para Análise de Projeto de Pesquisa -CAPPesq da Diretoria Clínica do Hospital das Clínicas e Faculdade de

Medicina da Universidade de São Paulo, protocolo número 946/05 (Anexo 2).

pdfMachine - is a pdf writer that produces quality PDF files with ease! Get yours now !

"Thank you very much! I can use Acrobat Distiller or the Acrobat PDFWriter but I consider your product a lot easier to use and much preferable to Adobe's" A.Sarras - USA 


\section{RESULTADOS}

\subsection{Caracterização dos sujeitos}

Iniciaram o estudo 25 alunos, sendo três homens e vinte e duas mulheres com idade média de 19,2 $( \pm 0,8)$ anos. Não houve desistência; porém uma prova prática relativa à avaliação do desempenho de um aluno, registrada por meio do filme, foi descartada por questões técnicas da gravação, que não permitia uma avaliação adequada; ficando, portanto, válidos 24 filmes para a avaliação das habilidades profissionalizantes. Os dados obtidos pelo relato escrito deste aluno foram considerados para estudo.

\subsection{Caracterização dos peritos}

Os peritos participantes foram 10 fisioterapeutas, professores, atuantes nas áreas de massoterapia e que foram consultados previamente sobre a possibilidade de fazerem a avaliação da definição operacional e da seqüência de habilidades estipuladas. Para tanto, receberam a lista com a devida seqüência temporal e definição operacional das habilidades propostas.

Todos os fisioterapeutas atingiram uma pontuação maior que 5, o que os caracterizou como peritos $\left(\mathrm{Fehring}^{56}\right)$. A pontuação individual de cada perito encontra-se no Apêndice 10.

Foram utilizadas todas as sugestões de melhoria citadas por eles para as definições operacionais, descritas a seguir. 


\subsection{Resultados da validação das definições operacionais e seqüência}

temporal das habilidades

Nesta fase foi realizado o estabelecimento das definições operacionais, a partir de valores atribuídos pelos fisioterapeutas peritos, a cada definição operacional das habilidades propostas numa escala tipo Likert ${ }^{55}$, conforme a pertinência de suas características.

Obteve-se um retorno de $100 \%$ do preenchimento dos escores por parte dos peritos.

Pelo julgamento das definições operacionais das 21 habilidades profissionalizantes, realizado pelos 10 fisioterapeutas peritos, nenhuma das habilidades recebeu escore menor que 0,80 ; três habilidades receberam escore maior que 0,90 e menor que 1 , sendo 0,92 para a habilidade de "preparo do local de tratamento" e 0,95 para as habilidades "feedback sobre avaliação" e "explicação sobre intervenção a ser realizada". As demais habilidades tiveram um escore de 1,0 para suas definições.

Nas habilidades:

- Vestimenta do Fisioterapeuta - foi sugerido incluir na definição operacional a utilização de sapatos adequados e confortáveis para a massoterapia;

- Preparo do local do tratamento - foi incluído na definição operacional, de acordo com os peritos, que o ambiente deveria ser calmo, a luz boa sem ser excessiva para o paciente, a temperatura amena, podendo ter som ambiente com música calma;

- Feedback sobre avaliação - solicitaram que o aluno devesse relacionar os achados clínicos com a intervenção a ser realizada. 
As demais definições foram acatadas de forma positiva pelos peritos, sem sugestões de alteração ou complementação.

Não houve sugestão de mudança na seqüência temporal, pois obteve-se o escore de 1, de acordo com o julgamento dos 10 fisioterapeutas peritos.

\subsection{Resultados referentes às atividades avaliadas na situação aluno-} paciente

\subsubsection{Tempo total da prova}

O tempo total da prova (interação) dos 24 alunos foi de 1588 minutos sendo a média de 66,2 minutos.

\subsubsection{Tempo total da intervenção}

O tempo total da intervenção (massagem) dos 24 alunos foi de 1355 minutos, sendo o tempo médio de 56,4 minutos.

\subsubsection{Resultados das habilidades avaliadas pelo instrumento de filmagem}

Dezenove das 21 habilidades foram avaliadas conforme a metodologia adotada apontando como: adequada, parcialmente adequada, inadequada e não realizada (Figura 2).

O autocuidado físico teve a análise dos dados feitos a partir do tempo, da forma (adequada, parcialmente adequada e inadequada) e da postura escolhida. A comunicação foi analisada de acordo com a definição de terapêutica e não terapêutica $^{30}$. Os resultados referentes ao autocuidado físico e à comunicação serão apresentados posterior às demais habilidades por exigirem maior detalhamento.

Doze das dezenove habilidades executadas foram avaliadas como adequadas pelos 24 alunos que participaram do estudo, a saber: 
- vestimenta do terapeuta

- preparo do local de tratamento

- chamada do paciente

- explicação sobre intervenção

- drapejamento

- posicionamento na maca

- intervenção

- ajudar o paciente a sentar-se na maca

- ajudar o paciente a sair da maca

- auxiliar o paciente a vestir-se

- despedir-se adequadamente

- preencher a ficha de evolução

As habilidades acomodar o paciente sentado, mensurar a freqüência cardíaca pré intervenção e questionamento sobre intercorrência física ou emocional durante a semana, tiveram sua execução realizada de forma parcialmente adequada por 1 (um) aluno em cada habilidade. Ocorrências: um aluno iniciou a anamnese com o paciente em pé e, após alguns instantes, pediu para sentar-se; um aluno mensurou a freqüência cardíaca pré-intervenção logo após o início da intervenção e outro aluno não questionou de maneira suficiente sobre intercorrências físicas ou emocionais. Os demais alunos realizaram estas habilidades de forma adequada. Larin ${ }^{60}$ também $^{-1}$ concorda que, na relação fisioterapeuta-paciente, a existência de habilidades profissionais adequadas impede que exista uma relação muito pessoal que prejudique a prática clínica. 
Na habilidade feedback sobre avaliação, 2 (dois) alunos realizaram a habilidade de forma parcialmente adequada, dando informações insuficientes sobre seus achados clínicos ao paciente. Os demais alunos fizeram-na adequadamente. Observamos, assim como $\operatorname{Larin}^{60}$, que a experiência clínica promove um estímulo ao aprendizado, aumentando assim o conhecimento prático e teórico, e aumentando sua responsabilidade e auto confiança.

Nenhuma habilidade foi realizada de forma inadequada por parte dos alunos.

Já com relação às habilidades não realizadas, houve 1 (um) aluno que não realizou coleta de freqüencia cardíaca pós-intervenção, 1 (um) aluno não acomodou o paciente sentado após a intervenção, 2 (dois) alunos não realizaram a habilidade de coleta de freqüencia cardíaca pré-intervenção, assim como não realizaram a avaliação funcional básica e 4 (quatro) alunos não deram feedback sobre os achados da avaliação. No entanto, essas habilidades foram realizadas pelos demais alunos (Figura 3).

O índice de concordância obtido após o pareamento com os resultados da avaliação das habilidades profissionalizantes feita pelo examinador independente foi superior a $0,93 \mathrm{em}$ todas as habilidades pesquisadas.

Especificamente as habilidades questionamento sobre intercorrências físicas ou emocionais, avaliação funcional básica, feedback, drapejamento e acomodar o paciente sentado tiveram um índice de concordância entre 0,93 a 0,95 e as demais habilidades tiveram um índice de concordância de 0,96 a 0,98. 


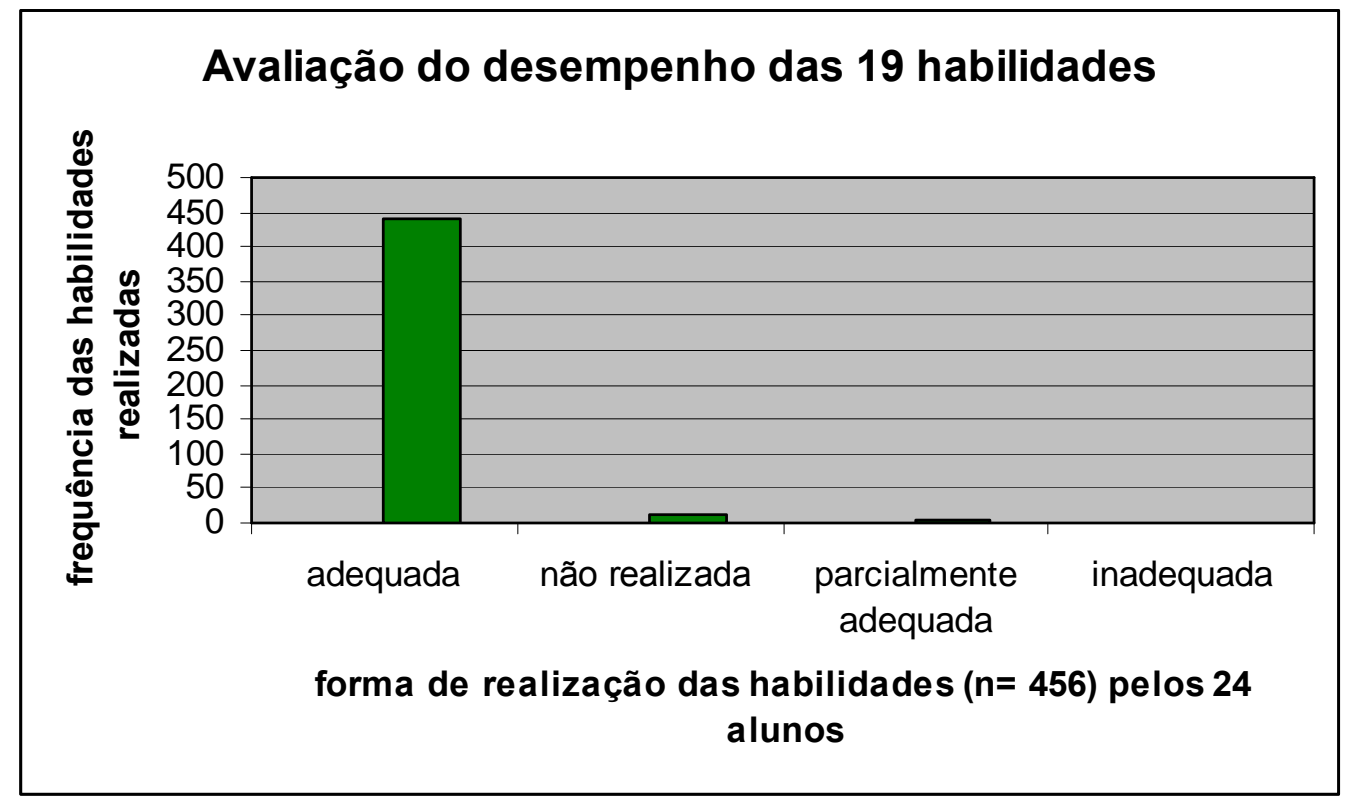

Figura 2 - Ilustração da adequação das habilidades 


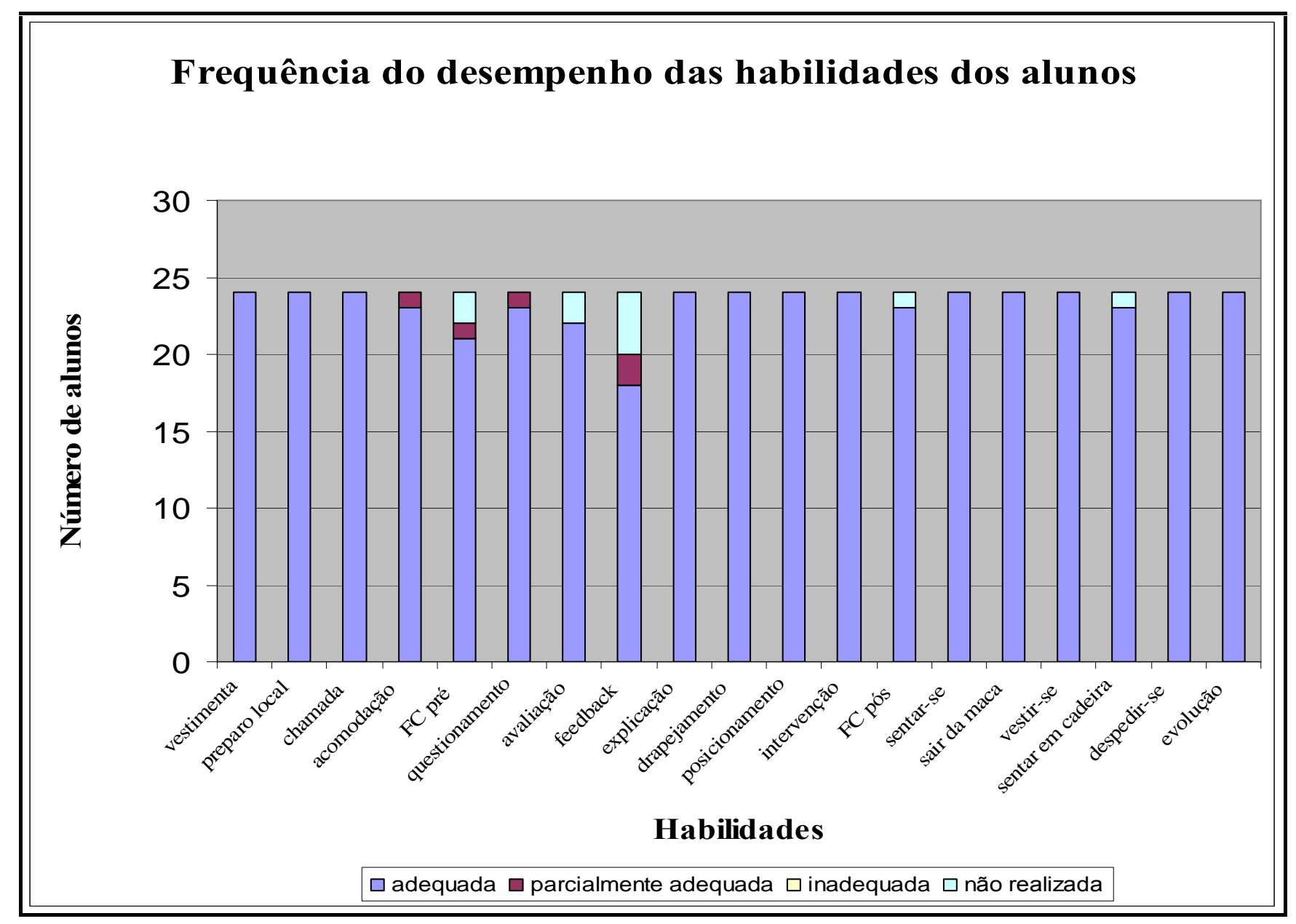

Figura 3 - Freqüência do desempenho das habilidades dos alunos

"Thank you very much! I can use Acrobat Distiller or the Acrobat PDFWriter but I consider your product a lot easier to use and much preferable to Adobe's" A.Sarras - USA 
As habilidades autocuidado físico e comunicação mereceram destaque em seu resultado, pela relevância e continuidade durante toda a intervenção observada.

\subsubsection{Autocuidado Físico}

Os resultados encontrados na habilidade de autocuidado físico demonstram que a postura ereta foi a mais utilizada, de forma adequada em $43,4 \%$ do tempo total da intervenção. A postura esgrimista foi utilizada, de forma adequada, em 17,5\% do tempo, seguida da inclinada em $10 \%$ do tempo. As demais posturas como vaivém, tai chi, sentada em banco totalizaram $22,7 \%$. Nota-se a ausência da utilização da postura sentada em maca.

Posturas parcialmente adequadas foram observadas durante um período reduzido de tempo, totalizando em $2,4 \%$ do tempo total (Figura 4 ).

Não houve nenhuma postura adotada de forma inadequada, que pudesse acarretar lesões físicas ao aluno ou implicasse na aplicação de manobras técnicas inadequadas junto ao paciente.

Os resultados referentes ao autocuidado físico apresentam um índice de concordância de 0,95 quando comparados com os dados do examinador independente. 


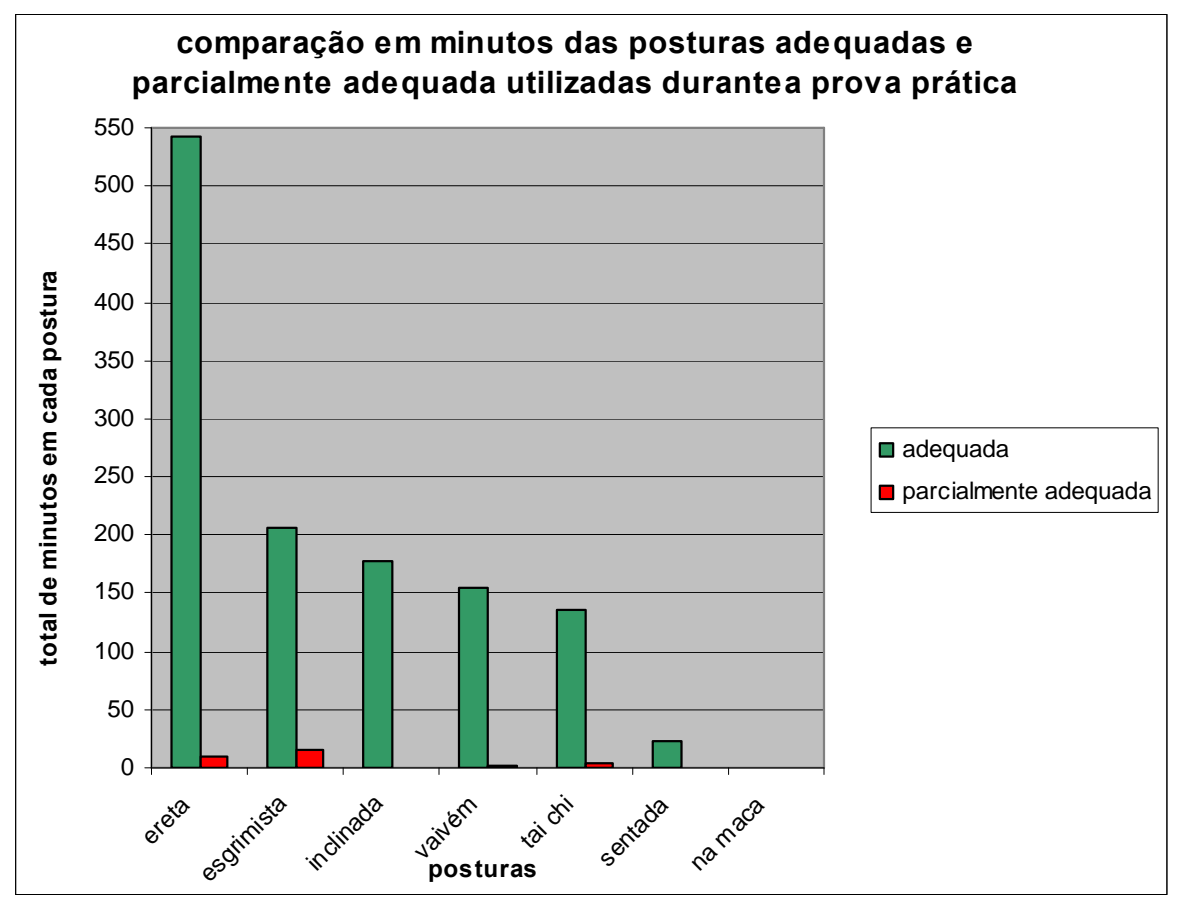

Figura 4 - Resultado em minutos da forma e postura utilizada durante a prova prática.

\subsubsection{Comunicação}

Durante a análise de 24 atendimentos, 2004 sentenças foram descritas e classificadas de acordo com Stefanelli ${ }^{30}$, com média de 90 sentenças por atendimento. Os fisioterapeutas falaram $72 \%$ do total de sentenças.

A comunicação foi considerada terapêutica em $86 \%$ das sentenças realizadas pelo aluno durante a intervenção. A comunicação não terapêutica totalizou $14 \%$ das sentenças realizadas pelos alunos (Figura 5).

A comunicação de forma não terapêutica foi observada durante a realização da massagem principalmente na forma de indução de respostas por parte dos alunos, obtendo como respostas um único "sim" ou "não". 


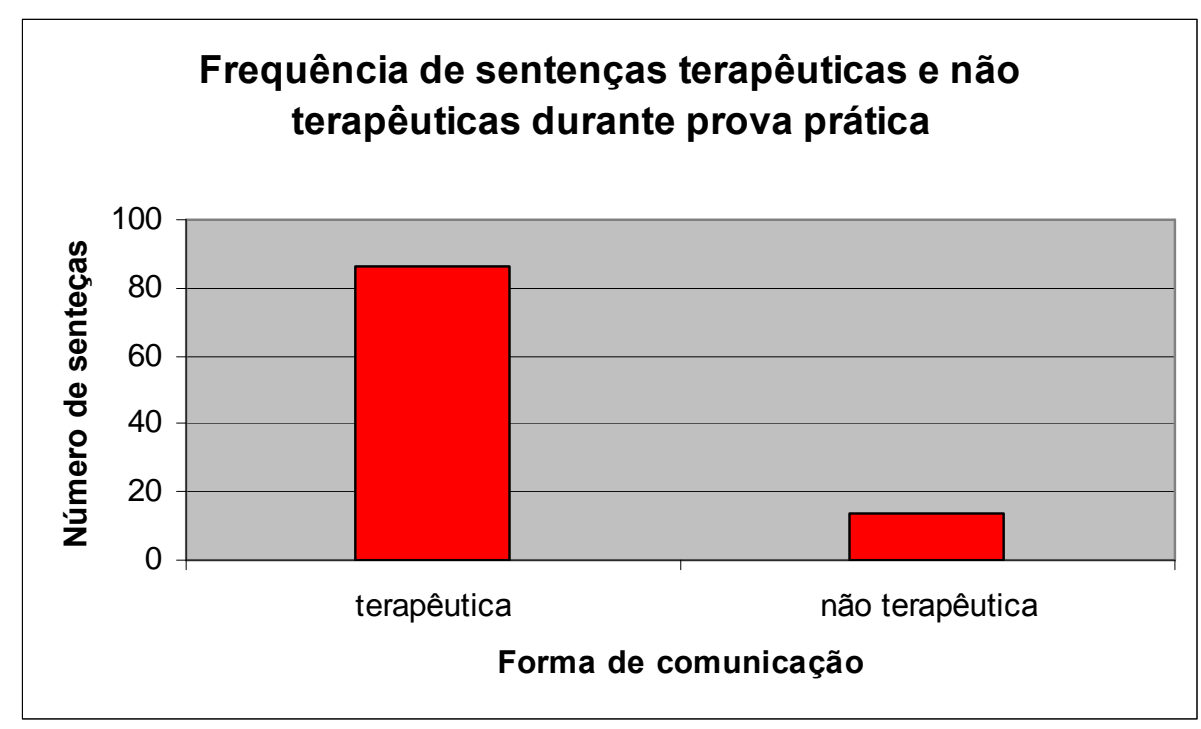

Figura 5 - Resultado da forma da comunicação utilizada.

O índice de concordância entre o pesquisador e o examinador independente, na habilidade de comunicação, foi de 0,92. Por ser uma habilidade não cognitiva, acreditase que haja uma dificuldade maior em julgar ou estabelecer padrões de acordo com a interpretação individual, porém o índice encontrado é satisfatório segundo Fehring ${ }^{58}$.

\subsection{Resultado da avaliação dos alunos sobre a experiência de aprendizado e}

\section{treinamento realizado a partir do relato escrito}

Os relatos escritos individuais dos alunos com relação à disciplina, monitoria e ensino de habilidades profissionalizantes foram resumidos e categorizados. Em $85 \%$ dos relatos feito pelos alunos foi pontuado que a existência de um roteiro foi fator de segurança e domínio no desenvolvimento da sessão de massoterapia; em relação à rotina empregada para o ensino das habilidades profissionalizantes $76 \%$ dos alunos a consideraram importante e necessária, com citação de que facilitou a relação com o paciente trazendo os alunos mais próximos da realidade clínica. A habilidade de 
autocuidado físico foi destacada como importante para o desenvolvimento profissional e apropriada para a situação por $40 \%$ dos alunos.

A presença do monitor foi destacada por $52 \%$ dos alunos como importante para a fixação do conteúdo teórico-prático aprendido, e igualmente foi avaliado de forma positiva o conteúdo programático da disciplina. Contudo, algumas opiniões sugerem necessidade de um repensar para possível reajuste do programa oferecido: $20 \%$ deles mencionaram a necessidade de aumentar a carga horária da monitoria, $8 \%$ dos alunos mencionaram que as habilidades profissionalizantes foram "frias" e $8 \%$ sugeriram que a parte prática da massoterapia ocorresse de forma simultânea com a demonstração do professor. 


\section{DISCUSSÃO}

No presente estudo, explorou-se uma área da fisioterapia clínica que é normalmente lembrada como muito importante no ensino de graduação; porém, nem sempre, tão representativa na literatura, a relação fisioterapeuta-paciente. Os fisioterapeutas pouco têm publicado, especificamente, sobre o processo de ensinoaprendizagem de habilidades profissionalizantes.

De forma geral, a proposta de ensino foi considerada pelos autores e alunos, satisfatória para o desenvolvimento de habilidades na relação fisioterapeuta-paciente, em consonância com Altamaier ${ }^{16}$ e Hojat $^{17}$, pois mencionam que para ocorrer o desenvolvimento cognitivo deve ser incluído também o treinamento técnico. Jette ${ }^{12}$ afirma que os alunos nos primeiros anos de graduação devem dar início ao treinamento de sua independência clínica, mesmo que ainda não seja em todas as situações vivenciadas.

Analisando o histórico do ensino superior em fisioterapia no Brasil, observou-se uma valorização do indivíduo, da terapêutica, da especialidade e da utilização de métodos e técnicas sofisticadas ${ }^{15,59}$. Assim, o futuro profissional fisioterapeuta deve aprender não só a técnica e os fundamentos a serem utilizados junto aos pacientes, mas também a ter uma conduta profissional adequada, respeitando a individualidade do paciente e estabelecendo uma relação profissional formal para com este.

Para este estudo optou-se pela inserção de um paciente na situação de prova para simular a situação clínica. May $^{18}$ ressalta que, segundo os supervisores clínicos, a maior dificuldade dos alunos em fazer a transição da sala de aula para a clínica é o aspecto não cognitivo, pois são características não treinadas de maneira formal durante o ensino da prática. 
Os alunos conseguiram administrar bem o tempo total da prova permitido, sem a necessidade de ultrapassar o limite estipulado ou até mesmo fazer um atendimento apressado, em que o paciente pudesse sentir falta da atenção desejada.

As 12 habilidades realizadas de forma adequada por $100 \%$ dos alunos nos demonstra que este conteúdo treinado durante o estudo foi absorvido por estes, de forma integral, durante a prática clínica. Acreditamos que estas habilidades se tornem rotina nos futuros atendimentos, sem a necessidade da atenção direcionada e entende-se que a manutenção adequada destas habilidades favoreça um atendimento competente, deixando o aluno bem centrado para lidar com suas incertezas e ansiedades. Assim, quando eles estiverem confortáveis com suas próprias habilidades, podem focar mais em seus pacientes, melhorando então o atendimento formal ${ }^{60}$.

Mesmo sendo a primeira situação real do aluno em fazer esta transferência da sala de aula para a clínica, o que poderia deixá-lo angustiado e ansioso, observou-se que estes foram capazes de realizar, como por exemplo, as habilidades de preparo do local de tratamento, explicação sobre intervenção a ser realizada e despedida, adequadamente, sem dificuldades, ou incorretamente. A opinião dos alunos nos assegura deste preparo:

A programa proposto foi bom, pois nos deixa mais próximos da realidade (nos tira daquela dimensão de aulas)”.

A habilidade de feedback sobre a avaliação apresentou maior dificuldade por parte do aluno durante a prova final. Foi realizada de forma parcialmente adequada por um aluno e não realizada por quatro alunos. Acreditamos que o aluno se sentia muitas vezes inseguro ou inibido em se comunicar com o paciente por ser uma pessoa desconhecida deste. Assim como Larin ${ }^{60}$, acreditamos que com a manutenção do treinamento formal desta habilidade, o aluno desenvolva maior experiência prática e 
consiga desenvolver uma terapia mais focada e diretiva. A habilidade de feedback necessitará de maior ênfase durante os futuros treinamentos, mesmo que o aluno nos transmita a sensação de confiança.

"...nos deu a idéia de como tratar o outro, o outro que não conhecemos..."

Remetendo à definição de Marques ${ }^{13}$ “ensinar é uma atividade efetiva se resultar em aprendizagem do aluno, na qual o conhecimento científico pode ser um instrumental poderoso para nortear um fazer competente; cabendo ao professor a responsabilidade pela proposição de objetivos, o arranjo e a programação de conteúdo de atividades, de tal forma que o aluno possa adquirir as habilidades no grau de competência desejado.”

Masetto $^{47}$ resume de maneira esclarecedora os fatores relacionados com o processo de aprendizagem, ao afirmar que este se refere ao processo de crescimento e desenvolvimento de uma pessoa em sua totalidade, abarcando três áreas do ser humano: - a do conhecimento que compreende toda a parte mental e intelectual do homem, onde ela não poderá se esgotar em assimilar algumas informações ou conhecimentos obtidos e repeti-los; - a de habilidades humanas e profissionais que abrange tudo que fazemos com os conhecimentos adquiridos; - e a área de atitudes e valores que compreende o desenvolvimento de valores pessoais, como ética, respeito aos outros, opiniões, honestidade intelectual, criticidade, curiosidade, criatividade e autonomia.

Acreditamos, como Masetto $^{47}$, que o ensino de habilidades profissionalizantes, principalmente as que estudam a relação fisioterapeuta-paciente, pode contribuir para melhor qualidade na formação do ser humano, que compreende a parte intelectual e emocional de seu paciente. O programa proposto deve abrir um espaço de reflexão para que o aluno e educadores repensem suas atitudes e valores, considerando a ética e o respeito ao próximo como exemplificado por um aluno: "O treinamento das habilidades do fisioterapeuta também foi importante, pois realmente existe uma 
dificuldade de relacionamento com o paciente no início e acredito que a formalidade realmente deve ser mantida”.

O estudo de Hayes ${ }^{15}$ constatou que 56,7\% dos comportamentos não cognitivos, ou seja, comunicação oral e profissionalismo, tiveram um desempenho insatisfatório na clínica dos alunos. Para Altamaier ${ }^{16}$ e Hojat $^{17}$ o aspecto cognitivo aborda treinamento e habilidade técnica. $\mathrm{O}$ aspecto não cognitivo abrange respostas comportamentais, habilidades interpessoais e comunicação. O estudo aqui apresentado tomou como base esta definição e diretriz e se propôs a organizar, respeitando o estabelecido por Marques $^{13}$, e ensinar habilidades não cognitivas a partir do código de ética da profissão. Hayes ${ }^{15}$ ainda cita que $28 \%$ dos comportamentos citados por médicos como problemas que afetam o desempenho dos estudantes é a comunicação e assim percebemos a importância em manter este treinamento com base em depoimento de um aluno: "As normas de conduta no atendimento de pacientes foi de grande importância para nós, pois leva-nos a uma postura adequada enquanto fisioterapeuta, ensinando a nos comunicar com eles. Assim acho que estas normas devem continuar na disciplina”.

Foi observado na presente pesquisa, que a habilidade para questionar intercorrência física ou emocional durante a semana, foi efetivada por $95,8 \%$ dos alunos de forma satisfatória, sem ultrapassar a privacidade do paciente nem requerer detalhes pessoais sobre acontecimentos; mostrando-se, porém, dispostos a ouvir as queixas dos pacientes.

Neste estudo, existe uma atenção direcionada à habilidade de comunicação, pois acredita-se que, a partir de uma comunicação eficiente, haverá uma intervenção adequada e a evolução satisfatória do tratamento. Assim como Jette ${ }^{12}$, acreditamos que o estudante deva ser educado, confiante, respeitoso; estar em condições emocionais de se relacionar com qualquer paciente; mostrar-se hábil em seus conhecimentos 
científicos e habilidades profissionalizantes, ganhando assim o respeito e confiança de seus pacientes.

Considerando a comunicação uma habilidade interpessoal necessária para assegurar a competência dos alunos durante um atendimento, a utilização desta habilidade foi considerada satisfatória, pois observou-se a comunicação terapêutica em mais de $80 \%$ das sentenças ditas pelos alunos, favorecendo uma terapia mais formal e diretiva, posicionando o paciente numa situação de segurança caso fosse necessário questionar ou esclarecer alguma dúvida com seu terapeuta. Alguns autores como ${ }^{61,62,63}$ enfatizam a necessidade da competência em comunicação na área da saúde, por parte dos profissionais, diante da crescente promoção da saúde e na participação do paciente no cuidado que requer muitas vezes ações relacionadas diretamente com a boa comunicação do profissional. Assim mostramos a necessidade de trabalhar o emissor (terapeuta) não considerando diretamente a resposta do receptor (paciente) em virtude da latência da percepção da sensação, sentimentos e dúvidas. Pesquisas anteriores mostram que os comportamentos afetivos são necessários para uma interação efetiva entre o fisioterapeuta e o paciente ${ }^{3}$.

Jette $^{12}$ afirma que determinar o nível e adequação do desempenho no atendimento clínico dos estudantes é um processo complexo que ocorre num contexto com grande variedade clínica, tipos de paciente e experiência tanto do estudante quanto do professor.

Os resultados encontrados na habilidade de comunicação nos mostram quanto o treinamento da habilidade afetou positivamente o desempenho. Isso nos chama a atenção para a questão de que os professores e supervisores clínicos precisam identificar precocemente os comportamentos tanto cognitivos como não cognitivos inaceitáveis na prática clínica; a fim de poder intervir, solucionar o fator prejudicial e evitar que a 
comunicação deficiente afete negativamente em $57 \%$ da performance clínica dos estudantes, como encontrado por Hayes ${ }^{15}$. A comunicação interpessoal é uma habilidade necessária para todos que estão envolvidos direta ou indiretamente com o paciente, seja ele o próprio paciente, os seus familiares ou os profissionais da saúde.

O treinamento desta habilidade incentiva o aluno a ultrapassar barreiras de medo, insegurança e desconhecimento, deixando-o mais confiante para orientar e instruir seu paciente em relação às recomendações, orientações e cuidados, demonstrando assim um maior controle da situação clínica. A comunicação inadequada encontrada em $14 \%$ das sentenças eram especificamente em sentenças que induziam às respostas "sim" e "não" o que, de acordo com Stefanelli" ${ }^{30}$, deve ser evitado, pois muitas vezes o paciente fica sem alternativa para dar outra resposta que não a contida na pergunta e fica evidente o que o profissional quer ouvir como resposta. É o tipo de comunicação que não estimula nem propicia a expressão verbal dos sentimentos ou pensamentos do outro.

É com o aprimoramento da competência em comunicação humana, tornando o seu uso cada vez mais eficiente e benéfico para o paciente, família e comunidade, que atingiremos o cuidado competente e humanitário àquele que necessita da assistência a saúde $^{30}$.

Vale lembrar que da mesma forma, durante a formação do fisioterapeuta também se devem enfatizar a segurança e a prevenção de dores musculoesqueléticas adquiridas no ambiente de trabalho, por meio da postura e do autocuidado físico utilizado pelo profissional. O aprendizado prático da mecânica corporal e segurança física do profissional são essenciais neste momento de graduação, um aluno deixa claro, em seu relato, esta compreensão: “Achei que a parte do cuidado com a postura foi 
bastante importante e a maneira como foi passada foi eficiente, pois acho que todos aprenderam a cuidar da postura durante o atendimento".

Os futuros profissionais devem ser devidamente treinados antes de serem efetivados em seus empregos sendo assim necessário um ensino na graduação sobre prevenção de doenças ocupacionais, introduzindo não só os conhecimentos técnicos, mas os conhecimentos práticos da prevenção em saúde ${ }^{36}$.

Considerando que em 97,6\% do tempo total da intervenção observada, o aluno utilizou-se de postura adequada, este estudo tem como expectativa que, a partir do ensino prático e aprendizado do autocuidado físico, sejam evitadas ou minimizadas as futuras lesões, contribuindo então para a diminuição do alto índice de dores ocupacionais do fisioterapeuta como encontrado nos estudos de $\mathrm{Holder}^{44}$; $\mathrm{Cromie}^{4}$ e Bork $^{5}$.

Os alunos mostraram a compreensão da importância da prevenção de lesões físicas por meio de seus relatos dizendo:

“...talvez se não tivesse tomado consciência sobre esse assunto, provavelmente sofreria conseqüências futuras piores."

"A orientação quanto a postura foi boa e bem enfatizada".

O estudo direcionado para o autocuidado físico e comunicação demonstrou um aprendizado satisfatório para uma boa evolução terapêutica, investigando avaliações mais amplas e detalhadas em estudos posteriores.

Ao final da pesquisa, a opção por utilizar o feedback gerado pelo professor e pesquisadora com relação à prova prática do aluno se baseou no estudo de Roberts e Bucksey $^{64}$ ao afirmarem que, na prática clínica, a gravação em filme de um dos primeiros atendimentos do aluno pode contribuir com uma informação rica e material 
para reflexão, ajudando a identificar os pontos a serem mudados ou melhorados nos futuros atendimentos.

Pereira ${ }^{65}$ mostra como a pessoa descobre-se ao se observar, por exemplo, numa filmagem, percebendo-se positiva ou negativamente nas interações. Desta forma optouse por devolver a prova final dos alunos, gravadas em VHS, juntamente com a opinião e sugestão da pesquisadora, para que o aluno pudesse se analisar e identificar fatores a serem modificados em sua prática clínica.

Já quanto ao relato escrito gerado pelo aluno, cinco alunos pontuaram que durante o ensino da prática de massoterapia eles realizassem a técnica junto com a demonstração da técnica feita pelo professor. Este é um aspecto limitante a modificar no programa, de acordo com a dinâmica e desenvolvimento da aula, já que pelo grande número de seqüências de manobras haveria um número de interrupções muito grande e que talvez prejudicasse a percepção do aluno do desenvolvimento de uma terapia completa e não segmentada.

Foi possível observar com os dados obtidos no relato feito pelos discente, que o emprego de monitores mostrou-se satisfatório e foi acolhido de forma positiva pelos alunos indo de acordo com Hayes ${ }^{15}$ que cita que quando os estudantes recebem feedback sobre sua performance, ocorre uma resposta positiva em seu aprendizado e mudança de comportamento: "Acho que a monitoria seja tão importante quanto as aulas no aprendizado das técnicas de massagem. Isso é algo que deve continuar".

A citação de um aluno nos mostra com clareza seu entendimento sobre a monitoria: "Foi muito proveitoso para tirar dúvidas das aulas e aprofundar o conhecimento, melhorar a técnica e nosso comportamento, além de todos os alunos terem a possibilidade de estar praticando o que foi aprendido em aula e o melhor, sendo corrigido em tempo real." 
Os alunos, em 20\%, demonstraram em seus relatos a importância da monitoria e sugeriram que houvesse um aumento da carga horária durante a disciplina como observado na citação do aluno: "A monitoria foi muito importante. Se tivesse mais tempo seria ótimo."

Existe uma possibilidade de mudança em projetos futuros, mas depende também da disponibilidade de horário do aluno e do monitor em período extra-classe.

O presente estudo sugere que os educadores da área da saúde, tanto em sala de aula como na clínica, devam dar uma atenção direcionada também para os fatores não cognitivos e demonstra bons resultados no treinamento, com aprovação dos alunos, observado no relato escrito.

"O programa de habilidade proposto foi de grande ajuda para o aprendizado das técnicas de massagem mas principalmente para nossa conduta em relação ao paciente”.

O programa de ensino teve boa adesão e aceitação. Segundo os alunos, o programa foi proveitoso e sugeriu-se sua reaplicação para os próximos anos.

A inserção dos conteúdos propostos na pesquisa exigiu, do aluno, maior esforço para atingir novos objetivos que demandavam organização e disciplina. Neste sentido, existia a possibilidade de que estes se sentissem tolhidos em sua espontaneidade e submetidos a uma rotina limitante. Porém, a avaliação do relato escrito mostrou que os alunos aprovaram o conteúdo inserido na disciplina e incentivaram a continuação do programa para os anos seguintes.

A adesão de $100 \%$ dos alunos ao programa demonstrou a compreensão, por parte deles, da importância destas habilidades em sua vida profissional, entendendo a situação de treinamento como uma experiência compartilhada por meio de feedback e disponibilidade da professora e da pesquisadora em auxiliar na aprendizagem, sem 
vigilância, julgamento ou autoritarismo. Um trecho do relato de um aluno nos mostra com clareza essa compreensão e opinião:

"O treinamento foi bom para memorizar aos poucos um procedimento que nos torna mais preparado. Fazendo isso, mesmo que somente nas aulas, nos torna mais seguros depois para atender um paciente seriamente”.

A forma de ensino escolhida mostrou-se eficiente para capacitar o aluno nas habilidades profissionalizantes propostas no programa.

O aluno teve a lista de habilidades treinada de maneira formal. Espera-se, contudo, que com este conhecimento, ele possa criar sua própria rotina de habilidades profissionalizantes, a partir de um pensamento crítico e com seus valores pessoais, durante seu atendimento, sem necessariamente reproduzir exatamente a estabelecida neste estudo.

Acredita-se que a experiência de ensinar, de maneira formal e integrada, fundamentos, técnicas e habilidades profissionalizantes, valorizou as atividades treinadas, mostrou-se eficiente e estimulante, gerando questionamentos sobre a importância, limites e formalidade no relacionamento fisioterapeuta-paciente. 


\section{CONCLUSÃO}

O programa de ensino proposto mostrou-se eficaz, produzindo aprendizado das habilidades de relação fisioterapeuta-paciente selecionadas para este estudo. As 21 habilidades descritas mostraram-se relevantes para a intervenção fisioterapêutica, contemplando a maioria das sugestões e indicações de conteúdo oferecidas pela literatura e atenderam às normas éticas da profissão.

A colaboração dos peritos foi de grande auxílio na elaboração das definições operacionais e da escolha das habilidades profissionalizantes.

Este trabalho permitiu compreender a importância da presença de conceitos cognitivos e não cognitivos no curso de graduação em Fisioterapia; ou seja, que o graduando necessita ter em seu currículo, conteúdos que lhe permitam adquirir informações consistentes abrangendo teorias, técnicas, habilidades, mas também possa desenvolver aspectos pessoais que envolvam suas emoções e sua interação com o paciente sempre em busca de um atendimento humanizado.

As habilidades profissionalizantes necessitam ser estimuladas e seria aconselhável que estivessem contempladas no currículo do curso. Atitudes preventivas devem ser incentivadas, o autocuidado físico necessita ser valorizado e o aluno precisa ser conscientizado de seus limites, limitações, possibilidades, dificuldades e cuidados com seu corpo e suas emoções, buscando estar ciente do alcance de sua profissão e de sua responsabilidade social, científica e de seu conforto físico e emocional. 


\title{
HOSPITAL DAS CLÍNICAS
}

DA

FACULDADE DE MEDICINA DA UNIVERSIDADE DE SÃO PAULO

\author{
TERMO DE CONSENTIMENTO LIVRE E ESCLARECIDO
}

I - DADOS DE IDENTIFICAÇÃO DO SUJEITO DA PESQUISA OU RESPONSÁVEL LEGAL

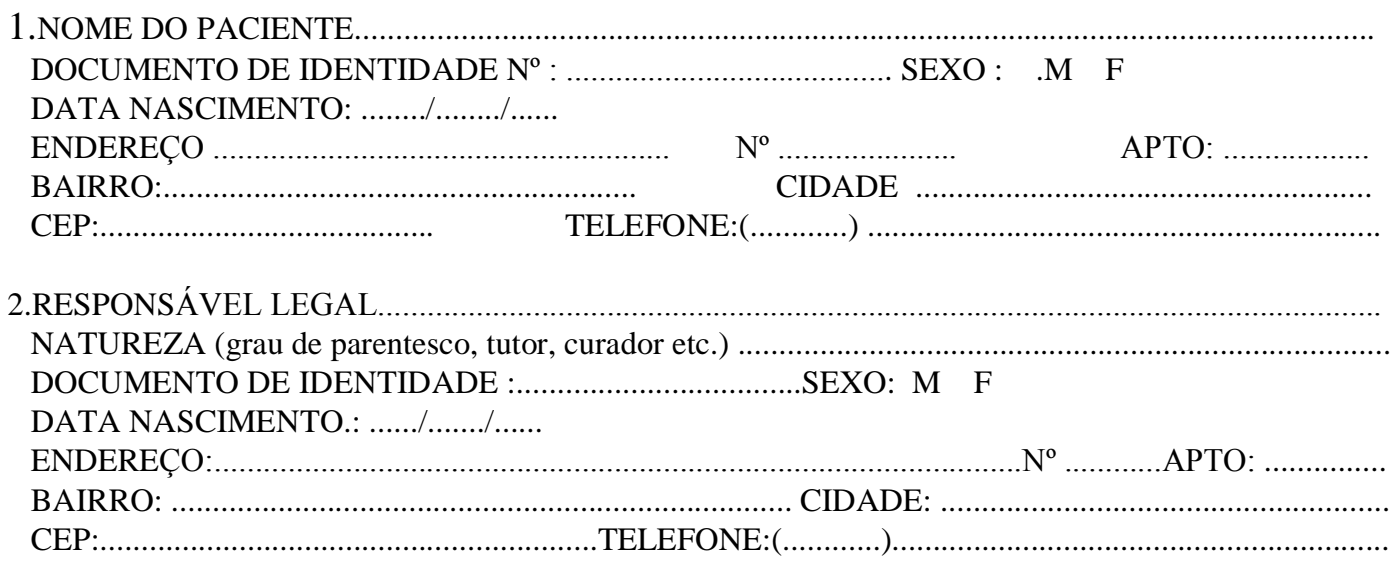

\section{II - DADOS SOBRE A PESQUISA CIENTÍFICA}

1. PROTOCOLO DE PESQUISA:

TÍTULO: Ensino de Massoterapia: Habilidades envolvidas na relação fisioterapeuta-paciente PESQUISADOR: Beatriz Calil Padis Campos

CARGO/FUNÇÃO: Fisioterapeuta INSCRIÇÃO CONSELHO REGIONAL N 44720 - F

UNIDADE DO HCFMUSP: Departamento de Fisioterapia, Fonoaudiologia e Terapia Ocupacional, Centro de Docência e Pesquisa (CDP) - Cidade Universitária - São Paulo

2. AVALIAÇÃO DO RISCO DA PESQUISA:

$\begin{array}{lll}\text { SEM RISCO } & \text { RISCO MÍNIMO ( } \mathbf{X}) & \text { RISCO MÉDIO } \\ \text { RISCO BAIXO } & \text { RISCO MAIOR }\end{array}$

(probabilidade de que o indivíduo sofra algum dano como consequência imediata ou tardia do estudo)

3.DURAÇÃO DA PESQUISA : Um ano

pdfMachine - is a pdf writer that produces quality PDF files with ease! Get yours now !

"Thank you very much! I can use Acrobat Distiller or the Acrobat PDFWriter but I consider your product a lot easier to use and much preferable to Adobe's" A.Sarras - USA 


\section{III - REGISTRO DAS EXPLICAÇÕES DO PESQUISADOR AO PACIENTE OU SEU REPRESENTANTE LEGAL SOBRE A PESQUISA CONSIGNANDO:}

\section{JUSTIFICATIVA E OS OBJETIVOS DA PESQUISA}

Os recursos terapêuticos manuais são utilizados pelo fisioterapeuta em suas rotinas clínicas e hospitalares. O ensino de massoterapia aborda o aprendizado de condutas a serem realizadas durante a relação terapeuta- paciente, autocuidado com a postura, além do desempenho técnico adequado. O objetivo deste estudo é determinar o aprendizado dos alunos de segundo ano destes conteúdos em situação formal de prova, onde terapeuta e paciente estarão sendo filmados durante uma sessão completa de massagem clássica de corpo inteiro. O filme será posteriormente avaliado pelo professor e um fisioterapeuta observador independente, além do aluno que estará executando a função de massoterapeuta. Posteriormente o filme será arquivado e, nenhuma exibição, mesmo com fins didáticos, será permitida. Este material só poderá ser utilizado para fins de comparação com outras pesquisas que envolvam ensino de massoterapia, como material de comparação de aprendizagem. O professor-pesquisador estará a disposição de cada aluno para informações em caso de dúvidas sobre o encaminhamento da pesquisa e seus resultados.

2. PROCEDIMENTOS QUE SERÃO UTILIZADOS E PROPÓSITOS, INCLUINDO A IDENTIFICAÇÃO DOS PROCEDIMENTOS QUE SÃO EXPERIMENTAIS.

Aulas, aplicação de questionários e prova prática filmada.

\section{DESCONFORTOS E RISCOS ESPERADOS}

Nenhum

\section{BENEFÍCIOS QUE PODERÃO SER OBTIDOS}

Aprendizado específico em habilidades profissionalizantes, autocuidado físico e comportamento ético.

\section{PROCEDIMENTOS ALTERNATIVOS QUE POSSAM SER VANTAJOSOS PARA O INDIVÍDUO}

Leitura de textos

\section{IV - ESCLARECIMENTOS DADOS PELO PESQUISADOR SOBRE GARANTIAS DO SUJEITO DA PESQUISA CONSIGNANDO:}

Os alunos terão acesso, a qualquer tempo, às informações sobre procedimentos, riscos e benefícios relacionados à pesquisa, inclusive para dirimir eventuais dúvidas. Terá a liberdade de retirar seu consentimento a qualquer momento e de deixar de participar do estudo, sem que isto traga prejuízo ao seu aprendizado ou às suas notas.

Especificamente no que se refere a notas, o aluno será avaliado no aprendizado e no desempenho de técnicas de Recursos Terapêuticos Manuais e da fundamentação relacionada a execução e aplicação destas técnicas. Em momento algum o comportamento do aluno, no que diz respeito aos comportamentos previstos de serem ensinados serão avaliados com finalidade de atribuição de nota. Desta forma, a avaliação do comportamento bem como a informação ao aluno sobre seu desempenho nestes aspectos não farão parte da sua nota de avaliação do desempenho da disciplina.

Haverá salvaguarda da confidencialidade, sigilo e privacidade das informações, as fitas com a gravação de cada aluno só serão utilizadas pela pesquisadora responsável e após a coleta dos dados as fitas serão devolvidas para os respectivos alunos com uma carta contendo um feedback sobre os dados colhidos.

Os riscos que se podem prever para esta pesquisa são os riscos a que os alunos estão sujeitos durante o aprendizado da aplicação terapêutica da massagem em situação aluno-aluno, ou seja, dor muscular por uma manobra inadequada realizada durante o período de aprendizado. Neste caso, como é de rotina na disciplina, o professor responsável (neste caso o pesquisador responsável) se responsabilizará pela assistência fisioterapêutica e acompanhamento do aluno queixoso, responsabilizando-se inclusive para encaminhá-lo aos

\section{pdfMachine - is a pdf writer that produces quality PDF files with ease!} Get yours now !

"Thank you very much! I can use Acrobat Distiller or the Acrobat PDFWriter but I consider your product a lot easier to use and much preferable to Adobe's" A.Sarras - USA 
serviços do Hospital Universitário da Universidade de São Paulo (Hospital ao qual o aluno da Universidade São Paulo tem acesso ao atendimento), caso se faça necessário.

A disciplina de Recursos Terapêuticos Manuais, bem como a pesquisa proposta, não prevê a possibilidade de indenização por eventuais danos à saúde, até porque este recurso nunca se fez necessário.

V. INFORMAÇÕES DE NOMES, ENDEREÇOS E TELEFONES DOS RESPONSÁVEIS PELO ACOMPANHAMENTO DA PESQUISA, PARA CONTATO EM CASO DE INTERCORRENCIAS CLÍNICAS E REAÇÕES ADVERSAS.

Beatriz Calil Padis Campos

Rua Dr. Homem de Melo, 568

Sao Paulo - SP cep: 05007-001

Telefone: 11- 3862-8948 / 8369-9750
Fátima Aparecida Caromano

Rua Cipotânea, 51

Cidade Universitária - SP cep: 05360-000

Telefone: 11-3091-7451

\section{CONSENTIMENTO PÓS-ESCLARECIDO}

Declaro que, após convenientemente esclarecido pelo pesquisador e ter entendido o que me foi explicado, consinto em participar do presente protocolo de Pesquisa.

Sao Paulo, de de 200 .

Assinatura do sujeito da pesquisa

Assinatura do pesquisador

ou responsável legal 


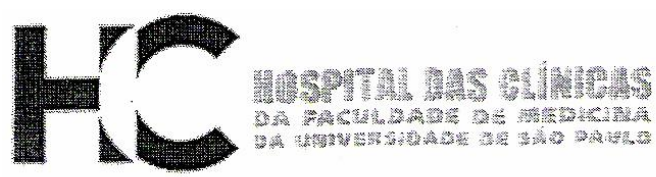

\section{APROVAÇÃO}

A Comissão de Ética para Análise de Projetos de Pesquisa - CAPPesq da Diretoria Clínica do Hospital das Clínicas e da Faculdade de Medicina da Universidade de São Paulo, em sessão de 10.05.06, APROVOU o Protocolo de Pesquisa $n^{\circ}$ 946/05, intitulado: "Ensino de Massoterapia: Comportamentos envolvidos na relação terapeuta-paciente e autocuidado físico do fisioterapeuta" apresentado pelo Departamento de FISIOTERAPIA, FONOAUDIOLOGIA E TERAPIA OCUPACIONAL, inclusive o Termo de Consentimento Livre e Esclarecido.

$$
\text { Cabe ao pesquisador elaborar e apresentar à }
$$

CAPPesq, os relatórios parciais e final sobre a pesquisa (Resolução do Conselho Nacional de Saúde $n^{\circ} 196$, de 10.10.1996, inciso IX. 2, letra " $c$ ")

Pesquisador(a) Responsável: Profa. Dra. Fátima Aparecida Caromano Pesquisador (a) Executante: Sra. Beatriz Calil Padis Campos

CAPPesq, 10 de Maio de 2006.

$$
\text { bulds caitho }
$$

PROF. DR. EUCLIDES AYRES DE CASTILHO

Presidente da Comissão de Ética para Análise de Projetos de Pesquisa

\footnotetext{
Comissão de Ética para Análise de Projetos de Pesquisa do HCFMUSP e da FMUSP Diretoria Clínica do Hospital das Clínicas da Faculdade de Medicina da Universidade de São Paulo Rua Ovídio Pires de Campos. 225, $5^{\circ}$ andar - CEP 05403010 - Săo Paulo - SP Fone: 011 - 30696442 fax : 011 - 30696492 - e-mail : cappesq@hcnet.usp.br / secretariacappesa2@hcnet.usp.br
} 


\title{
HOSPITAL DAS CLÍNICAS
}

DA

FACULDADE DE MEDICINA DA UNIVERSIDADE DE SÃO PAULO

\author{
TERMO DE CONSENTIMENTO LIVRE E ESCLARECIDO
}

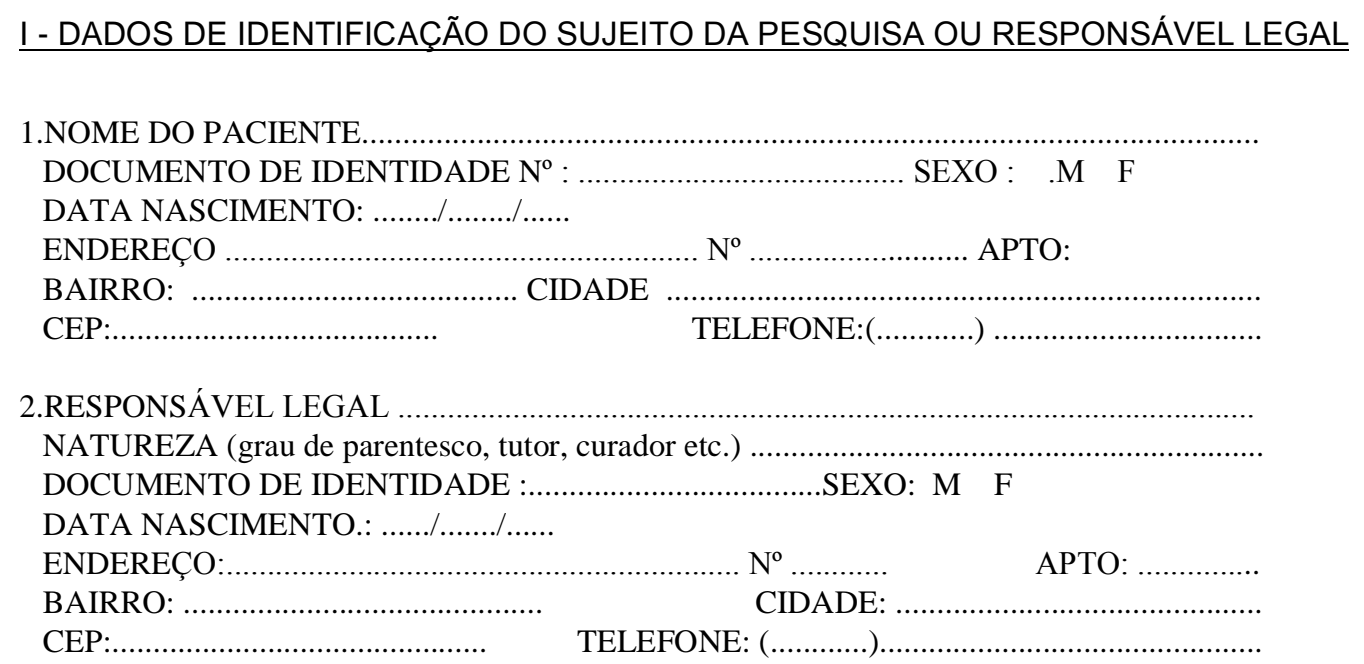

\section{II - DADOS SOBRE A PESQUISA CIENTÍFICA}

1. PROTOCOLO DE PESQUISA

TÍTULO: Ensino de Massoterapia: Habilidades envolvidas na relação fisioterapeuta-paciente. PESQUISADOR: Beatriz Calil Padis Campos

CARGO/FUNÇÃO: Fisioterapeuta INSCRIÇÃO CONSELHO REGIONAL Nº 44720 - F

UNIDADE DO HCFMUSP: Departamento de Fisioterapia, Fonoaudiologia e Terapia Ocupacional, Centro de Docência e Pesquisa (CDP) - Cidade Universitária - São Paulo

2. AVALIAÇÃO DO RISCO DA PESQUISA:

$\begin{array}{lll}\text { SEM RISCO } & \text { RISCO MÍNIMO (X) } & \text { RISCO MÉDIO } \\ \text { RISCO BAIXO } & \text { RISCO MAIOR }\end{array}$

(probabilidade de que o indivíduo sofra algum dano como consequência imediata ou tardia do estudo)

3.DURAÇÃO DA PESQUISA : Um ano

III - REGISTRO DAS EXPLICAÇÕES DO PESQUISADOR AO PACIENTE OU SEU REPRESENTANTE LEGAL SOBRE A PESQUISA CONSIGNANDO:

1. JUSTIFICATIVA E OS OBJETIVOS DA PESQUISA 
Os recursos terapêuticos manuais são utilizados pelo fisioterapeuta em suas rotinas clínicas e hospitalares. O ensino de massoterapia aborda o aprendizado de condutas a serem realizadas durante a relação terapeuta- paciente, autocuidado com a postura, além do desempenho técnico adequado. O objetivo deste estudo é determinar o aprendizado dos alunos de segundo ano destes conteúdos em situação formal de prova, onde terapeuta e paciente estarão sendo filmados durante uma sessão completa de massagem clássica de corpo inteiro. O filme será posteriormente avaliado pelo professor e um fisioterapeuta observador independente, além do aluno que estará executando a função de massoterapeuta. Posteriormente o filme será arquivado e, nenhuma exibição, mesmo com fins didáticos, será permitida. Este material só poderá ser utilizado para fins de comparação com outras pesquisas que envolvam ensino de massoterapia, como material de comparação de aprendizagem. O professor-pesquisador estará à disposição de cada paciente para informações em caso de dúvidas sobre o encaminhamento da pesquisa e seus resultados.

\section{PROCEDIMENTOS QUE SERÃO UTILIZADOS E PROPÓSITOS, INCLUINDO A IDENTIFICAÇÃO} DOS PROCEDIMENTOS QUE SÃO EXPERIMENTAIS.

Aplicação de massagem clássica de corpo inteiro

\section{DESCONFORTOS E RISCOS ESPERADOS}

Desconforto mínimo caso seja provocado pela inabilidade do aluno na aplicação de alguma técnica de massoterapia clássica.

\section{BENEFÍCIOS QUE PODERÃO SER OBTIDOS}

Relaxamento muscular e conhecimento técnico.

\section{PROCEDIMENTOS ALTERNATIVOS QUE POSSAM SER VANTAJOSOS PARA O INDIVÍDUO}

Leitura de textos

\section{IV - ESCLARECIMENTOS DADOS PELO PESQUISADOR SOBRE GARANTIAS DO SUJEITO DA} PESQUISA CONSIGNANDO:

1. acesso, a qualquer tempo, às informações sobre procedimentos, riscos e benefícios relacionados à pesquisa, inclusive para dirimir eventuais dúvidas.

2. liberdade de retirar seu consentimento a qualquer momento e de deixar de participar do estudo, sem que isto traga prejuízo à continuidade da assistência.

3. salvaguarda da confidencialidade, sigilo e privacidade.

pdfMachine - is a pdf writer that produces quality PDF files with ease! Get yours now !

“Thank you very much! I can use Acrobat Distiller or the Acrobat PDFWriter but I consider your product a lot easier to use and much preferable to Adobe's" A.Sarras - USA 
4. disponibilidade de assistência no HCFMUSP, por eventuais danos à saúde, decorrentes da pesquisa.

5. viabilidade de indenização por eventuais danos à saúde decorrentes da pesquisa.

V. INFORMAÇÕES DE NOMES, ENDEREÇOS E TELEFONES DOS RESPONSÁVEIS PELO ACOMPANHAMENTO DA PESQUISA, PARA CONTATO EM CASO DE INTERCORRÊNCIAS

CLÍNICAS E REAÇOES ADVERSAS

\begin{tabular}{|l|l|}
\hline Beatriz Calil Padis Campos & Fátima Aparecida Caromano \\
Rua Dr. Homem de Melo, 568 & Rua Cipotânea, 51 \\
Sao Paulo - SP cep: 05007-001 & Cidade Universitária - SP cep: 05360-000 \\
Telefone: $11-3862-8948$ / 8369-9750 & Telefone: 11-3091-7451 \\
\hline
\end{tabular}

\section{CONSENTIMENTO PÓS-ESCLARECIDO}

Declaro que, após convenientemente esclarecido pelo pesquisador e ter entendido o que me foi explicado, consinto em participar do presente protocolo de Pesquisa.

Sao Paulo, de de 200 .

Assinatura do sujeito da pesquisa

Assinatura do pesquisador

ou responSável legal 


\section{REFERÊNCIAS}

1. Bevilacqua, F et al. Manual de Exame Clínico.. $7^{\mathrm{a}}$ edição. São Paulo: Cultura Médica; 1985.

2. Rios IC. Relação Médico-Paciente: Tempos de pasteurização da subjetividade. Ser Médico. Órgão do Conselho Regional de Medicina do Estado de SP. Out/nov/dez 1999. Ano II n 9 .

3. Payton OD, Nelson C, St. Clair Hobbs M. Physical therapy patients' view of health care professionals. Physiother Theory Pract. 1998;14:211-221.

4. Cromie JE, Robertson VJ, Best MO. Work-related musculoskeletal disorders in physical therapists: prevalence, severity, risk and response. Phys Ther. 2000;80:336-351.

5. Bork BE, Cook TM, Rosecrane JC, et al. Work-related musculoskeletal disorders among physical therapists. Phys Ther. 1996;76:827-835.

6. Harber P, Billet E, Gutowski M, SooHoo K, Lew M, Roman A. Occupational low-back pain in hospital nurses. J Occup Med. 1985; 27(7):518-24.

7. Vieira J, Nunes MP, Martins M. Directing student response to early patient contact by questionnaire. Medical Education. 2003;37:119:125.

8. Humphris GM, Kaney S. Assessing the development of communication skills in undergraduate medical students. Med Educ. 2001; 35(3):225-31.

9. Cantwell BM, Ramirez AJ. Doctor-patient communication: a study of junior house officer. Med Education. 1997;31:17-21.

10. Cassar MP. Manual de Massagem Terapêutica. São Paulo. Manole. 2001. 
11. Fritz S. Fundamentos da massagem terapêutica. São Paulo: Manole; 2000.

12. Jette DU, Bertoni A, Coots R, Johnson H, McLaughlin C, Weisback C. Clinical instructors'perception of behavior that comprise entry -leval clinical performance in physical therapist students: A qualitative study. Phys Ther. 2007;87(7):833-843.

13. Marques AP. Um delineamento de linha de base múltipla para investigar efeitos de procedimentos de ensino sobre diferentes comportamentos envolvidos em avaliação goniométrica. [dissertação]. Universidade Federal de São Carlos; 1990.

14. Revista Crefito 3. Documento de recomendação para o ensino de ética e deontologia nos cursos de fisioterapia do I Encontro Paulista de docents da disciplina de Ética e Deontologia. São Paulo. 2006; 03(1).

15. Hayes KW, Hurber G, Rogers J, Sanders B. Behaviors that cause clinical instructors to question the clinical competence of physical therapist students. Phys Ther. 1999;79:653-667.

16. Altamaier EM, McGuinness G, Wood P, et al. Defining successful performance among pediatric residents. Pediatrics. 1990;85:139-143.

17. Hojat M, Borenstein BD, Veloski JJ. Cognitive and noncognitive factors in predicting the clinical performance of medical school graduates. $J$ Med Educ. $1988 ; 63: 323-325$.

18. May WW, Morgan B, Lemke JC et al. Model for ability-based assessment in physical therapy. Journal of Physical Therapy Education. 1995;9(1):3-6. 
19. Jette DU, Portney LG. Construct validation of a model for professional behavior in physiotherapy students. Phys Ther. 2003; 83: 433-443.

20. Messias IA. O ambiente de trabalho e sintomas de um grupo de fisioterapeutas da cidade de São Paulo [ Dissertação]. São Paulo: Departamento de Saúde Ambiental da Faculdade de Saúde Publica da Universidade de São Paulo; 1999.148p.

21. Machado MH. Os médicos no Brasil: um retrato da realidade. Rio de Janeiro: Fiocruz; 1997.

22. Girot EA. Assessment of competence in clinical practice: a phenomenological approach. J. Adv. Nurs. 1993; 18:114-119.

23. Sanford J, Stratford D, Solomon P. Clinical evaluation: physical therapists ranking of competences. Med Tech. 1993;15:369-378.

24. Tinga CE, Adams CL, Bonnett BN, Ribble CS. Survey of veterinary technical and professional skills in students and recent graduates of a veterinay college. J Am Vet Med Assoc. 2001;219:924-931.

25. Windish DM, Paulman PM, Goroll AH, Bass EB. Do clerkship directors think medical students are prepared for the clerkship years? Acad Med. 2004;79:5661.

26. Wolff-Burke M. Clinical instructors description of physical therapist professional behavior. Journal of Physical Therapy Education. 2005;19(1):6775.

27. Porrit L. Communication: choices for nurse. Edinburg: Churchill Livingstone; 1984. 
28. Ruesch J, Bateson G. Communication: the social matrix of psychiatry. New York: WWNortom; 1951.

29. Littlejohn, SW. Fundamentos teóricos da comunicação humana. Tradução A. Cabral. Rio de Janeiro: Zahar; 1982.

30. Stefanelli MC, Carvalho EC. A comunicação nos diferentes contextos de enfermagem. Sao Paulo: Manole; 2005.

31. Sundeen JS, Stuart GW, Ranbin FAD. Nurse-client interaction: implementing the nursing process. 6 ed. St. Louis: Mosby, 1998, 359p.

32. Stefanelli MC. Comunicação com o paciente: teoria e ensino. São Paulo: Robe; 1993.

33. Faulconer DR, Nursing Management. Todays or Nurse, Washington, 1983; $5(6): 46$.

34. Watzlavick P, Beavin JH \& Jackson DD. Pragmática da comunicação humana. São Paulo: Cultrix; 2000.

35. Rossi OS, Batista NA. O ensino da comunicação em graduação em medicina uma abordagem. Interarface - Comunicação, Saúde, Educ. 2006; 10(19):93102.

36. Dortch HL, Trombly, CA. The effects of education on hand use with industrial workers in repetitive jobs. Am J Occup Ther. 1990; 44:777-782.

37. Helfenstein M. Lesões por esforços repetitivos. Prevenção e Tratamento. São Paulo: Schering-Plough; 1999. 
38. Stubbs DA, Buckle PW, Hudson MP et al. Back pain in the nursing profession, part I. Epidemiology and pilot methodology. Ergonomics. $1983 ; 26: 755-765$.

39. Videman T, Nurminem T, Tola, $\mathrm{S}$ et al. Low back pain in nurses and some loading factors at work. Spine. 1984;9:400-404.

40. Molumphy M, Unger B, Jensen GM, Lopopolo RB. Incidence of work-related low back pain in physical therapists. Phys Ther. 1985:65:482-486.

41. Scholey M, Hair M. Back pain in physiotherapists involved in back care education. Ergonimics. 1989;32:179-190.

42. Trelha CS, Santos RB. A comunidade como sala de aula: Experiência de nove anos do curso de Fisioterapia em um projeto multiprofissional e interdisciplinar. Fisioterapia em Movimento, Curitiba.2003;16(1):41-46.

43. Silverstein BA, Fine LJ, Armstrong TJ. Occupational factors and carpal tunnel syndrome. Am J Ind Med. 1987;11(3):343-58

44. Holder NL, Clark HA, DiBlasio JM, et al. Cause, prevalence, and response to occupational musculoskeletal injuries reported by physical therapist and physical therapist assistant. Phys Ther. 1999;79:642-652.

45. Mantovani M. O ensino do estudo. In: Lane, JC. O processo de ensino e aprendizagem em medicina. São Paulo: Fundo Editorial Byk; 2000, p. 43 -49.

46. Gonçalves E.L. Médicos e Ensino na Medicina no Brasil. São Paulo: Edusp; 2002. 
47. Masetto M. Discutindo o processo ensino/aprendizagem no ensino superior. In: Marcondes E, Gonçalves EL. Educação Médica. São Paulo: Sarvier;1998, p.11-49.

48. Maciel RV, Silva PTG, Sampaio RF, Drummond, AF. Teoria, prática e realidade social: uma perspectiva integrada para o ensino de fisioterapia. Fisioterapia em Movimento, Curitiba; 2005; 18(1):11-17.

49. Muniz JWC. Desenvolvimento da criatividade no emprego da metodologia de solução de problemas na formação dos profissionais de saúde do curso de Fisioterapia, na disciplina Fisioterapia nas disfunções cardiovasculares. Fisioterapia em movimento. 1998-1999;12(2).

50. Joyner B, Young L. Teaching medical students using role play: Twelve tips for successful role plays. Medical Teacher. 2006; 28(3):225-229.

51. Jesus CAC. Raciocínio clínico de graduandos e enfermeiros na construção de diagnóstico de enfermagem. [tese]. Ribeirão Preto: Escola de Enfermagem de Ribeirão Preto, Universidade de São Paulo; 1999.

52. Marques AP. Cadeias Musculares: Um Programa para Ensinar Avaliação Cisioterapêutica Global - 2a ed. São Paulo: Manole; 2005.

53. Braun MB, Simonson, SJ. Massoterapia.São Paulo: Manole. 2007.

54. Ingram D. Opinions of physical therapy education program directors on essential functions. Physical Therapy. 1997;77(1):37-39.

55. Jamieson S. Likert Scale: how to (ab)use them. Blackwell Publishing LTD. Medical Education. 2004;38:1212-1218. 
56. Fehring RJ. The Fehring model. In: Carrol-Jonhson RM; Paquete M. Classification of nursing diagnoses: proceedings of the Tenth Conference. Philadelphia: JB Linppincott, 1994: p 55-62.

57. Fehring RJ. Validation diagnostic labels: standardized methodology. In: Hurley ME. Classification of nursing diagnoses: proceedings of the sixth conference of North American Nursing Diagnosis Association. St. Louis: The C.V. Mosby, 1986: p. 183-190.

58. Fehring RJ. Methods to validate nursing diagnoses. Heart and Lung. St. Louis, 1987; 16(6): 625-29.

59. Trelha CS; Gutierrez PR; Matsuo T. Prevalência de sintomas músculoesqueléticos em fisioterapeutas da cidade de Londrina. Revista Fisioterapia. Universidade São Paulo. 2004 jan/jun;11(1):15-23.

60. Larin H, Wessel J, Al-Shamlan A. Reflections of physiotherapy students in the United Arab Emirates during their clinical placements: A qualitatite study. BMC Med Educ. 2005;5:3.

61. Carlson R. The nurses's guide to better communication. Glenvier: Scott \& Foresman; 1984.

62. Bridge W, Clark JM. Comunication in nursing care. Chichester: John Wiley; 1987.

63. Arnold E, Boggs K. Interpersonal relationship: Professional communication skills of nurses. Philadelphia: Saunders, 1989.

64. Roberts L, Bucksey S. Communicating with patients: what happens in practice? Phys Ther. 2007; 87(5): 586-594. 
65. Pereira LL. Vivenciando a comunicação como descoberta [tese]. São Paulo (SP): Escola de Enfermagem da Usp; 1999.

pdfMachine - is a pdf writer that produces quality PDF files with ease! Get yours now !

"Thank you very much! I can use Acrobat Distiller or the Acrobat PDFWriter but I consider your product a lot easier to use and much preferable to Adobe's" A.Sarras - USA 


\section{Check List para coleta dos dados das habilidades através da filmagem}

Apêndice 1

Aluno:

Duração:

\begin{tabular}{|l|l|l|l|l|}
\hline Habilidade & Adequada & Parcialmente adequada & Inadequada & Não realizada \\
\hline 1. Vestimenta & & & & \\
\hline Cabelo preso & & & & \\
\hline Maquiagem & & & & \\
\hline Branco ou avental & & & & \\
\hline Brincos ou presilhas & & & & \\
\hline Sapato & & & & \\
\hline Shorts & & & & \\
\hline Saia & & & & \\
\hline Bermuda & & & & \\
\hline Roupa transparente & & & & \\
\hline 2. preparo do local & & & & \\
\hline Toalhas limpas & & & & \\
\hline Travesseiro & & & & \\
\hline Cadeira & & & & \\
\hline Cremes - óleos & & & & \\
\hline Toalha mão & & & \\
\hline 3. chamada paciente & & & \\
\hline Formal & & & \\
\hline Apresentação & & & \\
\hline Acompanhamento até sala & & & \\
\hline
\end{tabular}

Beatriz Calil Campos

pdfMachine - is a pdf writer that produces quality PDF files with ease!

\section{Get yours now !}

"Thank you very much! I can use Acrobat Distiller or the Acrobat PDFWriter but I consider your product a lot easier to use and much preferable to Adobe's" A.Sarras - USA 


\begin{tabular}{|l|l|l|l|l|}
\hline Habilidade & Adequada & Parcialmente adequada & Inadequada & Não realizada \\
\hline 5. FC pré & & & & \\
\hline 6. questionamento & & & & \\
\hline 7. avaliação & & & & \\
\hline 8. Feedback & & & \\
\hline 9. explicação sobre intervenção & & & \\
\hline 10. drapejamento & & & \\
\hline 11. posicionamento maca & & & \\
\hline 12. Autocuidado físico * & & & \\
\hline 13. intervenção & & & \\
\hline 14. FC pós & & & \\
\hline 15. ajudar o paciente sentar- & & & \\
\hline 16. sair da maca & & & \\
\hline 17. vestir-se & & & \\
\hline 18. acomodar sentado & & & \\
\hline 19. despedir-se & & & \\
\hline 20. preenchimento da evolução & & & \\
\hline 21. comunicação* & & & \\
\hline
\end{tabular}

Os itens marcados com * não serão avaliados por este instrumento. product a lot easier to use and much preferable to Adobe's" A.Sarras - USA 


\section{Check list para avaliação das posturas utilizadas}

Aluno:

Data:

\begin{tabular}{|c|c|c|c|c|c|c|c|c|c|}
\hline & \multicolumn{6}{|c|}{ Postura } & \multicolumn{3}{|c|}{ Forma } \\
\hline & Esgrimista & Inclinada & $\begin{array}{l}\text { Tái } \\
\text { chi }\end{array}$ & Ereta & Vaivém & $\begin{array}{l}\text { Sentada } \\
\text { maca }\end{array}$ & Adequada & $\begin{array}{l}\text { Parcialmente } \\
\text { adequada }\end{array}$ & Inadequada \\
\hline 1 ' & & & & & & & & & \\
\hline 2 & & & & & & & & & \\
\hline & & & & & & & & & \\
\hline $3^{\prime}$ & & & & & & & & & \\
\hline $4^{\prime}$ & & & & & & & & & \\
\hline $5^{\prime}$ & & & & & & & & & \\
\hline $6^{\prime}$ & & & & & & & & & \\
\hline $7^{\prime}$ & & & & & & & & & \\
\hline $8^{\prime}$ & & & & & & & & & \\
\hline $9^{\prime}$ & & & & & & & & & \\
\hline $10^{\prime}$ & & & & & & & & & \\
\hline $11^{\prime}$ & & & & & & & & & \\
\hline $12^{\prime}$ & & & & & & & & & \\
\hline $13^{\prime}$ & & & & & & & & & \\
\hline $14^{\prime}$ & & & & & & & & & \\
\hline $15^{\prime}$ & & & & & & & & & \\
\hline $16^{\prime}$ & & & & & & & & & \\
\hline $17^{\prime}$ & & & & & & & & & \\
\hline $18^{\prime}$ & & & & & & & & & \\
\hline $19^{\prime}$ & & & & & & & & & \\
\hline $20^{\prime}$ & & & & & & & & & \\
\hline ...60' & & & & & & & & & \\
\hline
\end{tabular}


Check list para avaliação da comunicação

Apêndice 3

Aluno:

Data:

\begin{tabular}{|c|c|c|}
\hline $\begin{array}{ll}\text { Sentenças } & \text { Comunicação } \\
\end{array}$ & $\begin{array}{l}\text { Comunicação } \\
\text { Terapêutica }\end{array}$ & $\begin{array}{l}\text { Comunicação } \\
\text { não terapêutica }\end{array}$ \\
\hline 1. & & \\
\hline 2. & & \\
\hline 3 & & \\
\hline 4. & & \\
\hline 5. & & \\
\hline 6. & & \\
\hline 7. & & \\
\hline 8. & & \\
\hline 9. & & \\
\hline 10. & & \\
\hline 11. & & \\
\hline 12. & & \\
\hline 13. & & \\
\hline 14. & & \\
\hline 15. & & \\
\hline 16. & & \\
\hline 17. & & \\
\hline 18. & & \\
\hline 19. & & \\
\hline 20. & & \\
\hline 21. & & \\
\hline 22. & & \\
\hline 23. & & \\
\hline 24. & & \\
\hline $25 \ldots$ & & \\
\hline
\end{tabular}

pdfMachine - is a pdf writer that produces quality PDF files with ease! Get yours now !

"Thank you very much! I can use Acrobat Distiller or the Acrobat PDFWriter but I consider your product a lot easier to use and much preferable to Adobe's" A.Sarras - USA 
Relato escrito - Opinião dos alunos sobre o treinamento realizado

Dê a sua opinião, sugestão ou crítica com relação à:

Disciplina

Monitoria

Ensino de habilidades treinadas 
Apêndice 5

Detecção, descrição e validação por peritos das habilidades envolvidas na relação fisioterapeuta-paciente durante a prática de massoterapia clínica revisão da literatura e estudo observacional *

* Artigo submetido para Revista Brasileira de Fisioterapia

pdfMachine - is a pdf writer that produces quality PDF files with ease! Get yours now !

"Thank you very much! I can use Acrobat Distiller or the Acrobat PDFWriter but I consider your product a lot easier to use and much preferable to Adobe's" A.Sarras - USA 
DETECÇÃO, DESCRIÇÃO E VALIDAÇÃO POR PERITOS DAS HABILIDADES ENVOLVIDAS NA RELAÇÃO FISIOTERAPEUTA-PACIENTE DURANTE A PRÁTICA DE MASSOTERAPIA CLÍNICA - REVISÃO DA LITERATURA E ESTUDO OBSERVACIONAL

BEATRIZ CALIL PADIS CAMPOS ${ }^{1}$

FATIMA APARECIDA CAROMANO ${ }^{1}$

1. Laboratório de Fisioterapia e Comportamento do Curso de Fisioterapia da Faculdade de Medicina da USP

Correspondência para

Fátima A. Caromano

Rua Cipotanea $n^{\circ} 51$ Cidade Universitária

SP - 05360-160 Brasil

e-mail: fcaromano@uol.com.br

Título curto: Detecção de habilidades durante massoterapia

Massoterapy abilities'detection

Palavras chaves: massagem (massage), comunicação (communication), comportamento (behavior), fisioterapia (physical therapy), condutas terapêuticas (therapeutical approaches)

pdfMachine - is a pdf writer that produces quality PDF files with ease! Get yours now !

"Thank you very much! I can use Acrobat Distiller or the Acrobat PDFWriter but I consider your product a lot easier to use and much preferable to Adobe's" A.Sarras - USA 


\section{Resumo}

Objetivo: detectar, descrever e validar por peritos as habilidades profissionalizantes envolvidas na relação fisioterapeuta-paciente durante prática de massoterapia clínica. Método: Sujeitos: 10 alunos treinados em massoterapia clássica, 10 voluntários adultos saudáveis que se submeteram a 12 sessões de massoterapia e 10 fisioterapeutas peritos na área. Local: Sala equipada para. Procedimentos: 1. revisão da literatura para fundamentar o estudo e elaborar lista das habilidades recomendadas na literatura. 2. observação direta de 120 atendimentos de massoterapia para levantamento de habilidades necessárias para execução adequada da massoterapia e elaboração de definição operacional. 3. validação da lista de habilidades e definições operacionais por peritos. Resultados: A revisão de literatura apontou para dez habilidades necessárias para prática de massoterapia clínica. A observação mostrou um conjunto de outras onze habilidades completares. A avaliação dos peritos mostrou que o material elaborado era pertinente e adequado ao propósito do estudo. Conclusão: O estudo gerou uma lista com habilidades e suas descrições operacionais a serem ensinadas e treinadas durante a aplicação de massoterapia em situação clínica que se fez importante devido à escassez de literatura sobre o tema e pela busca de desenvolver instrumentos de ensino para alcançar um atendimento clínico eficiente. O método se mostrou adequado para atingir o objetivo do estudo. 


\section{Abstract}

Detection, description and validation carried out by specialists of the abilities involved in the physical therapist-pacient relation during the clinical massotherapy practice - literature review and observational study

Goal: detection, description and validation carried out by specialists of the professionalizing abilities involved in the physical therapist-patient relation during the clinical massotherapy practice. Method: subjects: 10 students trained in classic massotherapy, 10 healthy adult volunteers who were submitted to 23 massotherapy sessions, and 10 physical therapists specialized in the area. Place: a room equipped for the purpose. Procedures: 1. literature review to justify the study and elaborate the list of abilities recommended in the literature. 2. direct observation of 120 massotherapy sessions for the survey of abilities needed for the adequate massotherapy execution and elaboration of the operating definition. 3. validation of the list of abilities and operating definitions by specialists. Results: the literature review pointed out ten abilities needed for the clinical massotherapy practice. The observation showed a set of eleven additional complementary abilities. The specialists' assessment showed that the elaborated material was pertinent and appropriate to the purpose of the study. Conclusion: the study yielded a list with abilities and their operating descriptions to be taught and trained during the massotherapy application in a clinical situation that became relevant due to the lack of literature about the subject as well as the search for developing teaching tools in order to reach an efficient clinical treatment. The method proved to be adequate to reach the goal of the study. 


\section{INTRODUÇÃO}

Cabe ao docente no ensino de Fisioterapia e na função de formador, estabelecer e promover o desenvolvimento de habilidades profissionalizantes permitindo aos alunos reflexão sobre a relação fisioterapeuta-paciente na atuação profissional, especialmente durante a aplicação de massoterapia clínica, por ser este um recurso que demanda exposição do corpo e contato físico. Esses momentos requerem ética e profissionalismo, já que o corpo manipulado apresentará diferentes respostas ao ser tocado e tratado ${ }^{1}$.

Normalmente na disciplina de Recurso Terapêuticos Manuais existe um direcionamento e uma maior atenção ao ensino de técnicas de massoterapia e manipulação. Concomitantemente, existem dois conteúdos que, normalmente, não são ensinados de forma sistematizada e são introduzidos na forma de orientações. São eles, as habilidades profissionais envolvidas na relação fisioterapeuta-paciente e o autocuidado físico durante a execução de manobras, utilizando posturas corretas de atendimento e evitando compensações corporais e sobrecargas musculoesqueléticas de acordo com possibilidades do aluno e adaptando a atividade corporal aos seus limites físicos.

O aluno deve aprender não só a técnica a ser utilizada nos pacientes, mas como ter uma conduta profissional adequada, respeitando a individualidade do paciente e estabelecendo uma relação profissional formal e cordial para com este. $\mathrm{O}$ relacionamento profissional adequado entre fisioterapeuta e paciente deverá favorecer segurança, conforto e confiança, pois, muitas vezes, o fisioterapeuta observando e investigando os sinais e sintomas apresentados pelo paciente, detectará os aspectos emocionais, sociais, ambientais e somáticos que são desencadeados ou 
desencadeantes da patologia ou da disfunção ${ }^{1}$. Para Rios $^{2}$, a fala dos pacientes nos revela o quanto a doença, para eles, é algo externo às suas vidas mas, na verdade, está ligada ao modo de ser e viver de cada um.

De outro lado, o profissional fisioterapeuta usa seu corpo como instrumento de trabalho, seja executando manobras técnicas ou servindo como resistência a um determinado movimento, mobilizando segmentos corporais, ou ainda, servindo como modelo de movimento ou postura para o paciente. $\mathrm{O}$ aprendizado, treinamento e manutenção da qualidade física é uma questão de conforto e sobrevivência profissional para o fisioterapeuta.

As atividades realizadas pelo fisioterapeuta requerem esforços constantes e repetitivos que podem provocar lesões ou levar a exaustão, como já foi demonstrado em diferentes estudos ${ }^{3,4,5}$. Enquanto profissional da área da saúde, seu autocuidado abrange a dimensão corporal e emocional, pois, o profissional convive com questões ligadas a dores, doenças, disfunções, estresse familiar e até a morte. O ideal seria o fisioterapeuta ter uma rotina de autocuidado físico e cuidado emocional, que conduzisse com disciplina e perseverança.

O ensino de habilidades envolvidas na relação terapeuta-paciente tem sido bastante explorado na pesquisa e no ensino médico ${ }^{6,7,8}$. Publicações sobre este tema são recentes na Fisioterapia, embora existam algumas pesquisas que apresentam elementos esclarecedores no que se refere a conteúdos e formas de ensino nesta área, estimulando a operacionalização de rotinas de ensino ${ }^{9,10,11}$. 


\section{OBJETIVO}

Detectar, descrever e validar uma lista de habilidades profissionalizantes envolvidas na adequação da relação fisioterapeuta-paciente durante prática de massoterapia clínica.

\section{MÉTODO}

Participantes: Dez estudantes do sexto semestre de graduação em Fisioterapia, com idade média de 19,5 anos, 10 voluntários saudáveis para as sessões de massoterapia, sendo seis mulheres e quatro homens com idade média de 46 anos e, 10 fisioterapeutas definidos como peritos na área. Os participantes foram informados sobre os procedimentos e assinaram o termo de consentimento livre e esclarecido aprovado pelo comitê de ética da instituição com protocolo número $946 / 05$.

Local: Sala de aula preparada para massoterapia.

Procedimentos: Inicialmente foi feito uma pesquisa bibliográfica sobre o assunto nas bases de dados Pubmed, Medline e Lilacs, bem como em artigos e livros isolados, para fundamentar o estudo e estabelecer uma primeira lista de habilidades profissionalizantes recomendadas pela literatura ${ }^{10,11,12,13,14}$.

Respeitando esta primeira lista, foi programado que cada aluno aplicasse massagem clássica em um participante adulto saudável, desconhecido do aluno, por 12 sessões que aconteceram uma vez por semana. Os alunos, aprovados na disciplina de Recursos Terapêuticos Manuais, foram treinados de forma complementar para prática de massoterapia durante 40 horas e receberam orientações verbais sobre o uso do check list que continha as 10 habilidades selecionadas a partir da literatura, que deveriam ser realizadas durante esta fase da pesquisa.. 
Os atendimentos foram observados, de forma direta pelas pesquisadoras. As observações seguiram as premissas estabelecidas por $\operatorname{Matos}^{4}$ a fim de avaliar e detectar outras habilidades essenciais durante o atendimento de massoterapia, com objetivo de aperfeiçoar a primeira lista. Durante as observações dos atendimentos havia um roteiro para auxiliar a identificação das habilidades profissionais que não constavam na primeira lista e, assim, poder completá-la. A partir das observações detectou-se mais onze habilidades a serem contempladas.

Foi elaborada uma lista de 21 habilidades profissionalizantes entendidas como eticamente adequadas para o atendimento de massoterapia, envolvendo atividades cognitivas, por exemplo, posicionamento do paciente na maca, e uma atividade não cognitiva - a comunicação do terapeuta com o paciente. Na seqüência, foram elaboradas as definições operacionais para cada uma das 21 habilidades listadas. As habilidades foram numeradas em seqüência temporal de execução.

A lista de habilidades e suas definições operacionais foram avaliadas, com a finalidade de validação, por dez peritos selecionados de acordo com o proposto por Fehring $^{15}$. A avaliação da lista de habilidades pelos peritos considerou 4 itens definidos previamente: facilidade de checagem, conteúdo, seqüência de apresentação das habilidades e a definição operacional de cada habilidade listada. Cada item (e no caso do quarto item os 21 sub-itens) foram classificados em adequado ou inadequados e no segundo caso, o perito fazia sugestão de modificação.

\section{RESULTADOS}

O levantamento bibliográfico resultou na seleção de 10 habilidades entendidas pelos autores como necessárias para um atendimento fisioterapêutico, a saber, chamada do paciente, questionamento sobre intercorrências na semana, coleta 
de sinais vitais, explicação sobre a intervenção, ajudar para o paciente se vestir, orientações, confirmação do horário da próxima sessão, despedir-se adequadamente, registrar e arquivar as fichas.

Como resultado da observação direta das terapias foi detectado outras onze habilidades necessárias para a complementação do atendimento em massoterapia, sendo elas; utilizar vestimenta adequada, preparar do local de tratamento, acomodar o paciente sentado, avaliar aspectos funcionais do paciente, dar feedback sobre avaliação, desnudar os diferentes segmentos corporais do paciente, posicionar do paciente na maca, manter autocuidado físico, intervenção, ajudar o paciente a sentar e sair da maca e comunicação verbal.

A seleção das habilidades a partir da literatura e da observação direta das terapias resultou numa lista composta por 21 habilidades. Para estas habilidades desenvolveram-se definições operacionais e seqüência temporal de execução.

Este material foi encaminhado para os peritos, via correio e correio eletrônico. Os peritos fizeram sugestões quanto às definições operacionais das habilidades: vestimenta do fisioterapeuta, dar feedback sobre avaliação, supervisionar a acomodação do paciente, dar orientações e esclarecimento necessários, e não alteraram a seqüência temporal proposta. Após acatar todas as sugestões, por serem muito pertinentes, estabeleceu-se a lista final de habilidades necessárias para uma realização adequada de sessão de massoterapia clínica, como descrito a seguir.

1.Utilizar vestimenta adequada: Apresentar-se com cabelo preso e/ou penteado (no caso de cabelo curto), ausência de maquiagem ou maquiagem suave, jaleco ou roupa branca sem decotes. É permitido o uso de acessórios como brinco ou presilhas 
discretos. Usar sapatos ou sandálias que propiciem estabilidade e nunca usar chinelos, shorts, saia curta, bermuda ou roupas transparentes.

2. Preparar o local para tratamento: Preparar o local de tratamento com toalhas, lençóis, cobertores e travesseiros limpos, cadeira e materiais utilizados na massoterapia, como, creme ou óleo, adstringente, algodão e toalha de mão. Deixar fichas de avaliação e canetas disponíveis. Disponibilizar esfigmomanômetro e cronômetro para mensuração de pressão arterial e freqüência cardíaca.

3. Chamar o paciente: Chamar formalmente o paciente pelo nome, apresentando-se e acompanhando-o até a sala de atendimento.

4. Acomodar o paciente sentado: Auxiliar ou supervisionar a acomodação do paciente, em cadeira, sempre que possível, para anamnese e mensuração da freqüência cardíaca pressão arterial.

5. Mensurar freqüência cardiaca e pressão arterial pré-intervenção: Posicionar o paciente sentado, de forma confortável e com o braço apoiado e realizar as medidas de acordo com padronização da literatura..

6. Questionar sobre intercorrências fisicas ou emocionais durante a semana: Questionar e verificar ocorrência de algum tipo de intercorrência durante a semana que precedeu o atendimento e que possa ter desencadeado dor ou desconforto musculoesquelético. Perguntar de forma a especificar que o paciente não precisa contar o que aconteceu de emocional que o deixou, por exemplo, aborrecido, aumentando sua dor na região cervical, e precisa somente reportar a se aconteceu algo ou não. No caso de intercorrências físicas é interessante que o paciente relate a intercorrência para que o fisioterapeuta possa avaliar como este fato afetou a função corporal. 
7. Avaliar aspectos funcionais do paciente: Iniciar a avaliação clínica baseando-se na anamnese e avaliação da postura e da mobilidade.

8. Dar feedback sobre a avaliação: Dar informações claras, em linguagem simples, ao paciente, sobre os achados da avaliação e sobre o raciocínio clínico de como estes fatos devem afetar a sessão de massoterapia.

9. Explicar sobre a intervenção a ser realizada: Dar informações ao paciente sobre o recurso fisioterapêutico que será aplicado, e questionar sobre dúvidas por parte do paciente. No caso deste estudo, sobre a massagem clássica.

10. Desnudar os diferentes segmentos corporais do paciente: Auxiliar o paciente a desnudar o segmento que será tratado e manter as regiões não tratadas cobertas com toalha, lençol, ou cobertor, fornecendo uma situação de segurança e conforto para o paciente e um ambiente profissional para o fisioterapeuta.

11. Posicionar o paciente na maca: Posicionar o paciente de forma que o mesmo fique na posição necessária para tratamento, sem sobrecarregar nenhuma região e de forma que ele se sinta confortável, utilizando para tanto, rolos, cunhas, travesseiros e lençóis.

12. Manter autocuidado físico: Executar a massagem em posturas adequadas, de forma a diminuir as sobrecargas articulares e eliminar a realização de força muscular desnecessária, como as estabelecidas por $\operatorname{Cassar}^{16}$ :

13. Intervir: Aplicar técnica adequadamente, sendo conhecedor dos fundamentos necessários para aplicação da mesma.

14. Mensurar freqüência cardíaca e pressão arterial pós-intervenção: $\mathrm{O}$ paciente encontra-se na posição deitada neste momento. Este dado é essencial para conhecimento da resposta cardiocirculatória do paciente à intervenção. 
15. Ajudar o paciente a sentar-se: Auxiliar o paciente a sentar-se na maca, após a massagem, para evitar contratura muscular, vertigem ou algum outro desconforto.

16. Ajudar o paciente sair da maca: Utilizar escadinha e/ou apoio manual, evitando qualquer tipo de acidente ao paciente.

17. Ajudar o paciente a vestir-se: Auxiliar o paciente se necessário.

18. Acomodar o paciente sentado em cadeira para receber as orientações.

19. Confirmar retorno e despedir-se: Agendar retorno e despedir-se formalmente.

20. Preencher da ficha de avaliação: Preenchimento dos dados coletados na anamnese, na avaliação funcional e dos achados resultantes da intervenção, caso tenha ocorrido.

21. Manter comunicação oral: A comunicação deve ser utilizada de acordo com as diretrizes de Stefanelli ${ }^{17}$ sobre comunicação terapêutica e não terapêutica, ou seja, linguagem clara, perguntas abertas que não direcionem a resposta, disponibilidade para o paciente, clareza na comunicação (questionar respostas que gerem dúvida), requisitar feedback por parte do paciente, valorizar relatos de sintomas durante intervenção e não permitir períodos prolongados de silêncio.

\section{DISCUSSÃO}

De acordo com o Documento de Recomendação para o Ensino de Ética e Deontologia nos cursos de Fisioterapia ${ }^{18}$, com a proposta de padronização de conteúdo disciplinar e de metas de atuação para o desenvolvimento dos conhecimentos inerentes a esta disciplina, estabeleceu-se que os professores de forma geral, deverão estimular a discussão da prática profissional embasada na ética e na deontologia a partir das experiências nas diversas situações de ensino; proporcionar interação entre os docentes e discentes e as diversas disciplinas no concernente à 
prática profissional pautada na ética e legislação; priorizar os campos de prática profissional como ambientes desencadeadores de discussão e desenvolvimento de atitudes e também estimular docentes e discentes para a realização de pesquisa na área de ética e deontologia.

Para que o ensino de fisioterapia se modifique Marques ${ }^{19}$ enfoca a necessidade de esforços conjuntos de professores, profissionais e alunos no sentido de criar condições para que o círculo vicioso de professores sem formação adequada formando profissionais despreparados seja rompido. Uma das formas seria preparar profissionais aptos a atuar de forma competente, com profissionalismo e respeito aos pacientes, com condições de rever freqüentemente a sua atuação e modificando-a, se necessário.

Hayes $^{20}$, baseado em Bloom (1956), cita que a formação profissional do fisioterapeuta consiste em educação de conhecimentos, habilidades e atitudes profissionais. Os educadores baseiam-se nos três domínios de aprendizado descritos por Bloom, sendo eles: cognitivo, psicomotor e afetivo. O domínio cognitivo e psicomotor seriam habilidades técnicas desenvolvidas pela prática, treino, estudo e repetição. O fator afetivo estaria ligado a habilidades mais sutis como uma relação interpessoal, capacidade de percepção da ligação do fator emocional com a patologia, desenvolvimento de formas mais adequadas para abordar a queixa apresentada pelo paciente.

O treinamento da habilidade afetiva do aluno vem sendo gradualmente integrado ao aprendizado dos domínios cognitivo e ao psicomotor, dando ao aluno a capacidade de desenvolver essa habilidade em sua prática, como proposto neste estudo. 
Para Altamaier ${ }^{21}$ e Hojat ${ }^{22}$ o aspecto cognitivo aborda treinamento técnico e habilidade prática. O aspecto não cognitivo abrange respostas comportamentais, habilidades interpessoais e comunicação. Neste sentido, este estudo explora habilidades e comportamento, embora, com finalidade didática, todos tenham sido denominados de habilidades.

May $^{12}$ ressalta que, segundo professores que atuam na prática clínica, a maior dificuldade dos alunos em fazer a transição da situação de sala de aula para a realidade é o aspecto não cognitivo, pois são características não treinadas de maneira formal durante o ensino.

No ensino da massoterapia podemos descrever como aspectos cognitivos; a técnica a ser desenvolvida, a postura utilizada pelo fisioterapeuta, a relação formal fisioterapeuta-paciente, a educação (ensino e orientação referente ao tratamento) do paciente, a administração do tempo da terapia, e a capacidade de pensar, refletir, comparar, analisa, criticar, justificar, argumentar e produzir. Já o aspecto nãocognitivo abrangeria a forma da comunicação verbal e não verbal, o processo afetivo sendo tanto o social quanto o profissional do fisioterapeuta para com o paciente e, a ética.

As habilidades não cognitivas são mais difíceis de serem avaliadas, principalmente quando o aluno ou recém formado tem conhecimento, habilidades manuais e técnicas satisfatórias e bem embasadas. Deficiência nas habilidades como alto nível de ansiedade, inabilidade para interpretar o paciente, dificuldade de aprender com seus erros e desconforto com informações ambíguas, são geralmente os fatores básicos para um atendimento carente ${ }^{11}$. 
O presente estudo limitou-se a pesquisar habilidades cognitivas e a comunicação verbal. As habilidades não cognitivas merecem estudos onde, de preferência, cada um dos fatores que afetam a qualidade do atendimento, como por exemplo, ansiedade do fisioterapeuta, possa ser estudado isoladamente, dentro de um conjunto de outras variáveis a serem consideradas que é bastante amplo. Também merece muita atenção os aspectos psicomotores, que são pré-requisitos para execução adequada das diferentes técnicas de recursos manuais, que incluem, propriocepção (essencial para palpação de diferentes tecidos), coordenação motora corporal e manual, uso adequado do corpo durante a aplicação de força muscular com as mãos, força muscular, coordenação direita- esquerda, principalmente dos membros superiores e coordenação entre ação motora e comando verbal.

May ${ }^{12}$ apresenta um modelo de avaliação de atributos profissionais para graduandos em fisioterapia apontando dez habilidades para avaliar o grau de competência do aluno, sendo elas: capacidade de aprendizado, habilidades interpessoais, uso efetivo do tempo, pesquisas, uso construtivo do feedback do paciente, resolução dos problemas, profissionalismo, responsabilidade, pensamento crítico e administração do estresse. A autora incentivou por meio do seu estudo, que educadores iniciassem a utilização das habilidades não cognitivas como uma ferramenta importante para seus ensinamentos, além de despertar interesse nas pesquisas sobre habilidade para os alunos de fisioterapia.

Em 1999, Hayes ${ }^{20}$ observou que deveria enfatizar uso dos fatores não cognitivos, como as habilidades interpessoais de comunicação para assegurar a competência profissional dos estudantes, visto que, a coleta de dados abrangente durante a anamnese é essencial para a ação clínica fisioterapêutica. 
Porrit ${ }^{23}$ afirma que a comunicação é base para toda interação humana, e a qualidade da interação é afetada pelos contextos sociais em que a comunicação ocorre. A comunicação na área da saúde vem merecendo pesquisas de estudiosos. A pesquisa da comunicação na fisioterapia é importante pela busca de conhecimentos que podem favorecer as práticas profissionais.

Para Stefanelli ${ }^{17}$ não existe uma teoria global de comunicação que explique suas origens, seu desenvolvimento nos indivíduos ou na sociedade ou mesmo suas funções ou papéis. As inúmeras formas de identificar, compreender e analisar a comunicação tem enriquecido a compreensão desse processo.

Sundeem ${ }^{24}$ e Stefanelli ${ }^{25}$ acreditam que o processo de comunicação pode ser afetado por diferentes variáveis. Esses podem trazer tanto benefícios como prejuízos para a compreensão das mensagens, podendo surgir fatos que impedem a evolução adequada do processo. As principais variáveis presentes no contexto da saúde são: o profissional da saúde e o paciente, a linguagem usada, o ambiente ou contexto, a disponibilidade de ambos e oportunidade profissional.

É importante que o profissional da saúde faça uso consciente de sua competência em comunicação, pois tudo que ele é, diz ou faz pode afetar o comportamento do paciente. O linguajar usado tanto pelo profissional quanto pelo paciente deve ter um significado comum para que a mensagem seja aprendida e compreendida por ambos. O profissional deve usar um vocabulário que possa ser compreendido, de acordo com a origem, escolaridade, cultura e crenças do paciente para valer-se do máximo de clareza possível ao empregar as palavras. Por fim, ambos precisam ter capacidade para ouvir. O ambiente implica não só o espaço físico utilizado pelas pessoas, como também as pessoas que interagem, sua cultura, 
mobiliário, iluminação, arejamento, temperatura, ruídos, condições de tempo e espaço. A disponibilidade pessoal do profissional é necessária e deve estar disponível para ser utilizado quando os pacientes assim precisarem. O senso de oportunidade diz respeito à sensibilidade do profissional em perceber se o momento é oportuno ou não para dar orientações ao paciente ${ }^{17}$.

A comunicação terapêutica, segundo Stefanelli ${ }^{17}$ é a competência do profissional de saúde em usar o conhecimento sobre comunicação humana, para ajudar o outro a descobrir e utilizar sua capacidade e potencial para solucionar conflitos; reconhecer as limitações pessoais; ajustar-se ao que não pode ser mudado e a enfrentar os desafios à auto-realização, procurando viver da forma mais saudável possível, tendo como meta encontrar um sentido para viver com autonomia. Fica claro que, o ensino da comunicação terapêutica é muito mais amplo do que o ensino de uma comunicação básica formal de relacionamento terapêuta-paciente, como abordado por este estudo.

O silêncio, muitas vezes, também pode ser utilizado de forma terapêutica como estratégia para estimular a expressão verbal de idéias e sentimentos do paciente, porém não se preconiza a permanência de duas pessoas em mutismo; o profissional tem que ter discernimento para saber quando falar e quando permanecer em silêncio.

Com relação ao autocuidado postural, Dortch ${ }^{26}$ sugere que as tarefas profissionais devam respeitar os fatores constitucionais de cada indivíduo, ou seja, sexo, biotipo, idade, condição física e psicológica e que os trabalhadores devem ser devidamente preparados antes de serem efetivados em seus empregos. 
Cromie $^{5}$ observou que $62,5 \%$ dos fisioterapeutas apresentavam dor lombar, já Bork $^{4}$ e ainda Cromie $^{5}$ perceberam que além da dor lombar, encontraram respectivamente, dor cervical $(24,7 \%$ e $47,6 \%)$, dor em ombros $(18,9 \%$ e $22,9 \%)$, dor torácica $(28,7 \%$ e $41 \%)$, dor em punhos e mãos $(29,6 \%$ e $21,8 \%)$ e dor em joelhos $(10,9 \%$ e $11,2 \%)$. Algumas pesquisas australianas demonstram que 33,6\% dos fisioterapeutas apresentam dores nos polegares e um em cada seis fisioterapeutas australianos, necessitaram mudar de carreira por causa da doença ocupacional.

Um achado interessante encontrado pela maioria dos pesquisadores citados como Molumphy ${ }^{27}$ e Scholey ${ }^{28}$ é que o primeiro episódio de dor musculoesquelética relacionada ao trabalho ocorre nos primeiros anos de prática ou entre os fisioterapeutas jovens. Molumphy ${ }^{27}$ encontrou que $29 \%$ dos fisioterapeutas apresentaram dores num período de doze meses de trabalho, sendo que 64\% desta população tinham 30 anos ou menos.

$\mathrm{Na}$ maior parte dos movimentos de massagem, a posição do fisioterapeuta é um aspecto essencial da técnica. A conscientização quanto à postura é uma combinação de posição do corpo, descarga de peso corporal e direção da pressão $^{16}$

O estudo de Trelha $^{29}$ verificou que os profissionais em inicio de carreira apresentavam maior sintomatologia, possivelmente pela inexperiência e pela maior dificuldade em pedir auxílio a outras pessoas para, por exemplo, levantar ou transferir o paciente.

De acordo com o alto índice de dores ocupacionais em fisioterapeutas, os autores assim como a literatura sugerem que intervenções sejam feitas durante a graduação para que essa incidência seja diminuída ${ }^{4,5,30}$. 
Este trabalho permitiu compreender a importância da presença de conceitos cognitivos e não cognitivos no curso de graduação em Fisioterapia. Isto significa que o graduando necessita ter em seu currículo conteúdos que o permitam adquirir informações consistentes abrangendo teorias, técnicas, habilidades, mas também possa desenvolver sua habilidade de comunicação com o paciente.

As habilidades profissionalizantes necessitam ser treinadas e seria aconselhável que estivessem contempladas no currículo do curso. Atitudes preventivas devem ser incentivadas, e o aluno ser conscientizado de seus limites, possibilidades e dificuldades pessoais para estar ciente do alcance de capacidade profissional, de sua responsabilidade social, científica e de seu conforto físico e emocional.

\section{Referências}

1. Bevilacqua, F. Manual de Exame Clínico. Editora Cultura Médica. $7^{\mathrm{a}}$ edição, 1985.

2. Rios IC. Relação Médico-Paciente: Tempos de pasteurização da subjetividade. Ser Médico. Órgão do Conselho Regional de Medicina do Estado de SP. Out/nov/dez 1999. Ano II nº 9.

3. Harber P, Billet E, Gutowski M, SooHoo K, Lew M, Roman A. Occupational low-back pain in hospital nurses. J Occup Med. 1985; 27(7):518-24.

4. Bork BE, Cook TM, Rosecrane JC, et al. Work-related musculoskeletal disorders among physical therapists. Phys Ther. 1996;76:827-835.

5. Cromie JE, Robertson VJ, Best MO. Work-related musculoskeletal disorders in physical therapists: prevalence, risk and response. Phys Ther. 2000;80:336351. 
6. Cantwell BM, Ramirez AJ. Doctor-patient communication: a study of junior house officer. Med Education. 1997;31:17-21.

7. Humphris GM, Kaney S. Assessing the development of communication skills in undergraduate medical students. Med Educ. 2001; 35(3):225-31.

8. Vieira J, Nunes MP, Martins M. Directing student response to early patient contact by questionnaire. Medical Education. 2003;37:119:125.

9. Fritz, S. Fundamentos da massagem terapêutica. Barueri: Manole, 2000.

10. Jette DU, Portney LG. Construct validation of a model for professional behavior in physiotherapy students. Phys Ther. 2003; 83: 433-443.

11. Jette DU, Bertoni A, Coots R, Johnson H, McLaughlin C, Weisback C. Clinical instructors'perception of behavior that comprise entry -leval clinical performance in physical therapist students: A qualitative study. Phys Ther. 2007;87(7):833-843.

12. May WW, Morgan B, Lemke JC et al. Model for ability-based assessment in physical therapy. Journal of Physical Therapy Education. 1995;9(1):3-6.

13. Ingram D. Opinions of physical therapy education program directors on essential functions. Physical Therapy. 1997;77(1):37-39.

14. Matos MA, Tomanaki GY. Análise do Comportamento no Laboratório Didático. São Paulo: Manole, 2002.

15. Fehring RJ. Validation diagnostic labels: standardized methodology. In: Hurley ME. Classification of nursing diagnoses: proceedings of the sixth Conference of North American Nursing Association. St. Louis: The C.V. Mosby, 1986: p. 183-190.

16. Cassar MP. Manual de Massagem Terapêutica. Barueri: Manole, 2001. 
17. Stefanelli MC, Carvalho EC. A comunicação nos diferentes contextos de enfermagem. Sao Paulo. Manole. 2005.

18. Revista Crefito 3. Documento de recomendação para o ensino de ética e deontologia nos cursos de fisioterapia do I Encontro Paulista de docentes da disciplina de Ética e Deontologia. São Paulo. 2006; 03(1).

19. Marques AP. Cadeias Musculares: Um Programa para Ensinar Avaliação Cisioterapêutica Global - 2a edição. Barueri: Manole. 2005.

20. Hayes KW, Hurber G, Rogers J, Sanders B. Behaviors that cause clinical instructors to question the clinical competence of physical therapist students. Phys Therapy. 1999;79:653-667.

21. Altamaier EM, McGuinness G, Wood P, et al. Defining successful performance among pediatric residents. Pediatrics. 1990;85:139-143.

22. Hojat M, Borenstein BD, Veloski JJ. Cognitive and noncognitive factors in predicting the clinical performance of medical school graduates. $J$ Med Educ. $1988 ; 63: 323-325$.

23. Porrit L. Communication: choices for nurse. Edinburg: Churchill Livingstone, 1984.

24. Sundeen JS, Stuart GW, Ranbin FAD. Nurse-client interation: implementing the nursing process. 6 ed. St. Louis: Mosby, 1998, 359p.

25. Stefanelli MC. Comunicação com paciente: teoria e ensino. São Paulo: Robe 1993.

26. Dortch HL, Trombly, CA. The effects of education on hand use with industrial workers in repetitive jobs. Am J Occup Ther. 1990; 44:777-782. 
27. Molumphy M, Unger B, Jensen GM, Lopopolo RB. Incidence of workrelated low back pain in physical therapists. Phys Ther. 1985:65:482-486.

28. Scholey M, Hair M. Back pain in physiotherapists involved in back care education. Ergonomics. 1989;32:179-190.

29. Trelha CS; Gutierrez PR; Matsuo T. Prevalência de sintomas músculoesqueléticos em fisioterapeutas da cidade de Londrina. Revista Fisioterapia. Universidade São Paulo. 2004 jan/jun.;11(1):15-23.

30. Holder NL, Clark HA, DiBlasio JM, et al. Cause, prevalence, and response to occupational musculoskeletal injuries reported by physical therapist and physical therapist assistant. Phys Ther. 1999;79:642-652. 
Fotos representativas das posturas empregadas durante a

Apêndice 6 massoterapia
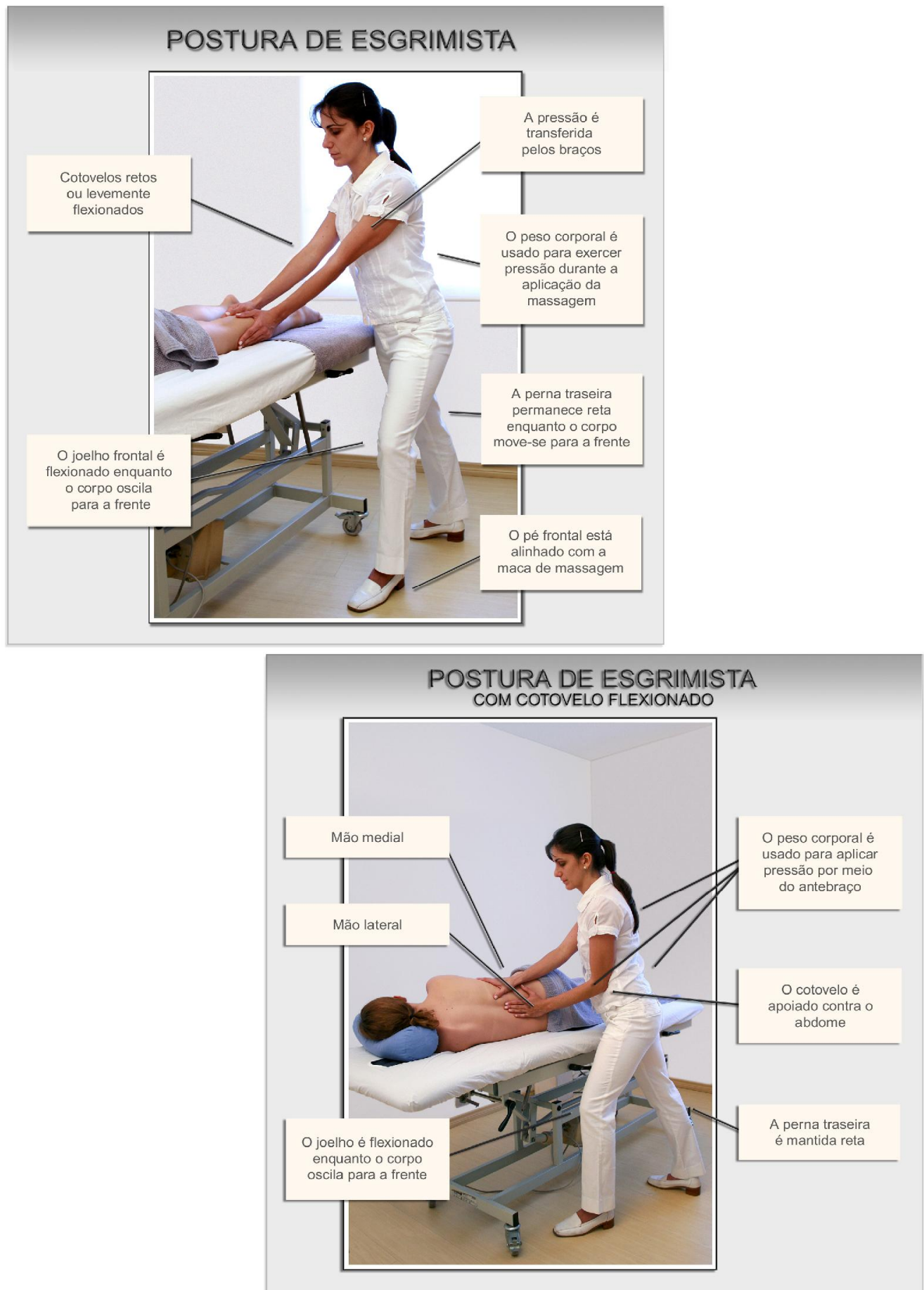

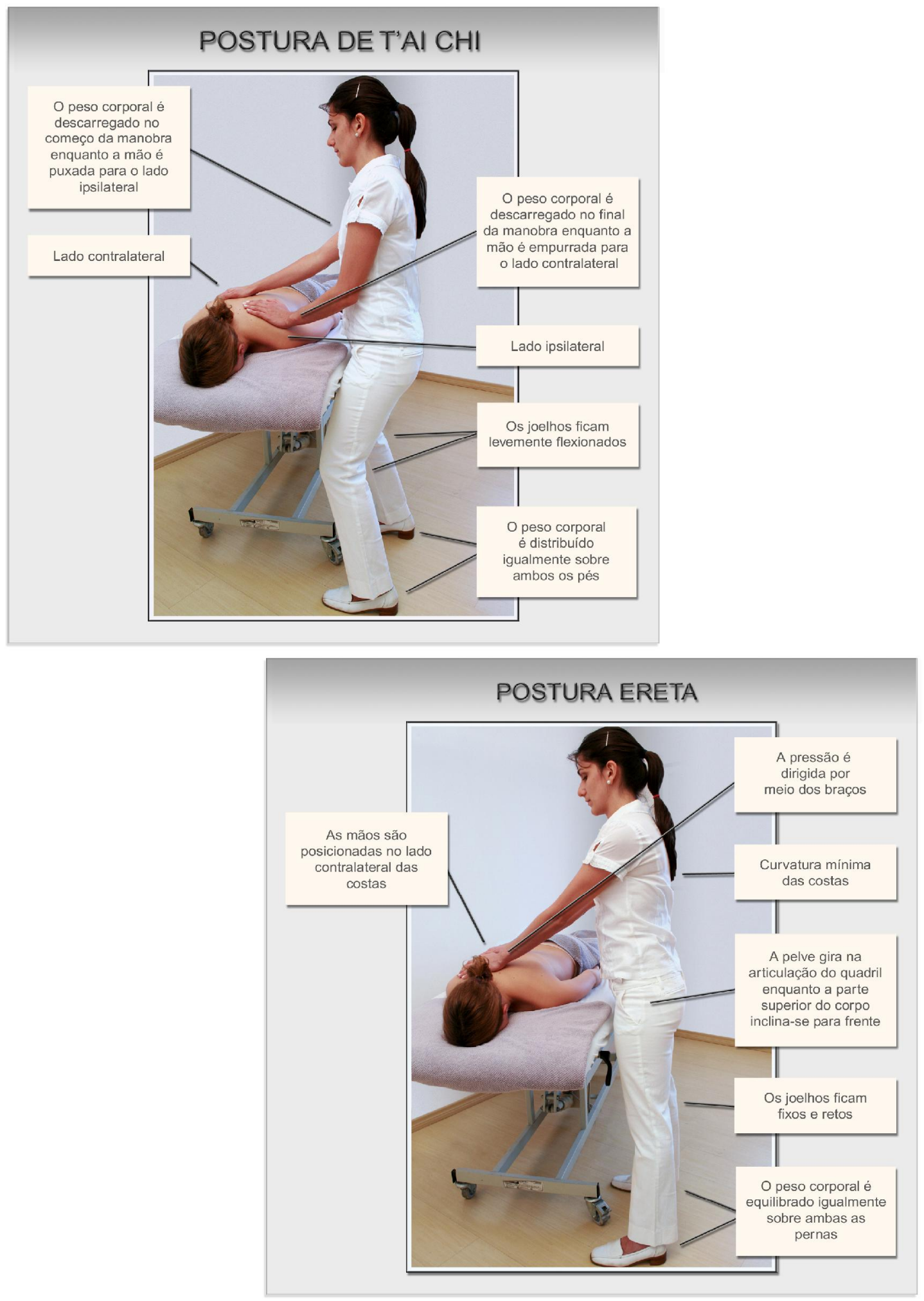

\section{pdfMachine - is a pdf writer that produces quality PDF files with ease! Get yours now !}

"Thank you very much! I can use Acrobat Distiller or the Acrobat PDFWriter but I consider your product a lot easier to use and much preferable to Adobe's" A.Sarras - USA 

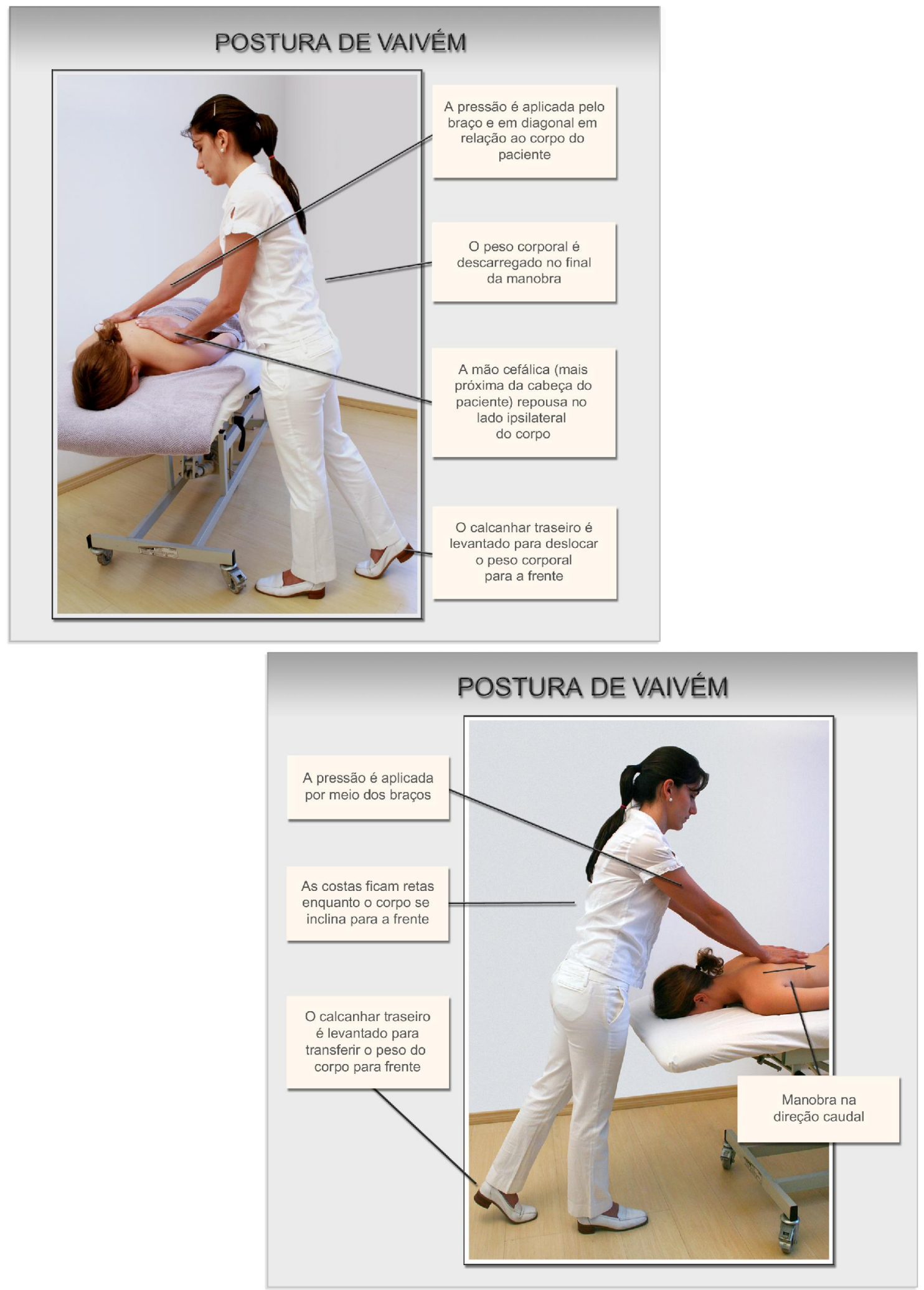

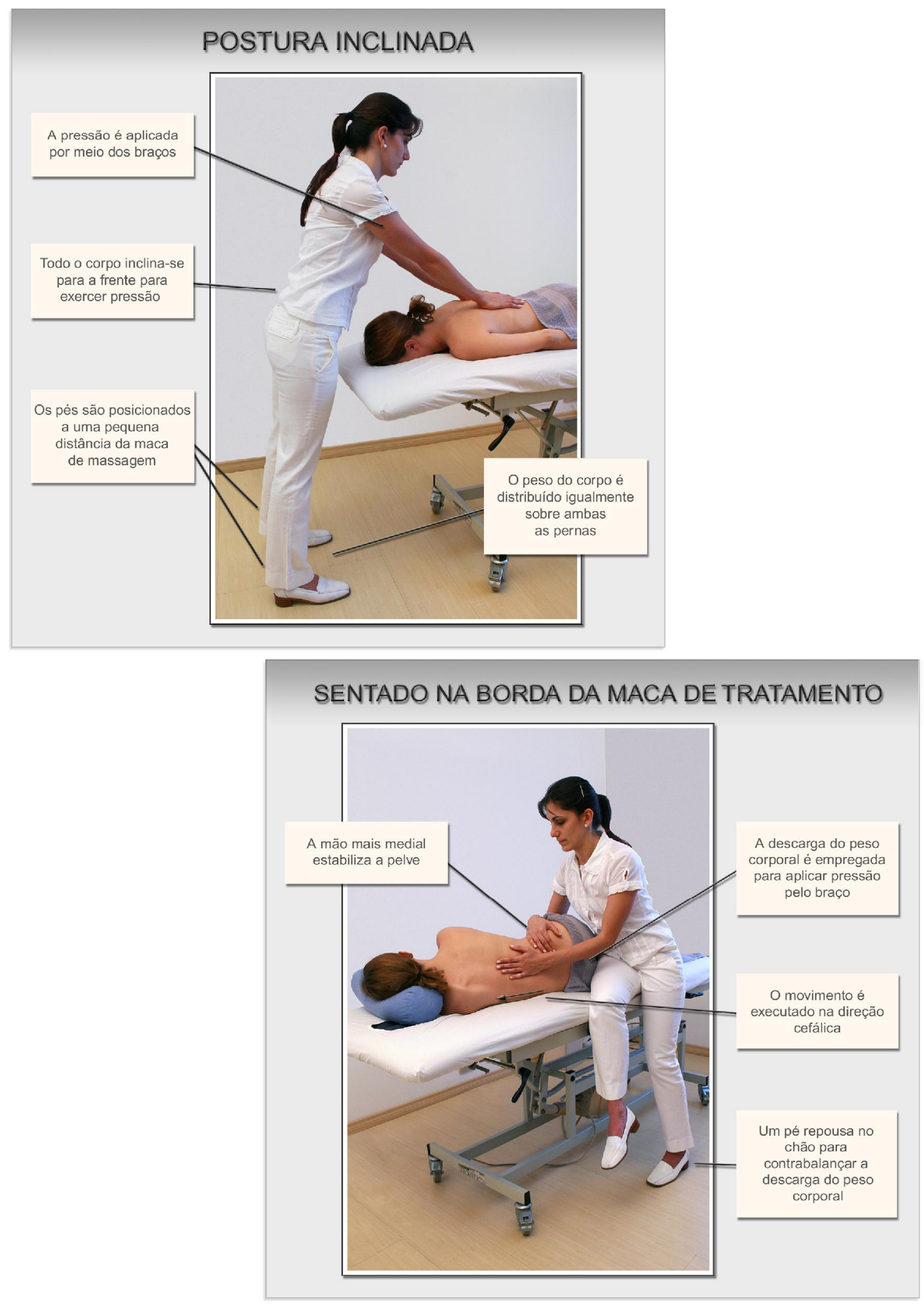


\section{Relatório de atendimento / Ficha de Evolução}

Paciente:

Terapeuta:

Data:

Anotações do terapeuta:

1. Freqüência cardíaca pré intervenção:

2. Intercorrências com o paciente na semana:

3. Avaliação Funcional básica:

4. Intervenção:

5. Freqüência cardíaca pós intervenção:

6. Relação dos achados da avaliação com os da intervenção:

7. Registro de intercorrências durante a terapia:

8. Orientações:

9. Anotações Extra: 


\section{Apêndice 8 \\ Escala para validação por peritos das definições operacionais das habilidades selecionadas}

\begin{tabular}{|c|c|c|c|c|c|}
\hline \multirow{2}{*}{$\begin{array}{l}\text { Dê sua opinião sobre às definições operacionais descritas a seguir, } \\
\text { utilizando MC - muito característico, } R C \text { - razoavelmente } \\
\text { característico, } C \text { - característico, } P C \text {-pouco característico e NC-não } \\
\text { característico. } \\
\text { 1.Vestimenta do fisioterapeuta: É considerada totalmente adequada } \\
\text { aqueles que se apresentem com cabelo preso e/ou penteado, ausência de } \\
\text { maquiagem ou maquiagem suave, avental ou roupa branca sem decotes, } \\
\text { acessórios como brinco ou presilhas discretos, ausência de chinelo, } \\
\text { shorts, saia curta, bermuda ou roupas transparentes }\end{array}$} & $\mathrm{MC}$ & $\mathrm{RC}$ & C & $\mathrm{PC}$ & $\mathrm{NC}$ \\
\hline & & & & & \\
\hline $\begin{array}{l}\text { 2. Preparo do local para tratamento: É considerado totalmente } \\
\text { adequado se para o preparo do local de tratamento foi providenciado } \\
\text { toalhas limpas, travesseiro, cadeira e materiais utilizados na } \\
\text { massoterapia, como, creme ou óleo, adstringente, algodão e toalha de } \\
\text { mão. }\end{array}$ & & & & & \\
\hline $\begin{array}{l}\text { 3. Chamada do paciente: É considerado totalmente adequado a } \\
\text { chamada formal do paciente, chamando-o pelo nome, apresentado-se e } \\
\text { acompanhando-o até a sala de atendimento. }\end{array}$ & & & & & \\
\hline $\begin{array}{l}\text { 4. Acomodação do paciente sentado: É considerado totalmente } \\
\text { adequado quando se auxilia ou supervisiona a acomodação do paciente, } \\
\text { em cadeira, para realização de coleta da freqüência cardíaca e dados de } \\
\text { anamnese }\end{array}$ & & & & & \\
\hline $\begin{array}{l}\text { 5. Mensuração de freqüência cardíaca pré-intervenção: É considerada } \\
\text { totalmente adequada a mensuração da freqüência cardíaca quando o } \\
\text { paciente for posicionado sentado, de forma confortável e com o braço } \\
\text { apoiado. A técnica utilizada foi a de palpação do pulso radial, durante um } \\
\text { minuto utilizando-se dos dedos indicador e médio, com o polegar fixado } \\
\text { no dorso do punho do paciente, sendo que o examinador usa a mão } \\
\text { direita para examinar o pulso esquerdo e vice versa. }\end{array}$ & & & & & \\
\hline $\begin{array}{l}\text { 6. Questionamento sobre intercorrências físicas ou emocionais } \\
\text { durante a semana: É considerada totalmente adequada quando o aluno } \\
\text { faz um breve questionamento para verificar algum tipo de intercorrência } \\
\text { na última semana que possa ter desencadeado dor ou desconforto } \\
\text { musculoesquelético. }\end{array}$ & & & & & \\
\hline $\begin{array}{l}\text { 7. Avaliação funcional básica do paciente: Considerada totalmente } \\
\text { adequada quando o aluno iniciar sua avaliação clínica baseando-se na } \\
\text { anamnese e observações da postura, e ainda, durante a massoterapia, o } \\
\text { aluno realizar sua avaliação, relacionando os achados funcionais e de } \\
\text { anamnese com possíveis causas de dor. }\end{array}$ & & & & & \\
\hline $\begin{array}{l}\text { 8. Feedback sobre a avaliação: O aluno deve dar informações claras, em } \\
\text { linguagem simples, ao paciente, sobre os achados e raciocínio clínicos da } \\
\text { avaliação funcional para que sua habilidade seja considerada como } \\
\text { totalmente adequada. }\end{array}$ & & & & & \\
\hline $\begin{array}{l}\text { 9. Explicação sobre a intervenção a ser realizada: Para que seja } \\
\text { considerada totalmente adequada o aluno deve dar informações ao } \\
\text { paciente sobre a massagem clássica de corpo inteiro, técnica utilizada } \\
\text { nesta pesquisa, que utiliza de manobras suaves como deslizamento, }\end{array}$ & & & & & \\
\hline
\end{tabular}




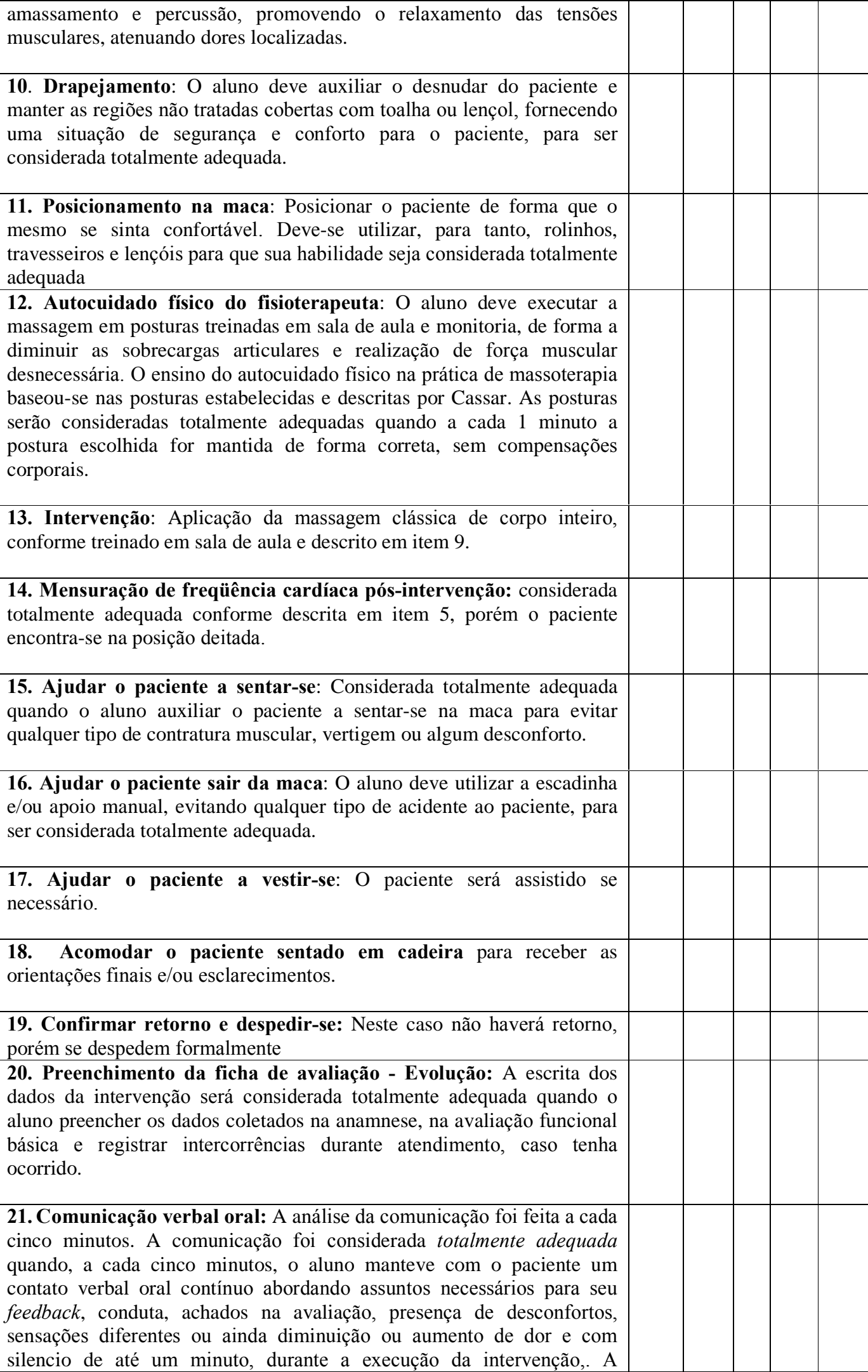


comunicação foi considerada parcialmente adequada, quando embora, a cada cinco minutos, a temática fosse pertinente ocorria interrrupções maiores do que dois minutos. A comunicação foi considerada inadequada (I) se a cada cinco minutos o contexto da terapia não era relevante ao tratamento, mas abordados assuntos alheios onde dispersava a atenção do aluno em seu trabalho e dificultava a busca da consciência corporal do paciente. E considerada não realizada quando, a cada cinco minutos, existia o silêncio prolongado maior do que três minutos, onde não havia nenhum tipo de comunicação verbal oral durante $o$ procedimento. Estabeleceu um período máximo de 30\% do tempo da intervenção para a comunicação inadequada e/ou não realizada como aceitável nesta fase de aprendizagem (segundo ano). Foi considerado tempo da intervenção aquele compreendido entre o início da massagem propriamente dita até a conclusão da mesma por verbalização de seu término, feita pelo aluno ou posicionando o paciente sentado na maca. 
Apêndice 9

\section{Escala para validação por peritos da seqüência adotada para ensino das habilidades}

De a sua opinião sobre a seqüiência de habilidades durante a prática da massoterapia.

1. Vestimenta do fisioterapeuta

2. Preparo do local de tratamento

3. Chamada do paciente

4. Acomodação do paciente sentado

5. Mensuração da freqüência cardíaca pré-intervenção

6. Questionamento sobre intercorrências física ou emocional durante a semana

7. Avaliação funcional básica do paciente

8. Feedback sobre avaliação

9. Explicação sobre a intervenção a ser realizada

10. Drapejamento

11. Posicionamento na maca

12. Autocuidado físico do fisioterapeuta

13. Intervenção

14. Comunicação Verbal

15. Mensuração da freqüência cardíaca pós intervenção

16. Ajudar o paciente a sentar-se

17. Ajudar o paciente a sair da maca

18. Ajudar o paciente a vestir-se, se necessário

19. Acomodar o paciente sentado em cadeira

20. Confirmar retorno e despedir-se

21. Evoluir em prontuário

( ) Concordo com a lista:

( ) Concordo parcialmente com a lista: quando sugere mudança em até 5 das 21 habilidades

( ) Discordo com a lista: quando sugere mudança em mais de 6 habilidades 
Apêndice 10

Pontuação individual de cada perito

\begin{tabular}{|l|l|l|l|l|l|l|l|l|l|l|}
\hline \multicolumn{1}{|c|}{ Sujeito } & $\mathbf{1}$ & $\mathbf{2}$ & $\mathbf{3}$ & $\mathbf{4}$ & $\mathbf{5}$ & $\mathbf{6}$ & $\mathbf{7}$ & $\mathbf{8}$ & $\mathbf{9}$ & $\mathbf{1 0}$ \\
Titulação - pontos & & & & & & & & & & \\
\hline Mestre - 4 & $\mathrm{X}$ & $\mathrm{X}$ & $\mathrm{X}$ & $\mathrm{X}$ & $\mathrm{X}$ & $\mathrm{X}$ & $\mathrm{X}$ & $\mathrm{X}$ & $\mathrm{X}$ & $\mathrm{X}$ \\
\hline $\begin{array}{l}\text { Pesquisa apresentada em evento } \\
\text { internacional -2 }\end{array}$ & & $\mathrm{X}$ & & & $\mathrm{X}$ & $\mathrm{X}$ & $\mathrm{X}$ & & $\mathrm{X}$ & \\
\hline Pesquisa publicada em periódico - 2 & $\mathrm{X}$ & $\mathrm{X}$ & $\mathrm{X}$ & $\mathrm{X}$ & $\mathrm{X}$ & $\mathrm{X}$ & $\mathrm{X}$ & $\mathrm{X}$ & $\mathrm{X}$ & $\mathrm{X}$ \\
\hline Doutorado - 2 & $\mathrm{X}$ & $\mathrm{X}$ & $\mathrm{X}$ & $\mathrm{X}$ & $\mathrm{X}$ & $\mathrm{X}$ & $\mathrm{X}$ & $\mathrm{X}$ & $\mathrm{X}$ & $\mathrm{X}$ \\
\hline Especialização - 2 & & $\mathrm{X}$ & $\mathrm{X}$ & $\mathrm{X}$ & $\mathrm{X}$ & & $\mathrm{X}$ & $\mathrm{X}$ & $\mathrm{X}$ & $\mathrm{X}$ \\
\hline Mestrado na área da pesquisa - 1 & & & $\mathrm{X}$ & & & & $\mathrm{X}$ & $\mathrm{X}$ & $\mathrm{X}$ & \\
\hline Pratica clinica com RTM - 1 & $\mathrm{X}$ & $\mathrm{X}$ & $\mathrm{X}$ & & & & $\mathrm{X}$ & $\mathrm{X}$ & $\mathrm{X}$ & $\mathrm{X}$ \\
\hline $\begin{array}{l}\text { Total de pontos } \\
\text { (Escore máximo }=14 \text { pontos) }\end{array}$ & $\mathrm{10}$ & $\mathbf{1 3}$ & $\mathbf{1 2}$ & $\mathbf{1 0}$ & $\mathbf{1 2}$ & $\mathbf{1 0}$ & $\mathbf{1 4}$ & $\mathbf{1 2}$ & $\mathbf{1 4}$ & $\mathbf{1 1}$ \\
\hline
\end{tabular}

